
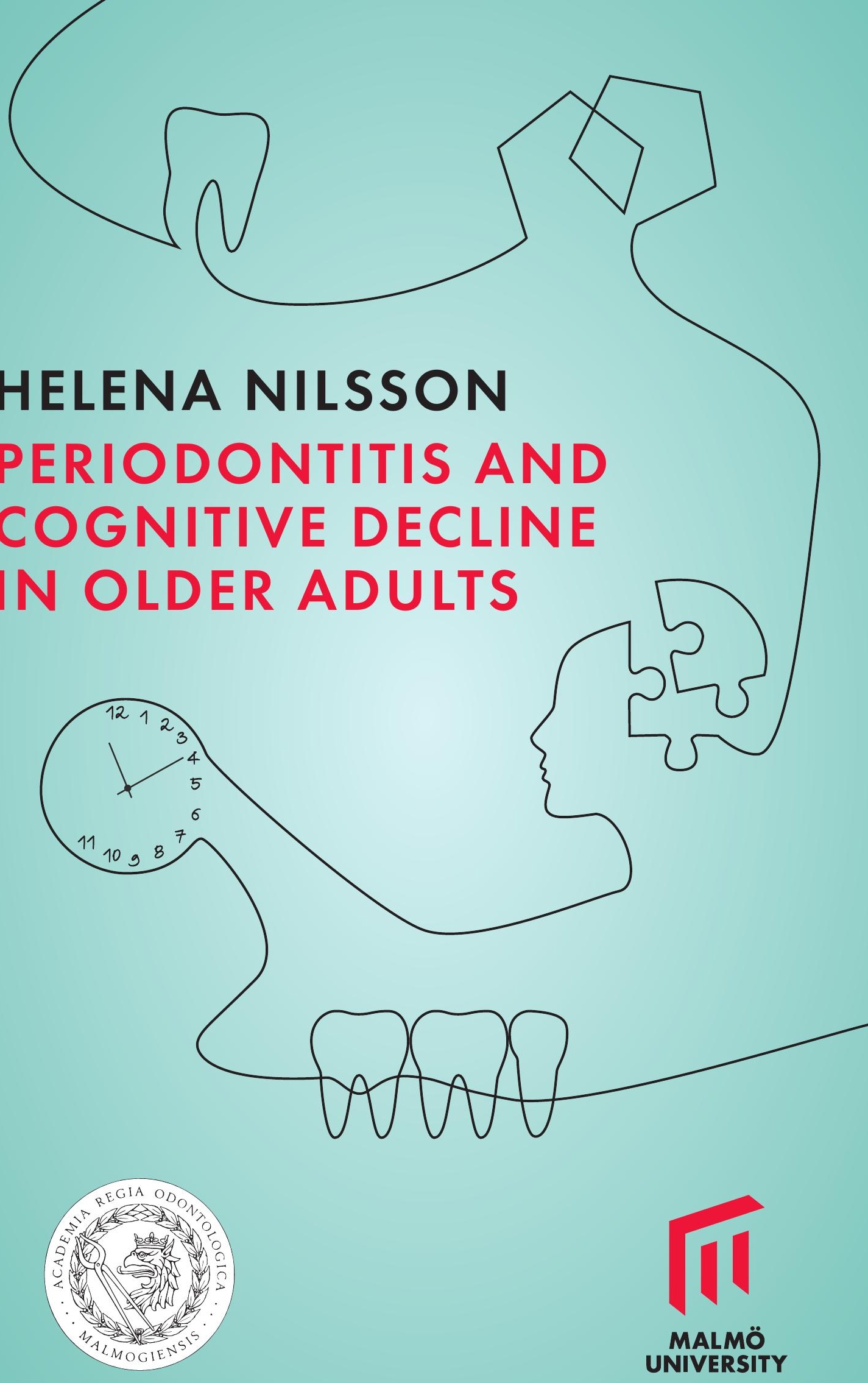



$$
-
$$


Malmö University, Faculty of Odontology Doctoral Dissertation 2019

(C) Copyright Helena Nilsson 2019 Coverpage Petronella Magnusson ISBN 978-9I-7 I04-997-I (print) ISBN 978-9I-7I04-998-8 (pdf) Holmbergs, Malmö 2019 


\section{HELENA NILSSON PERIODONTITIS AND COGNITIVE DECLINE IN OLDER ADULTS}

Malmö University, 2019

Faculty of Odontology Department of Periodontology 
This publication is available in electronic format at: https://muep.mau.se/ 
To Arvid, Anna and Moa 


\section{CONTENTS}

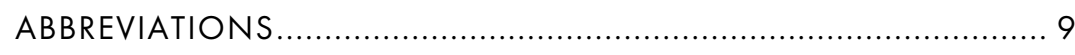

LIST OF PAPERS .............................................................. 10

THESIS AT A GLANCE ..................................................... 11

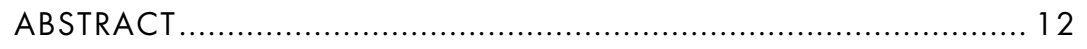

POPULÄRVETENSKAPLIG SAMMANFATTNING ...................... 15

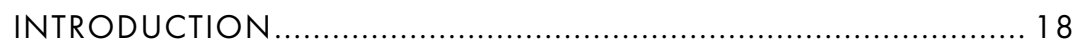

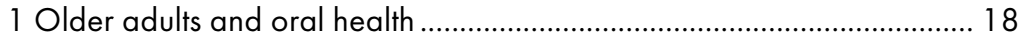

1:1 Tooth loss in older adults................................................................. 19

$1: 2$ Periodontitis in older adults ............................................................. 20

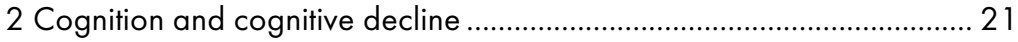

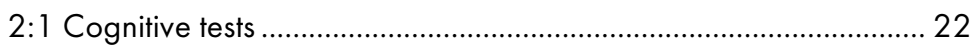

2:1:1 Mini-Mental State Examination .................................................... 22

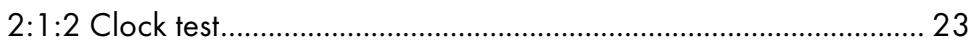

3 Periodontitis, tooth loss, and systemic diseases ....................................... 24

3:1 Periodontitis, tooth loss, and cognitive decline .............................. 24

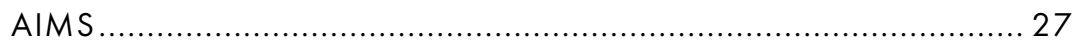

MATERIAL AND METHODS ................................................ 28

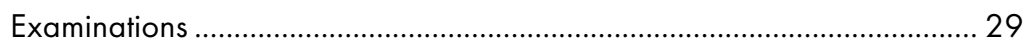

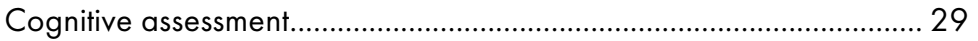

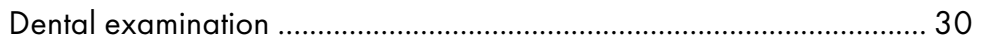

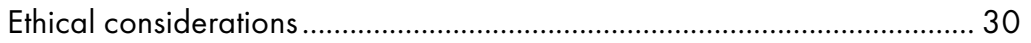

STATISTICAL ANALYSIS .................................................. 32

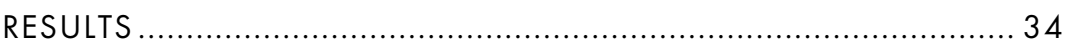




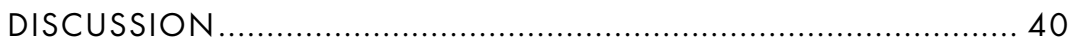

CONCLUSIONS ............................................................... 45

CLINICAL IMPLICATIONS AND SUGGESTIONS FOR FUTURE RESEARCH ....................................................................... 46

ACKNOWLED GEMENTS .................................................... 48

REFERENCES ................................................................. 50

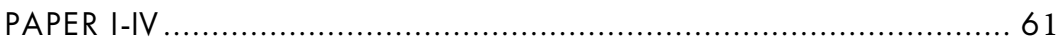





\section{ABBREVIATIONS}

AD- Alzheimer's disease

AUDIT- Alcohol Use Disorders Identification Test

CAL- Clinical Attachment Level

CEJ- Cemento Enamel Junction

CI- Confidence Interval

CT- Clock Test

MADRS- Montgomery-Asberg Depression Rating Scale

MCI- Mild cognitive impairment

MMSE- Mini-Mental State Examination

NS- No significant difference

OR- Odds ratio

PD- Pocket depth

SD- Standard Deviation

SNAC- Swedish National Study on Ageing and Care

WHO- World Health Organization 


\section{LIST OF PAPERS}

This thesis is based on the following four papers, which will be referred to by their Roman numerals in the text.

I. Nilsson H, Berglund J, Renvert S. Tooth loss and cognitive functions among older adults. Acta Odontologica Scandinavica 2014; 72:639-644.

II. Nilsson H, Sanmartin Berglund J, Renvert S. Periodontitis, tooth loss and cognitive functions among older adults. Clinical Oral Investigations 2018; 22:2103-2109

III. Nilsson H, Sanmartin Berglund J, Renvert S. Longitudinal evaluation of periodontitis and development of cognitive decline among older adults. Journal of Clinical Periodontology 2018; 45: 1142-1149

IV. Nilsson H, Sanmartin Berglund J, Renvert S. Longitudinal evaluation of periodontitis and tooth loss among older adults. Accepted for publication in Journal of Clinical Periodontology

Reprints were made with the permission of the publishers. 


\begin{tabular}{|c|c|c|c|c|}
\hline 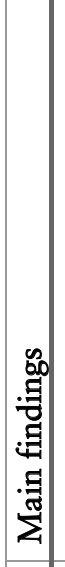 & 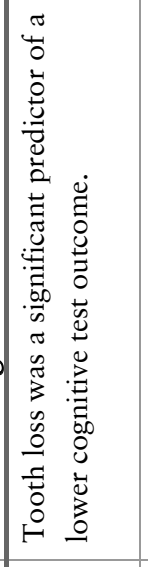 & 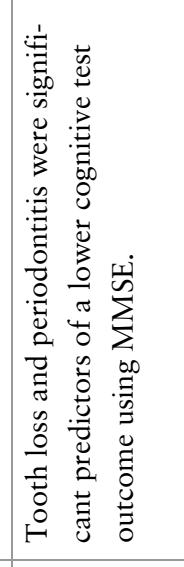 & 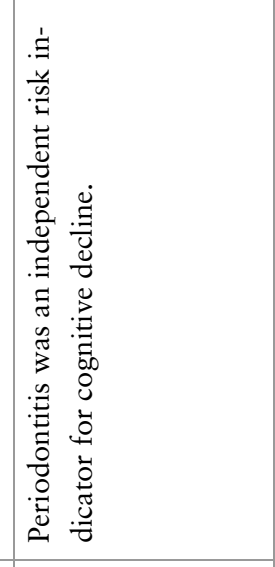 & 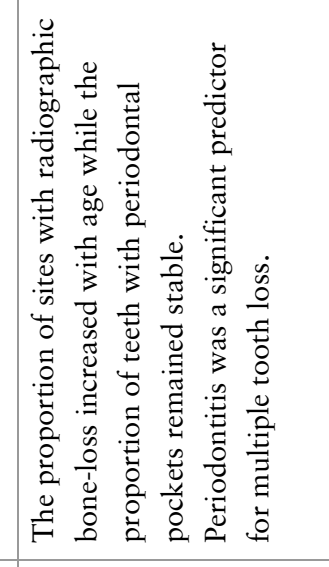 \\
\hline 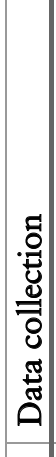 & 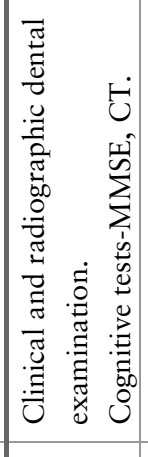 & 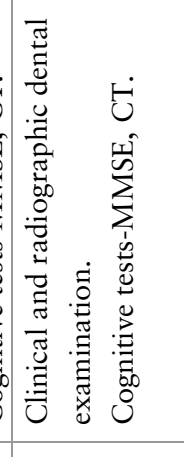 & 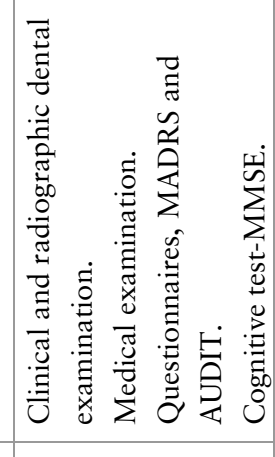 & 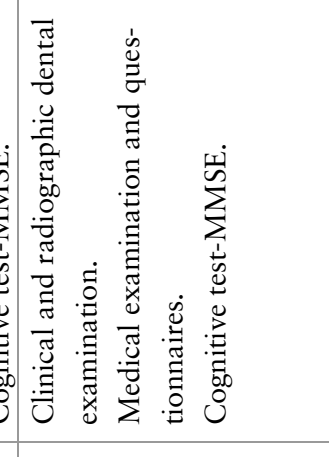 \\
\hline & $\frac{f}{\stackrel{I I}{I}}$ & 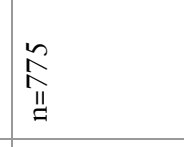 & $\underset{\substack{n \\
=}}{=}$ & $\begin{array}{l}n \\
\tilde{n} \\
=\end{array}$ \\
\hline $\begin{array}{l}.50 \\
0.00 \\
0\end{array}$ & 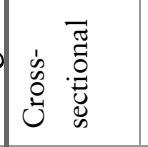 & 焉 & 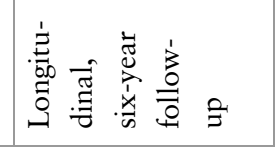 & 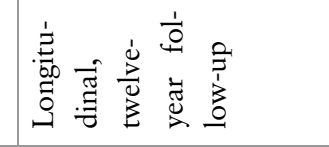 \\
\hline & 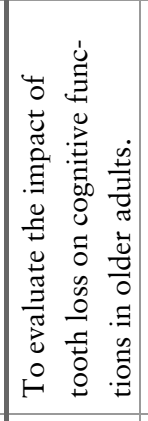 & 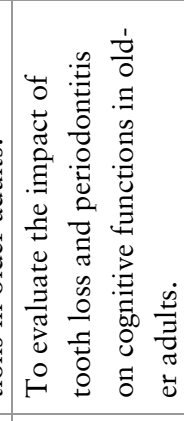 & 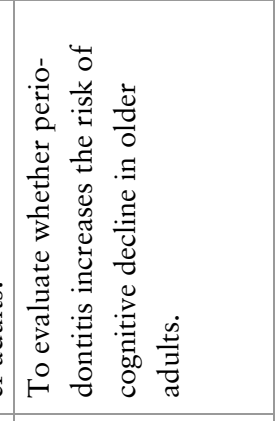 & 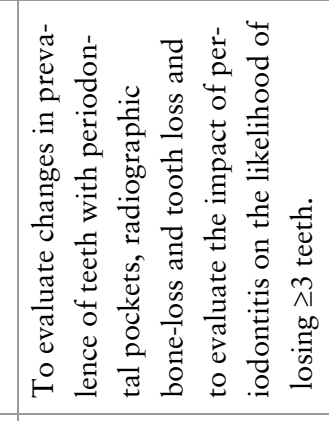 \\
\hline & & & 目 & $\geq$ \\
\hline
\end{tabular}




\section{ABSTRACT}

As a result of ongoing demographic transitions, populations throughout the world are ageing. Cognitive decline is a leading contributor to dependence and disability among older adults. Decline in cognitive abilities can also influence lifestyle factors associated with oral health. Increasing evidence suggest that more teeth are retained throughout life and therefore an increasing number of teeth are at risk of oral diseases.

Periodontitis is an inflammatory disease affecting the supportive tissues of the teeth resulting in alveolar bone loss and eventually tooth loss. Associations between periodontitis and systemic diseases with an inflammatory profile have been reported.

The overall aim of the present thesis was to evaluate a potential association between tooth loss, periodontitis, and cognitive decline and to describe changes in oral health-related parameters among older adults in a twelve-year follow-up.

In Paper I the impact of tooth loss on the risk for lower cognitive test score was evaluated in 1147 older adults. An examination including clinical and radiographic registration of number of teeth present was performed. Cognitive functioning was evaluated using Mini-Mental State Examination (MMSE) (cut-off <25) and Clocktest (CT) (cut-off <8). Number of teeth was categorised into edentulous, $1-19$ and $\geq 20$ teeth. The risk for low cognitive test score was statistically related to number of teeth. Results from the multiple logistic regression after adjustments for age and education demonstrated a statistically significant impact of being edentulous 
on cognitive functions. In addition, having 1 to 19 teeth had a significant impact on the risk for Clock-test $<8$ compared to the group having $\geq 20$ teeth.

In Paper II the impact of tooth loss and periodontitis on the risk for lower cognitive test outcome was evaluated in 775 dentate older adults. The clinical examination included periodontal probing and registration of number of teeth present. Panoramic radiographs were taken, and the extent of alveolar bone loss was evaluated at the mesial and distal aspect of each tooth and the proportion of readable sites $\geq 4 \mathrm{~mm}$ and $\geq 5 \mathrm{~mm}$ from the marginal bonelevel to cemento-enamel junction (CEJ) was assessed. Cognitive functioning was evaluated using MMSE (cut-off <25) and Clocktest (cut-off <8). Using MMSE, a sub-analysis was done between individuals with 25-27 points compared to the group with 28-30 points. Bone loss defined as having $\geq 4 \mathrm{~mm}$ distance from CEJ to marginal bone-level on $\geq 30 \%$ of readable sites and having 1-19 teeth had a significant impact on the cognitive test outcome using MMSE after adjustments for age, gender, and education. When excluding the individuals with the lowest test outcome $<25$, and then comparing the group with a score of 25-27 to the group with a score $\geq 28$, bone loss was still shown to have a significant impact on cognition. Having 1 to 19 teeth also influenced the risk for lower cognitive test-outcome using Clock-test.

In Paper III the impact of periodontal bone-loss on the risk for cognitive decline was evaluated in 715 older adults examined both at baseline and at a six-year follow-up. Cognitive decline was defined as a $\geq 3$-points deterioration using MMSE. All individuals included had a medical as well as a dental examination at baseline. Social variables were captured from questionnaires. One-hundred fifteen individuals experienced a $\geq 3$-points decline in MMSEresults during the six-year follow-up.

High age, elementary education, living alone, experience of ischemic heart disease, BMI $<25$, being edentulous, having 1-19 teeth and bone-loss defined as $\geq 4 \mathrm{~mm}$ from cemento-enamel junction to marginal bone level on $30 \%$ of readable sites were associated with decline in cognitive function. In the final analysis bone- 
loss, age, education, and $\mathrm{BMI}<25$ were significant predictors for cognitive decline.

In Paper IV the prevalence of periodontitis and change in periodontal variables and tooth loss were assessed over a twelve-year follow-up period. Individuals included had a medical as well as a clinical and radiographic dental examination at baseline. Periodontitis defined as having $\geq 2$ sites with $\geq 5 \mathrm{~mm}$ distance from cementoenamel junction to the marginal bone level and $\geq 1$ tooth with pockets $\geq 5 \mathrm{~mm}$ was evident in $39 \%$ of the population and $23 \%$ of the individuals lost $\geq 3$ teeth over the study period. Proportion of sites $\geq 4 \mathrm{~mm}$ and $\geq 5 \mathrm{~mm}$ from cemento-enamel junction to the marginal bone-level increased with age while proportion of teeth with pockets remained stable. Having periodontitis, living alone, and high age were significant predictors for multiple tooth loss. Individuals losing $\geq 3$ teeth had a lower number of teeth and a higher number of sites with bone loss $\geq 5 \mathrm{~mm}$ and teeth with pockets $\geq 5 \mathrm{~mm}$ at baseline. 


\section{POPULÄRVETENSKAPLIG SAMMANFATTNING}

Befolkningsgrupper över hela världen åldras. Försämring av kognitiv funktion bidrar i stor utsträckning till funktionsnedsättning och vårdberoende hos äldre. Försämring av kognitiva förmågor kan även påverka livsstilsfaktorer som är associerade till oral hälsa. Allt fler tänder behålls genom livet och därmed kan ett större antal tänder drabbas av orala sjukdomar. Parodontit är en inflammatorisk sjukdom som drabbar tändernas fäste och leder till förlust av ben och slutligen tandförlust. Parodontit har associerats till systemiska sjukdomar med inflammatorisk bakgrund. Det övergripande syftet med denna avhandling var att undersöka huruvida tandförlust och parodontit är relaterat till kognitiv försämring samt att $\mathrm{i}$ en långtidsuppföljning undersöka om parodontit är relaterat till tandförlust.

I Studie I utvärderades betydelsen av tandförlust för lägre testresultat på kognitiva tester. En klinisk och radiologisk undersökning där antal tänder registrerades genomfördes på 1147 individer. Kognitiv funktion utvärderades med hjälp av Mini-Mental Test, (MMT, på engelska kallat Mini-Mental State Examination, MMSE) (tröskelvärde <25) och Klock-test (tröskelvärde <8). Antal tänder kategoriserades till tandlösa, förekomst av 1-19 tänder eller $\geq 20$ tänder. Risk för lägre testresultat på de kognitiva testerna var statistiskt relaterat till antal tänder. Efter att man tagit hänsyn till ålder och utbildningnivå kvarstår tandlöshet som signifikant prediktor för $\mathrm{MMT}<25$ och Klock-test $<8$. En signifikant säkerställd 
skillnad påvisades dessutom mellan gruppen som hade 1-19 tänder vid jämförelse med gruppen som hade fler än 19 tänder för Klocktest $<8$.

I Studie II utvärderades betydelsen av antal tänder och förekomst av parodontal benförlust som prediktorer för lägre testresultat på de kognitiva testerna hos 775 individer. En radiologisk undersökning utfördes med panoramaröntgenteknik och proportionen av antal tandytor med benförlust registrerades. Den kliniska undersökningen inkluderade fickdjupsmätning och registrering av antal tänder. Ett lägre antal tänder (1-19) och förekomst av benförlust på $\geq 30 \%$ av tandytorna var signifikanta prediktorer för MMT $<25$ efter att hänsyn tagits till ålder, kön och utbildningsnivå. En kompletterande analys visade att dessa resultat kvarstod efter att de med MMT resultat <25 exkluderats och gruppen med bättre testresultat (28-30) jämförts med gruppen med intermediärt (25-27) testresultat. Förekomst av ett lägre antal tänder (1-19) var associerat till lägre testresultat avseende Klock-test $(<8)$.

I Studie III utvärderades betydelsen av parodontal benförlust för risken att drabbas av kognitiv försämring under en 6-årsperiod. Sjuhundrafemton individer undersöktes avseende kognitiv funktion både vid den första undersökningen och vid den uppföljande sexårs undersökningen. Endast de som hade ett testresultat avseende MMT $\geq 25$ inkluderades. Kognitiv försämring definierades som en minskning med tre poäng på MMT. Utöver en klinisk och radiologisk tandundersökning deltog alla individer i en medicinsk undersökning. Sociala och demografiska data insamlades via enkäter och skattningsinstrument. Etthundrafemton individer uppvisade en kognitiv försämring. Hög ålder, lägre utbildning, ensamboende, erfarenhet av ischemisk hjärtsjukdom, Body Mass Index, (BMI) $<25$, tandlöshet, förekomst av 1-19 tänder och benförlust på $\geq 30 \%$ av tandytorna var associerat till kognitiv försämring. Benförlust på $\geq 30 \%$ av tandytorna kvarstod som en signifikant prediktor för risken att utveckla kognitiv försämring. Andra faktorer av betydelse var ålder, utbildningsnivå och $\mathrm{BMI}<25$. 
I Studie IV studerades förekomsten av parodontit och tandförlust i en 12-årsuppföljning. Utöver en klinisk och radiologisk tandundersökning deltog alla individer i en medicinsk undersökning. Sociala och demografiska data insamlades via enkäter. Prevalensen av parodontit, definierat som en kombination av 2 tandytor med benförlust och minst en tand med fördjupad ficka $\geq 5 \mathrm{~mm}$, var $39 \%$. Tjugotre procent av individerna förlorade $\geq 3$ tänder. Proportionen av tandytor med benförlust ökade med stigande ålder medan proportionen av tänder med fördjupade fickor var oberoende av ålder. Parodontit ökade risken för förlust av flera tänder. Vid det första undersökningstillfället noterades ett högre antal tandytor med benförlust och tänder med fördjupade fickor $\geq 5 \mathrm{~mm}$ och ett lägre antal tänder hos gruppen som förlorade $\geq 3$ tänder under 12-årsperioden. Hög ålder, parodontit och ensamboende var signifikanta prediktorer för förlust av $\geq 3$ tänder. 


\section{INTRODUCTION}

\section{Older adults and oral health}

The proportion of older people in populations across the world is increasing (1). Increasing life expectancy in older age is related to this trend, especially in high-income countries $(1,2)$. The definition of old age or older adults has varied over time, but in many countries, the time of retirement, 60 - 65 years of age, has been used. Globally, the number of persons aged 60 and above is expected to more than double by 2050 and at that time all major areas of the world, except Africa, will have a population of which nearly a quarter or more are aged 60 and older (3). For many individuals, added life years are accompanied by health, a good quality of life and possibilities to participate in social and working-life activities $(1,4)$. Oral health is an essential factor in healthy ageing $(5,6)$. Political, economic, social, and medical changes have over the years influenced the prerequisites for maintaining good oral health. The approach of dental professionals to preventive-oriented dentistry and various forms of dental insurances may have had an impact on the prevention of oral diseases (7). Today, available evidence suggest that an increasing proportion of older adults retain their teeth and a functional dentition throughout life $(8,9)$. Physical and cognitive decline, comorbidity, and medication may, however, rapidly increase the prevalence of oral diseases. Hence, longitudinal studies aiming at identifying factors associated with oral diseases among older adults and strategies aiming to preserve oral health in these age cohorts are warranted. 


\section{1:1 Tooth loss in older adults}

Tooth loss in older age cohorts is common and constitute a health concern. For the individuals affected, deterioration of chewing capacity and lower quality of life are reported $(5,10-12)$. In addition, tooth loss has been associated with systemic diseases such as cardiovascular disease $(13,14)$ and higher mortality $(6,15)$. Tooth loss among adults can be considered the final consequence of longstanding oral diseases but could also reflect patients' and professionals' attitudes as well as current trends and philosophies of dental care $(16,17)$. The relative contribution of oral diseases to tooth loss and edentulism have been addressed (18-20). In young and middle-aged individuals, many studies conclude that caries is the main reason for extraction and tooth loss (21-25). Among adults, however, an increasing proportion of teeth are lost due to periodontal disease $(21,26,27)$. A recent systematic overview and meta-analysis reported that in $2010,2.3 \%$ of the population world-wide was edentulous and that severe tooth loss, defined as having fewer than ten teeth (1-9), had decreased by $45 \%$ in the period 1990 to 2010 (9). Declining prevalence of edentulism has been reported from various cohorts in Sweden $(28,29)$ and from different parts of Europe (30). The mean number of remaining teeth decrease with age $(31,32)$ and has been reported to vary according to educational level and income $(32,33)$. Dye and coworkers reported a mean number of remaining teeth of 21.8 for the age cohort 65-74 and 19.7 for individuals $\geq 75$ years and older (32). In Sweden the mean number of teeth has increased among older adults. In 1973 the mean number of teeth for 60-year-olds was 18, in 2013 this number had increased to 25 . For 70 -year-olds the equivalent figures were a mean number of 13 teeth in 1973 and 22 teeth in 2013 (31). The incidence of tooth loss among individuals aged 55,65 or 75 was assessed over a ten-year follow-up period by Fure and coworkers (34). An increasing mean number of teeth lost was reported for the different age cohorts: $0.9,1.5$, and 3.1 (34). Similar results have been reported in a longitudinal cohort study of individuals born 1930/32 and 1950/52 in Germany demonstrating a mean tooth loss of 2.6 and 1.2 respectively over the eight-year study period (35). 
The number of teeth sufficient for a functional dentition has been a matter of discussion among dental professionals (36). A full dental arch was long considered as the treatment goal and as necessary for an adequate masticatory function. This goal was, however, questioned and a shorter arch, consisting of 20 teeth, came to be considered sufficient for a functional dentition $(37,38)$. In line with these reports, the World Health Organization, WHO, has proposed, that a functional dentition, should be the target for oral health among older adults (39).

\section{1:2 Periodontitis in older adults}

Periodontitis is an inflammatory disease affecting the supporting tissues of the teeth. The resulting inflammatory host response cause periodontal pocket formation, alveolar bone-loss, and, in its final stage, even tooth loss (40). Clinical and radiographic measurements such as probing pocket depth, clinical attachment level change, and loss of marginal bone have been used to describe the extent and severity of the disease.

Data regarding prevalence of periodontitis, derived from fullmouth examinations, among older adults are rare. A report from 1994 of generally healthy, community-dwelling individuals over the age of 80 and living in the central parts of Stockholm, showed that $50 \%$ of the participants had severe periodontitis defined as four or more sites with a clinical attachment loss of $5 \mathrm{~mm}$ or more and at least one of these sites having a pocket depth of $4 \mathrm{~mm}$ or more (41). More recent studies regarding prevalence of periodontitis in older adults demonstrate substantially different results. Using the same diagnostic criteria, the severe form of periodontitis was reported to affect $11 \%$ and $23 \%$ of the elderly population in the United States $(42,43)$. Data from an elderly population in Niigata, Japan, demonstrated a prevalence rate of $2 \%$ and in two populations in Germany prevalence rates of $25.8 \%$ in Pomerania and $21.7 \%$ in West Germany were reported (44). In a repeated casecontrol study in Sweden, comparing periodontal status from 1973 to 2013 , the proportion of individuals with no or minimal experience of periodontal disease has increased between 2003 and 2013 and this was most pronounced in 80-year-olds (45). 


\section{Cognition and cognitive decline}

The word cognition refers to the mental processes of acquiring knowledge and understanding through thought, experience, and the senses. Cognitive functions are essential for well-being and independent living. Neurocognitive disorders encompass a group of disorders or syndromes that have cognitive impairment as their main defining feature (46). Degenerative neurocognitive disorders are divided into mild and major disorders with different etiological subtypes such as neurocognitive disorder due to Alzheimer's disease (AD) or Lewy body disease. Due to the stigma often associated with both the word dementia and the conditions it refers to the new terminology 'major neurocognitive disorders' is considered more suitable. The term 'dementia', generally used to describe a decline in cognitive abilities that is serious enough to interfere with daily life, may however still be in use, both in clinical practice and everyday speech.

The most common cause of major neurocognitive disorder is Alzheimer's disease. In addition to high age and genetic susceptibility, modifiable risk factors such as midlife hypertension, midlife obesity, smoking, depression, low education, psychosocial factors, and physical inactivity have been related to Alzheimer's disease $(47,48)$. Neurocognitive disorders and their consequences present a challenge that has a major impact on the individuals affected and on society as a whole. This challenge is amplified by the increasing prevalence of neurocognitive disorders seen in many parts of the world due to demographical changes and the fact that no curative treatments are available $(49,50)$.

It has been suggested that impairment in different cognitive domains occur more frequently in various subtypes of neurocognitive disorders. Episodic memory, orientation, and attention is often affected in the early stages of Alzheimer's disease $(51,52)$ whereas individuals affected by Lewy body disease can experience problems navigating themselves in relation to objects, but their memory capacity may remain intact $(53,54)$. 


\section{2:1 Cognitive tests}

Cognitive tests are established tools when evaluating risk for neurocognitive disorders and in screening settings for evaluation of individuals experiencing subjective cognitive decline. The cognitive abilities that the various cognitive tests intend to tap may differ in some perspectives and therefore a combination of tests has been recommended in clinical settings.

\section{2:1:1 Mini-Mental State Examination}

Mini-Mental State Examination, MMSE, has become one of the most widely used and cited cognitive tests since it was developed by psychiatry resident Susan Folstein and junior attending physician Marshal Folstein in 1975. The first section of the test includes orientation, memory, and attention whilst the second section focuses on naming, following commands, writing a sentence, and copying pentagons (55).

With the aim of reporting the distribution of MMSE, Crum and coworkers analysed MMSE scores from 18,056 individuals from five metropolitan areas in the United States and found that the outcome varies within the population by age and education (56). The total score that the test can result in is 30 points and Crum and coworkers' results also point to the skewed distribution of scores, with a heavy clustering at the higher scores (56).

Preliminary guidelines, regarding the evaluation of the total scores, have been suggested by Strobel and Palmqvist. After considering age and level of education, a sum of 28 points or higher may indicate normal cognitive functions, 25-27 points may indicate cognitive impairment and that further testing is recommended and a total score below 25 suggests cognitive impairment or that other factors such as physical impairments, difficulties with reading and writing, lack of motivation or inadequate language skills have significantly affected the outcome (57).

Change in MMSE score has been evaluated in an elderly population, in both short- (approximately three months) and long-term (approximately five years) follow-ups (58). A 2 - 4-point change has been considered sufficient to claim an individual significant 
change i.e. a change not caused by practice effects or measurements errors $(58,59)$. Test-retest reliability has been evaluated both among healthy subjects and among patients with Alzheimer's disease. A practice effect after three months has been reported among healthy subjects but not in patients with AD (60). In longer testretest intervals the practice effect is reduced or completely eliminated (58).

\section{2:1:2 Clock test}

The ability to draw a clock-face and successfully set the time when asked is obtained in early childhood. This task can become remarkably difficult when cognitive impairment is present. Clock drawing has been used in clinical practice to evaluate cognitive status for more than a hundred years. In one version of the test a predrawn circle on a piece of paper is given to the participant with instructions to fill in the numbers and set the clock to a specific time. In the other approach the subjects are instructed to freely draw a clock and set it to a specific time. The free-drawn clock test is considered more demanding with regards to executive abilities. Various scoring systems have been used and evaluated and the scoring method used for Manos 10-point Clock-test demonstrates relatively high sensitivity and specificity (61). Manos evaluated various cut-off scores in general hospital patients. A score of less than eight was considered as sensitive in identifying cognitive deficits associated with dementia (62). It has been suggested that various cognitive domains are being tapped by Clock-test (63) and due to its simplicity and speed of administration it has an important place when screening for neurocognitive disorders. 


\section{Periodontitis, tooth loss, and systemic diseases}

Over the last 30 years a large body of research has focused on the association and interactions between periodontitis and different systemic diseases. An association between poor dental health and myocardial infarction was first reported by Mattila in the late 1980s (64). After this, a number of publications focusing on the association between atherosclerotic vascular disease and periodontitis have been published (65-67). Other non-communicable diseases and conditions such as diabetes and adverse pregnancy outcomes have also been studied in relation to periodontitis $(68,69)$. The research field has been called "periodontal medicine" and include studies on the epidemiological association, potential biological mechanisms, and intervention studies (70).

\section{3:1 Periodontitis, tooth loss, and cognitive decline}

Tooth loss and periodontitis may also be associated with cognitive decline and neurodegenerative disorders. The act of chewing influences the sensory input to the brain, and it has been suggested that tooth loss may alter these signals, possibly affecting cognitive abilities and neurogenesis. This hypothesis is supported by animal studies performed in experimental settings evaluating spatial performance and hippocampal neurons loss after loss of molar support $(71,72)$. A partial reversion has been demonstrated after the molars where restored and the chewing function was re-established (73). The influence of the consistency of diet has also been studied (74). Animals that were fed on a soft, powdered diet demonstrated significant spatial memory dysfunction compared to those on a hard diet (74). Mastication could also be regarded as a form of psychical activity, stimulating cerebral blood flow. Experimental studies in humans have demonstrated that chewing may increase the blood flow to the brain (75) and reduced self-reported chewing ability has been associated to poorer cognitive functioning $(76,77)$. The hypothesis that tooth loss is associated with an increased risk of dementia in adults is supported by a recent systematic review (78).

One of the major reasons for tooth loss among older adults is periodontitis and above it has been stated that periodontitis is an 
inflammatory-driven disease. Periodontitis has also been shown to induce a systemic inflammation $(79,80)$. Although the supporting evidence is limited, mechanisms explaining a potential association between periodontitis and neurodegenerative disease, have been suggested. Proinflammatory cytokines such as IL-1, IL-6, and tumour necrosis factor- $\alpha$ may be released as a consequence of periodontal inflammation (81,82). Inflammatory mediators can be transported to the brain and affect the inflammatory state within the brain $(83,84)$. A feed-back cycle resulting in increasing inflammation and tissue destruction involving beta amyloid and cytokine production may be initiated (85). Another potential mechanism behind the association is direct invasion of periodontal pathogens to the brain. Infection with periodontal pathogens such as $P$. gingivalis has been shown to impair learning and memory abilities in animal studies (86). In a cross-sectional survey, individuals with the highest level of antibodies to $P$. gingivalis in serum were more likely to have poor delayed verbal recall and impaired subtraction compared to those with the lowest levels of such antibodies (87). Increased serum and plasma antibody levels against other periodontal pathogens such as A. Actinomycetemcomitans and T. Forsythia (88) and increased levels of F. Nucleatum and P. Intermedia (89) have been associated with Alzheimer's disease. Oral Treponema specimens, also found in periodontitis, have been detected in higher proportions in postmortem analysis of individuals with $\mathrm{AD}$ compared to donors without AD (90). The third mechanism that may explain the association is through microvascular pathology. Both neurocognitive disorder due to Alzheimer's disease and vascular neurocognitive disorder seem to have a vascular component. A mechanism connecting to periodontitis could be through the induction of atherosclerotic plaque and endothelial damage (91,92).

Cross-sectional studies indicate an association between periodontitis assessed by loss of alveolar bone on panoramic x-rays and cognitive impairment and AD $(93,94)$. Participants with a history of severe periodontitis were 2.1 times as likely to demonstrate cognitive impairment as those without periodontitis (94). Longitudinal follow-up studies with known cognitive status at baseline and ad- 
justments for additional exposures that are known to affect the outcome are rare.

However, in a longitudinal study on the incidence of mild cognitive impairment (MCI), presence of severe periodontitis at baseline and a higher degree of periodontal inflammation was significantly associated with a higher OR for MCI after adjustments (95). 


\section{AIMS}

- to evaluate the impact of tooth loss on cognitive functions in older adults.

- to evaluate the impact of periodontitis on cognitive functions in older adults.

- to evaluate whether periodontitis increases the risk of cognitive decline in older adults in a six-year follow-up.

- to evaluate longitudinal changes in the prevalence of teeth with periodontal pockets, radiographic bone-loss and tooth loss and to evaluate the impact of periodontitis on the likelihood of losing $\geq 3$ teeth in a twelve-year follow-up. 


\section{MATERIAL AND METHODS}

The four papers included in this thesis are based on data from the Swedish National Study on Ageing and Care (SNAC) which is a longitudinal multicentre study in Sweden (96). The overall aim of SNAC is to collect data from different domains, medical, psychological, social, and functional, and then study their relation to the need for social and medical services as well as care among the elderly.

Older adults in different age cohorts $(60,66,72,78,81,84,87$, 90,93 and 96 and older) were included in a prospective study. The participants are followed regularly, every sixth year in the younger cohorts and every third year in the older cohorts (from 78 years).

Four research centres representing different areas of Sweden are involved in SNAC. Karlskrona municipality in Blekinge (SNAC-B) is one of these centres. Persons from the ten age cohorts, drawn from the National Municipality Registry, were randomly selected and invited to participate in the baseline study in 2001. Data used in the present thesis were derived from participants in SNAC-B who agreed to participate in the baseline study (Study I, Study III, Study IV), the six-year follow-up study, to which new 60- and 81year-olds were also recruited (Study II), and the twelve-year followup examinations (Study IV).

In addition to the core study protocol, SNAC-B also include an evaluation of the participants' oral health. The oral examination includes both a clinical and a radiographic examination, a questionnaire focused on symptoms, the individual's perception of their 
own oral health, and various tests from saliva, gingival crevicular fluid, and expired air.

\section{Examinations}

Examinations were performed in a research clinic by members of the research team, specially trained for the purpose. If the participant for any reason was unable to come to the research centre the examination could be performed in their home. Information regarding level of education, living conditions, general health, lifestyle habits, utilisation of dental health care services and dental hygiene habits were collected based on questionnaires. The level of depression was evaluated using Montgomery Asberg Depression Rating Scale (MADRS) (97). Body mass index (BMI) was calculated as weight divided by height in square meters with light clothes. Alcohol Use Disorders Identification Test (AUDIT) was used to evaluate level of alcohol consumption and its consequences (98).

\section{Cognitive assessment}

Medical nurses performed the cognitive tests. Except for the medical nurse and the participant, no one else was allowed to be present in the room during the test or in any way disrupt the test procedure. Both the MMSE and the Clock-test were performed according to the same test protocol at the different visits.

The Clock-test was administered on a piece of paper with a predrawn circle. The participant was shown the piece of paper and the following instructions were given: this circle represents a clock face, please fill in the numbers so that it looks like a clock and then set the time to 10 minutes past 11 . A transparent circle divided into eighths was then used for scoring, summarised as follows: one point if the short hand points at 11 and one point for the long hand pointing at 2 and additionally one point was given for the $1,2,4,5,7,8,10$ and 11 if they are in the proper octant of the circle relative to number 12 . The test can result in a total score of 10 points, worst to best. 


\section{Dental examination}

The dental examinations were performed in one of the examination rooms at the research centre with a dental chair and adequate dental equipment. Periodontal probing was performed using a CP12 periodontal probe (Hu Friedy, Chicago, IL) at four sites per tooth. At the baseline and six-year follow-up only the deepest pocket at each tooth was registered. At the twelve-year follow-up all pockets at six sites were recorded and registered. Bleeding on probing was registered following periodontal probing. Dental caries was clinically registered as open cavity on the buccal and lingual surface of each tooth. A panoramic radiograph was taken using OP100 Instrumentarium Imaging, Tuusula, Finland with a standard exposure of $75 \mathrm{kV} / 10 \mathrm{~mA}$ at baseline and at the six-year follow-up. At the twelve-year examination a Gendex Orthoralix $920070 \mathrm{kV}, 4 \mathrm{~mA}$ was used. The extent of alveolar bone loss was measured at the mesial and distal aspects of the existing teeth. The number of interproximal sites that could be assessed from the panoramic radiographs was used to calculate the proportion of sites with a distance $\geq 4 \mathrm{~mm}$ and $\geq 5 \mathrm{~mm}$ between the alveolar bone level and the cemento-enamel junction (CEJ). An independent and experienced examiner masked to the information about medical and dental records performed all the radiographic measurements.

\section{Ethical considerations}

These studies comply with the ethical rules for research as described in the World Medical Association (WMA), Declaration of Helsinki (99). Four different ethical considerations should be fulfilled in clinical research; the information, the consent, the confidentiality and the utility requirement. All potential participants received detailed information about the study and were informed that participation was voluntary. They were also informed that they could withdraw from the study at any time without having to explain why and without any risk of consequences. All participants gave their signed informed consent before inclusion in the study. To protect the integrity of the study participants, identifying information was anonymised, coded, and stored. Only the principal 
investigator had access to the unique code key. The test leaders were educated in helping the participants to cope with feelings such as stress, anxiety and fear of failure that may be associated with participating in the cognitive tests. All data used for the studies had previously been approved by Regional Research Ethics Committee at Lund University (LU dnr LU-128-00,604-00,650-00 and 744$00)$. 


\section{STATISTICAL ANALYSIS}

\section{Paper I}

Contingency tables were created to explore frequency distribution regarding the candidate explanatory variables and intergroup differences were analysed using chi-squared test for categorical variables. A significance level of $5 \%$ was used (two-tailed). Logistic regression was performed to assess the impact of number of teeth on the likelihood of having CT $<8$ and MMSE $<25$, first univariate and thereafter with adjustments for explanatory covariables.

\section{Paper II and III}

Kappa statistics and reliability analysis were performed regarding inter- and intra- agreement for probing pocket measurements and for the reproducibility of sites with $\geq 5 \mathrm{~mm}$ from cemento-enamel junction to the alveolar bone level and for the distance between cemento-enamel junction to apex. Number of teeth, mean (SD) and median (IQR) were calculated (Paper II). Contingency tables were created to explore frequency distribution in the group with cognitive decline and the group not fulfilling the criteria for cognitive decline and in the group with periodontal bone-loss compared to the group not fulfilling the criteria for periodontal bone-loss. Intergroup differences were analysed using chi-squared test for categorical variables. Logistic regression was performed to assess the impact of number of teeth and bone-loss on the likelihood of MMSE $<25$ first univariate and thereafter with adjustments for explanatory covariables (Paper II). After exclusion of individuals with the lowest cognitive test outcome, logistic regression was performed to 
assess the impact of the covariables on the likelihood of having a MMSE-score of 25-27. The impact of periodontal bone-loss on the likelihood for cognitive decline ( $\geq 3 p$ MMSE) were analysed using logistic regression and variables were added in blocks based on number available for analysis and domain: demographic, medical, and social (Paper III).

\section{Paper IV}

Mean number of teeth, mean number of tooth loss, mean number and proportion of teeth with pockets $\geq 5 \mathrm{~mm}$, and mean number and proportion of sites with bone- loss $\geq 4 \mathrm{~mm}$ and $\geq 5 \mathrm{~mm}$ was analysed using Analysis of Variances (ANOVA), Bonferroni correction, and Kruskal Wallis test. Chi-square test for independence was used to explore the association between age groups and prevalence of periodontitis and dental caries respectively. Number of teeth (mean and median) and tooth loss (mean and median) in the group having periodontitis compared to the healthy group, were analysed using Student's t-test and Mann-Whitney U test. Subsequently, number of teeth, number of sites $\geq 5 \mathrm{~mm}$ and number of teeth with pockets $\geq 5 \mathrm{~mm}$ in the group loosing $\geq 3$ teeth compared to the group with no tooth loss or losing 1-2 teeth were analysed using Student's t-test and Mann-Whitney U test. The impact of the candidate explanatory variables on the risk of losing $\geq 3$ teeth was analysed first by univariate analysis and thereafter the influential explanatory variables were analysed using multiple logistic regression.

In all four papers odds ratio (OR), 95\% confidence interval (CI) and p-values were calculated; p-values $<0.05$ were regarded as statistically significant. A statistical software program (IBM SPSS version 20.0, 22.0 and 24.0, IBM Statistics, Amorak, NY,USA) was used for the analysis. 


\section{RESULTS}

During the baseline examination 2,312 individuals were invited and 1,402 agreed to participate.

Table 1.

Distribution of individuals in the different age cohorts at baseline.

\begin{tabular}{|c|c|c|c|c|c|c|}
\hline Age & 60,66 & 72,78 & 81,84 & 87,90 & $\geq 93$ & \\
\hline Invited & 528 & 515 & 632 & 502 & 135 & 2312 \\
\hline $\begin{array}{l}\text { Declined to } \\
\text { participate } \\
\text { (n) }(\%)\end{array}$ & $\begin{array}{l}131 \\
(25 \%)\end{array}$ & $\begin{array}{l}172 \\
(33 \%)\end{array}$ & $\begin{array}{l}277 \\
(44 \%)\end{array}$ & $\begin{array}{l}253 \\
(50 \%)\end{array}$ & \begin{tabular}{|l|}
77 \\
$(57 \%)$
\end{tabular} & 910 \\
\hline $\begin{array}{l}\text { Declined to } \\
\text { participate } \\
\text { in the dental } \\
\text { examination } \\
(\mathrm{n})(\%)^{*}\end{array}$ & $\begin{array}{l}29 \\
(7 \%)\end{array}$ & $\begin{array}{l}34 \\
(9.9 \%)\end{array}$ & $\begin{array}{l}66 \\
(18.6 \%)\end{array}$ & $\begin{array}{l}92( \\
37 \%)\end{array}$ & $\begin{array}{l}34 \\
(58.6 \%)\end{array}$ & 255 \\
\hline $\begin{array}{l}\text { Study cohort } \\
\text { (n) }\end{array}$ & 368 & 309 & 289 & 157 & 24 & 1147 \\
\hline
\end{tabular}

* proportion of individuals that declined to participate in the dental examination of those accepting to participate in the other parts of the study.

Cognitive tests, Mini-Mental State Examination, and Clock-test were performed in 1,364 (MMSE) and 1,256 (CT) individuals. A MMSE score below 25 was evident in 323 individuals and a Clock-test score below 8 in 346 individuals. After exclusion of individuals not completing MMSE due to functional disabilities such as hearing and visual impairment, an outcome below 25 was evident in 239 indi- 
viduals. A dental examination was performed in 1,147 individuals with the following age distribution: Young-old $(60,66) 32 \%$, Old $(72,78) 27 \%$ and Old-old $(\geq 81) 41 \%$. A higher level of education was reported in 170 individuals. The individuals were allocated into three groups: edentulous (17\%), 1-19 teeth $(40 \%)$ and $\geq 20$ teeth $(43 \%)$. Age and level of education was significantly associated to the number of teeth. Low cognitive test score was statistically related to the number of teeth. After adjustments for age and education in logistic regression analysis, a statistically significant impact of being edentulous on the likelihood for lower cognitive test outcome, OR 3.2 (MMSE) and OR 1.9 (CT) was demonstrated. Regarding the dentate groups, having 1-19 or $\geq 20$ teeth, a statistically significant difference was demonstrated for Clock-test, OR 1.5.

Conclusions: presence of teeth may be of importance for cognitive abilities among older adults.

In Study II, 775 dentate individuals examined during 2007-2009 were selected. Age distribution in the different cohorts were $43 \%$ in the Young-old cohort $(60,66), 32 \%$ in the Old cohort $(72,78$ years) and $25 \%$ in the Old-old cohort ( $\geq 81$ years). Alveolar bone loss, defined as having $\geq 4 \mathrm{~mm}$ from CEJ to marginal bone level at $\geq 30 \%$ of readable sites was evident in 115 individuals and associated with high age and male gender. In 249 individuals 1-19 teeth were present and this was associated with high age and a lower educational level. Prevalence of pockets $\geq 5 \mathrm{~mm}$ on $\geq 30 \%$ of teeth was evident in 50 individuals and more common among males. A MMSE-score of below 25 was evident in 64 individuals and 167 had an MMSE-score of 25-27. With regards to the Clock-test, 136 individuals scored $<8$.

Bone-loss and having 1-19 teeth influenced the risk for cognitive test-outcome using MMSE <25, after adjustments for age, gender, and education, OR 2.7 and 2.0 respectively. The impact of bone-loss and having 1-19 teeth remained after exclusion of the individuals with the lowest cognitive test outcomes $<25$, when comparing the group with an MMSE score of 25-27 to those with an MMSE score of $\geq 28$, OR 1.7 and 1.9 respectively. Having a lower number of teeth (1-19) also influenced the risk for lower cognitive test outcome using Clock-test. However, this was not significant in the final model. 
Conclusions: a history of periodontitis and tooth loss may be of importance for cognitive abilities and cognitive decline among older adults.

In Study III, 704 individuals examined both at baseline and at the six-year follow-up were selected. Cognitive decline defined as $a \geq 3$ -points deterioration in MMSE score from a predetermined level (MMSE $\geq 25$ ) at baseline was evident in 115 individuals. Periodontal bone loss defined as having $\geq 4 \mathrm{~mm}$ distance from CEJ to marginal bone level at $\geq 30 \%$ of readable sites was evident in 214 individuals. High age, elementary education, living alone, experience of ischemic heart disease, BMI $<25$, being edentulous, having 1-19 teeth, and bone loss was significantly associated with cognitive decline. Periodontal bone loss was significantly associated with high age, lower education, male gender, being a current or former smoker, experience of ischemic heart disease, living alone, fewer teeth (1-19), and presence of pockets ( $\geq 5 \mathrm{~mm}$ on $30 \%$ of teeth). Periodontal bone loss had a significant impact on the risk for cognitive decline, unadjusted OR 2.8 and adjusted OR 2.2.

Conclusions: a history of periodontitis may be of importance for development of cognitive decline among older adults. 
Table 2.

Logistic regression analysis for the outcome cognitive decline, based on deterioration $\geq 3 p$ from baseline to six-year follow-up using MMSE, the odds ratio for periodontal bone-loss unadjusted and adjusted for demographic, medical, and social variables.

\begin{tabular}{|c|c|c|c|c|c|c|c|c|c|c|}
\hline & 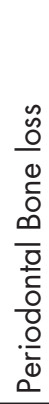 & 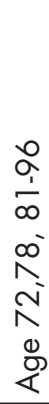 & $\frac{0}{0}$ & 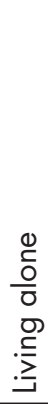 & 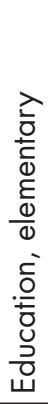 & 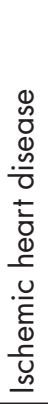 & 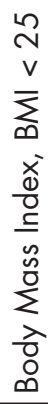 & 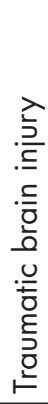 & 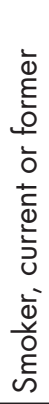 & 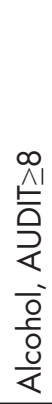 \\
\hline Unadjusted & $\begin{array}{l}\varpi \\
+ \\
+ \\
= \\
\infty \\
\infty \\
\sim\end{array}$ & & & & & & & & & \\
\hline Adjusted & 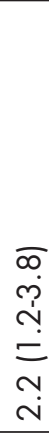 &  & $\begin{array}{l}\infty \\
\dot{\infty} \\
\text { ம் } \\
0 \\
0 \\
0\end{array}$ & 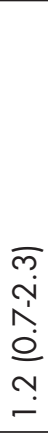 & 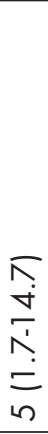 & 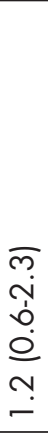 & $\begin{array}{l}\bar{\gamma} \\
\tilde{m} \\
\text { ஸे } \\
= \\
\bar{N}\end{array}$ & $\begin{array}{l}\bar{\sigma} \\
\bar{j} \\
\dot{y} \\
0 \\
\infty \\
0 \\
0\end{array}$ & $\begin{array}{l}\bar{m} \\
\stackrel{N}{ } \\
\\
\stackrel{0}{m} \\
\stackrel{-}{-}\end{array}$ & 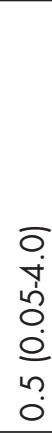 \\
\hline
\end{tabular}

Logistic regression model, unadjusted and adjusted for all included variables. Values in bold signify statistical significance $p<0.05$. Confidence interval, $\mathrm{Cl}(95 \%)$

After twelve years, 451 individuals examined at baseline were available for a follow-up dental examination. 
Flow-chart of the study population from baseline to the twelve-year follow-up examination.

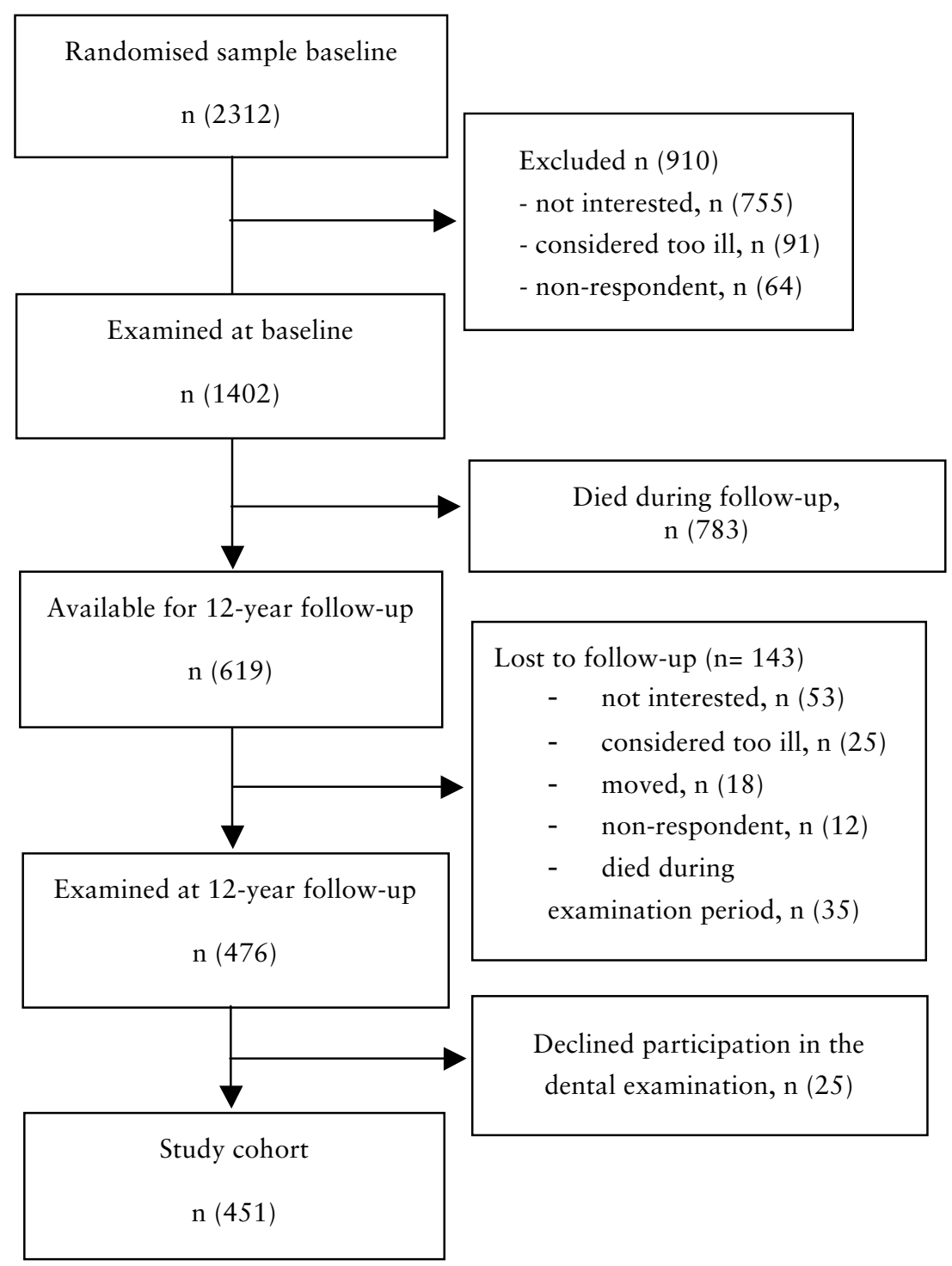


After exclusion of individuals lacking x-rays (49) and edentulous individuals (27) at baseline the results in Study IV are based on 375 individuals. A diagnosis of periodontitis defined as having $\geq 2$ sites with $\geq 5 \mathrm{~mm}$ from cemento-enamel junction to the marginal bone level and $\geq 1$ tooth with pockets $\geq 5 \mathrm{~mm}$ was evident in $39 \%$ of the individuals at baseline. Tooth loss over the study period was evaluated and is presented in the table below.

\section{Table 3.}

Number and proportion of individuals according to number of teeth lost during the twelve-year follow-up period.

\begin{tabular}{|l|c|c|c|c|c|c|}
\hline $\begin{array}{l}\text { Number of teeth } \\
\text { lost (n) }\end{array}$ & 0 & 1 & 2 & 3 & 4 & $\geq 5$ \\
\hline $\begin{array}{l}\text { Number of } \\
\text { individuals (n) }\end{array}$ & 144 & 90 & 55 & 27 & 15 & 44 \\
\hline Proportion (\%) & 38.4 & 24 & 14.7 & 7.2 & 4.0 & 11.7 \\
\hline
\end{tabular}

Twenty-three per cent of the individuals lost $\geq 3$ teeth during the study period. This group demonstrated a lower number of teeth at baseline and a higher number of sites $\geq 5 \mathrm{~mm}$ and teeth with pockets $\geq 5 \mathrm{~mm}$.

Having a diagnosis of periodontitis, living alone, and high age were significant predictors for tooth loss in the adjusted model. Proportion of readable sites $\geq 4 \mathrm{~mm}$ and $\geq 5 \mathrm{~mm}$ increased with age while no significant differences between the age cohorts regarding number and proportion of teeth with pockets $\geq 5 \mathrm{~mm}$ could be identified. Regarding tooth loss (mean) no significant differences were identified between the different age cohorts.

Conclusions: periodontitis is a risk factor for multiple tooth loss in older adults.

Altogether, in this cohort of older adults, having a diagnosis of periodontitis increased the risk for multiple tooth loss and cognitive decline was associated to tooth loss and a history of periodontitis. 


\section{DISCUSSION}

This thesis focuses on the association between periodontitis, tooth loss, cognitive functions, and longitudinal changes in oral health in older adults. Two of the papers included in the thesis are crosssectional (Paper I and II) whilst the other two papers are longitudinal follow-up studies (Paper III and IV). In paper I we found a significant impact of the number of teeth on cognitive functions, evaluated with Clock-test and MMSE. In paper II both the number of teeth and periodontal bone-loss had a significant impact on cognitive test outcome using MMSE. Cognitive impairment and dementia have been associated to tooth loss by other researchers (100102). Complete tooth loss was recently reported to be associated with lower MMSE score (102). In addition, both partial and complete tooth loss were associated with a steeper decline in MMSE score compared to the group without tooth loss, over a nine-year follow-up period (102). However, other studies have failed to demonstrate an association between tooth loss and cognitive functioning $(103,104)$. The reasons for discrepant findings may be found in different study designs. Another explanation may be related to the assessments of tooth loss. In our studies, information regarding tooth loss was collected from a clinical dental examination while other studies have used self-reported data and questionnaires, which may affect the accuracy of the collected information. Having 1-19 teeth influenced the risk for lower cognitive test outcome using both MMSE and Clock-test. Prevalence of periodontal bone-loss and pockets depths $\geq 5 \mathrm{~mm}$, evaluated in Paper II, were however not significantly related to the cognitive test outcome us- 
ing Clock-test. The different cognitive tests may assess various cognitive abilities which could explain the different outcomes. Traditionally, the Clock-test was suggested to reflect visuoconstructive impairments. The Clock-test is not sensitive to language skills and seems to be less affected by depressive symptoms. The MMSE includes evaluation of memory capacity, which is usually affected early in Alzheimer's disease. MMSE is the most frequently used test assessing a potential association between oral health and cognitive function (105). In paper II the impact of periodontal bone-loss on the risk for lower cognitive test outcome was still present after exclusion of individuals having MMSE <25, when comparing the group with a MMSE score of 25-27 to those having MMSE $\geq 28$. These results are in line with other studies demonstrating that the impact of number of teeth and attachment loss on the risk for cognitive impairment is unrelated to the level of cognitive impairment (106). Oral hygiene habits and bleeding index have, however, been related to a gradient of cognitive impairment, demonstrating poorer values with a greater severity of cognitive impairment $(106,107)$.

In Paper II no significant association was evident between having a probing pocket depth $\geq 5 \mathrm{~mm}$ on $30 \%$ of the teeth, which was evident in $6.7 \%$ of the study population, and lower cognitive test outcome. The prevalence rate may be related to this finding. Generalised marginal bone loss, defined as having lost $1 / 3$ of the root length in $30 \%$ of the teeth, has been associated with Alzheimer's disease and cognitive impairment, in cross-sectional setting, by others (93). Although periodontal bone-loss and tooth loss are considered the result of a life-time burden of oral disease the study design in Papers I and II cannot confirm a causal relation. Temporal bias (reverse causality), i.e. that cognitive decline causes periodontitis, is also conceivable. Another factor that may affect the validity of the results in Papers I and II are unknown or unmeasured confounders, i.e. residual confounding. In addition to age and education, observational studies exploring the association between tooth loss and dementia adjust for a variety of factors such as cardiovascular risk factors, depression, smoking, and alcohol intake (78). Another issue influencing the possibility to compare and draw conclusions regarding a possible association between periodontitis 
and neurocognitive disorders is the fact that a variety of measures, markers, and diagnostic criteria have been used to define both diseases (108). Tonsekar addresses these issues and suggests a more uniform assessment of both oral health and cognitive status (108).

In Paper III, a longitudinal follow-up study, the impact of periodontal bone-loss on the risk for cognitive decline was evaluated after adjustments for demographic, medical, and lifestyle factors. Longitudinal studies demonstrate that cardiovascular fitness in midlife is associated with lower risk for dementia (109) and cardiovascular risk factors in midlife are related to Alzheimer's disease (47). Having periodontitis has been identified as a risk factor for myocardial infarction and stroke $(65,66)$ and in Paper III experience of ischemic heart disease was associated to both cognitive decline and periodontal bone-loss. Midlife has been suggested as "window of vulnerability" when it comes to the effect of cardiovascular risk factors on dementia and a high BMI in midlife seems to be related to an increased risk of later-life dementia (47). In Paper III having a $\mathrm{BMI}<25$ was a significant risk factor for cognitive decline over the six-year follow-up. A pattern of decline in BMI over time in individuals who develop dementia has been demonstrated (110) and the impact of late life BMI on the risk for dementia is less clear (111). Longitudinal studies evaluating the impact of periodontitis on the risk for developing cognitive decline in individuals characterised as cognitively healthy at baseline are very limited. A higher risk for cognitive decline has however been reported for individuals with severe periodontitis compared to individuals without periodontitis (95). Consistent results were reported when using different definitions of periodontitis (95). In a study by Iwasaki and coworkers, the cut-off of $\geq 3$ points using MMSE for cognitive decline was adopted, and such a decline was evident in $24.7 \%$ of the participants over a three-year period (112). In our study, $16.3 \%$ of the individuals experienced cognitive decline over six years. As cognitive decline is more prevalent with increasing age the selected sample is of importance for the prevalence rates and in the study by Iwasaki and coworkers individuals aged $>75$ years were included (112). Systematic reviews have been published to determine whether evidence supports the association between perio- 
dontitis and dementia (113-115). Leira and coworkers found that the pooled OR for the association between periodontitis and Alzheimer's disease was 1.69 and when including only severe periodontitis the OR was 2.29 (115).

In Paper IV the prevalence of periodontitis, defined as having at least two sites with $\geq 5 \mathrm{~mm}$ distance from CEJ to marginal bone level and at least one tooth with pockets $\geq 5 \mathrm{~mm}$, was $39 \%$. No significant differences in prevalence rates were identified between the different age cohorts. In a systematic review and meta-analysis, the prevalence of severe periodontitis peaked at age 40 and remained stable in older age (116). New cases developed with increasing age, but the incidence was low and fairly constant (116). The distribution of periodontitis in relation to age has been reported by Billings and coworkers in two general population samples (117). Although differences were observed between the populations studied, the age-dependent distribution of CAL, PD, and recession presented the same pattern; mean attachment loss increased with age while mean pocket depth remained fairly constant (117). In addition, a skewed distribution of attachment loss within each age cohort was reported (117). These results are in line with ours. A loss of $\geq 3$ teeth over the twelve-year study period was evident in $23 \%$ of the individuals. Clustering of multiple tooth loss in a subpart of the studied populations has been reported by others $(24,118)$. In addition to periodontitis at baseline, living alone was associated to tooth loss ( $\geq 3$ teeth). Person-level characteristics, such as smoking, systemic diseases, and socioeconomic factors have been associated to an increased tendency towards tooth loss (119121). In Study IV, frequency of dental visits, level of education, MMSE, use of interdental care devices, BMI, diabetes, and ischemic heart disease were not significantly associated to multiple tooth loss ( $\geq 3$ teeth). This may be related to the characteristics of the population studied, with high level of both dental care attendance and oral hygiene routines. The mean annual tooth loss for the entire population studied was 0.15 . A higher mean annual tooth loss has been reported for individuals $\geq 50$ years compared to younger cohorts (122). 
Periodontitis has been associated to future tooth loss and in Study IV individuals with periodontitis lost more teeth than those characterised as healthy. Beck and coworkers reported that teeth with a high level of attachment loss at baseline had a higher probability of being lost during a five-year follow-up period (119). Similar results have been reported by other researchers $(25,120)$. Probing pocket depths of $5 \mathrm{~mm}$ have also been reported as a risk factor for tooth loss (123). No significant differences in tooth loss (mean) between the different age cohorts were identified in our study. Conflicting results have, however, been reported (35).

The characteristics of the study cohort is of importance especially in longitudinal studies. The impact of disease modifiable and confounding factors may vary between different cohorts and hence influence the results. Additionally, individuals available for the final analysis may in many aspects differ from the drop-outs. This effect, known as selective attrition, is a well-known limitation especially with regards to studies of older adults. In Papers I and II, individuals available for the final analysis were younger and presented higher cognitive test-outcomes than the non-attendants. In Paper III, the group not selected for the final analysis were found to be older and more likely to have a lower level of education, live alone, have ischemic heart disease, have a BMI $<25$, have fewer teeth and be edentulous, and to be more likely to have bone-loss and periodontal pockets than the selected study cohort. Therefore, an influence of attrition of the results in these studies cannot be completely ruled out. Despite a potential healthy survivor effect, the large randomised sample improve the external validity of the results.

Another methodological limitation may be the lack of registration of clinical attachment (CAL) as a measure of disease severity. It has been proposed that CAL should be included in epidemiological studies reporting severity of periodontitis. However, the use of panoramic x-rays is considered a robust marker of cumulative burden of periodontal disease and the risk for misclassification is considered as low, especially as the definition for bone-loss requires that $\geq 30 \%$ of the sites are affected. 


\section{CONCLUSIONS}

- Tooth loss was a significant predictor of a lower cognitive test outcome.

- Periodontitis, evident as radiographic bone-loss, was a significant predictor of a lower cognitive test outcome using MMSE.

- Periodontitis, evident as radiographic bone-loss, was an independent risk indicator for incident cognitive decline in a sixyear follow-up.

- The proportion of sites with radiographic bone-loss increased with age while the proportion of teeth with periodontal pockets remained stable.

- Periodontitis was a significant predictor for multiple tooth loss in a twelve-year follow-up. 


\section{CLINICAL IMPLICATIONS AND SUG- GESTIONS FOR FUTURE RESEARCH}

As cognitive impairment is a predictor for the transition from health and independence to disease and dependence, strategies focusing on how to support older individuals with cognitive decline in maintaining oral health, are needed. Studies aimed at early identification of cognitive decline and how to support essential functions and thereby reducing the negative impact on oral health are therefore warranted. In clinical practice, dentists and dental hygienists should offer individualised prophylactic treatment regimes based on the patient's needs and taking into account the patient's psychological and cognitive abilities. One strategy to support individuals in their everyday life may be the use of digital aids. Such aids may be applications on mobile units, reminding the user about oral health-related behaviours. Intervention studies on how such solutions can assist older adults are needed. Another issue of importance is how older individuals with physical and psychological limitations maintain their contact with dental professionals and access adequate dental care throughout life. How the oral health care system can best provide high quality care in the future to this growing segment of the population needs to be further explored.

Additional studies exploring if periodontitis is a risk factor for different forms of neurodegenerative diseases and potential pathological mechanisms for this association are needed. Such studies may benefit from using different forms of biomarkers, cognitive tests and diagnostic instruments. 
Evaluating individuals' experiences of living with cognitive decline can shed light upon its influence on the impact on oral health. Studies using a qualitative or mixed research methodology are therefore also warranted.

Finally, identifying factors associated with periodontitis and tooth loss both in independent, well-maintained older adults, and in care-dependent elderly are required. The impact of living alone and of other social conditions associated with the ageing process needs to be taken into consideration when evaluating the risk of oral diseases and tooth loss. Prophylactic dental care may in addition to social support prevent further tooth loss and thereby reduce the costs for oral rehabilitation. 


\section{ACKNOWLEDGEMENTS}

I would like to express my appreciation and sincere gratitude to all those who have helped and supported me throughout my research.

All study participants. The studies in this thesis are based on The Swedish National Study on Ageing and Care (SNAC), which is financially supported by the Swedish Ministry of Health and Social Affairs and by the participating county councils, municipalities, and university departments. I am grateful to the participants and to the counties and municipalities whose contributions made this thesis possible.

Professor Stefan Renvert, my main supervisor, for your support and constructive feedback and for giving me the opportunity to do the research.

Professor Johan Sanmartin Berglund, co-supervisor, for your support and for giving valuable input on the manuscripts.

Peter Abrahamson, Head of Specialisttandvården, Halland, for support and encouragement. Thank you for creating a fun and creative unit.

Members of Department of Research and Development, Halland for all kind of assistance during the process and for your friendly and supportive nature. A special mention to Amir Baigi, Ulf 
Strömberg, Sasa Pejicic and Anders Holmén for sharing your statistical knowledge.

Erik Resebo, Ulrika Isaksson, Hans Krona and Christina Karlsson for their professionalism and valuable support with all kinds of issues regarding collection of data.

Daniel Nebel, for support and friendship.

Petronella Magnusson, for creating the front cover.

Cecilia Hallström Parker for help with grammar review of the final thesis.

Christina Stenervik, for excellent assistance in secretarial issues and for your encouragement and friendly attitude.

Viveca Wallin Bengtsson, friend and research colleague for your kind and warm personality.

All my friends and colleagues at Specialisttandvården, Halland, for friendship and support.

To Jan for being my life companion and the best father to our three children Moa, Anna and Arvid, who are more important to me than anything else.

My beloved family, Per-Olof, Gunvor, Rasmus, Magnus and Emelie for love, support, and encouragement throughout my life.

Region Halland and Southern Health Care Region for financial support. 


\section{REFERENCES}

(1) WHO. World report on ageing and health. Geneva, Switzerland: World Health Organization; 2015.

(2) Christensen K, Doblhammer G, Rau R, Vaupel JW. Ageing populations: the challenges ahead. Lancet 2009 October 03;374(9696):1196-1208.

(3) United Nations, Department of Economic and. World Population Prospects: The 2015 Revision, Key Findings and Advance Tables. 2015.

(4) GBD 2013 DALYs and HALE Collaborators, Murray CJ, Barber RM, Foreman KJ, Abbasoglu Ozgoren A, Abd-Allah F, et al. Global, regional, and national disability-adjusted life years (DALYs) for 306 diseases and injuries and healthy life expectancy (HALE) for 188 countries, 1990-2013: quantifying the epidemiological transition. Lancet 2015 November 28;386(10009):2145-2191.

(5) Muller F, Shimazaki Y, Kahabuka F, Schimmel M. Oral health for an ageing population: the importance of a natural dentition in older adults. Int Dent J 2017 September 01;67 Suppl 2:7-13.

(6) Holm-Pedersen P, Schultz-Larsen K, Christiansen N, Avlund K. Tooth loss and subsequent disability and mortality in old age. J Am Geriatr Soc 2008 March 01;56(3):429-435.

(7) Guarnizo-Herreno CC, Watt RG, Stafford M, Sheiham A, Tsakos G. Do welfare regimes matter for oral health? A multilevel analysis of European countries. Health Place 2017 July 01;46:65-72.

(8) Schwendicke F, Krois J, Kocher T, Hoffmann T, Micheelis W, Jordan RA. More teeth in more elderly: Periodontal treatment needs in Germany $1997-$ 2030. J Clin Periodontol 2018 December 01;45(12):1400-1407.

(9) Kassebaum NJ, Bernabe E, Dahiya M, Bhandari B, Murray CJ, Marcenes W. Global Burden of Severe Tooth Loss: A Systematic Review and Metaanalysis. J Dent Res 2014 July 01;93(7 Suppl):20S-28S. 
(10) Echeverria MS, Wunsch IS, Langlois CO, Cascaes AM, Ribeiro Silva AE. Oral health-related quality of life in older adults-Longitudinal study. Gerodontology 2019 June 01;36(2):118-124.

(11) Kosaka T, Ono T, Kida M, Kikui M, Yamamoto M, Yasui S, et al. A multifactorial model of masticatory performance: the Suita study. J Oral Rehabil 2016 May 01;43(5):340-347.

(12) Sheiham A, Steele J. Does the condition of the mouth and teeth affect the ability to eat certain foods, nutrient and dietary intake and nutritional status amongst older people? Public Health Nutr 2001 June 01;4(3):797-803.

(13) Asai K, Yamori M, Yamazaki T, Yamaguchi A, Takahashi K, Sekine A, et al. Tooth loss and atherosclerosis: the Nagahama Study. J Dent Res 2015 March 01;94(3 Suppl):52S-58S.

(14) Munoz-Torres FJ, Mukamal KJ, Pai JK, Willett W, Joshipura KJ. Relationship between tooth loss and peripheral arterial disease among women. J Clin Periodontol 2017 October 01;44(10):989-995.

(15) Osterberg T, Carlsson GE, Sundh V, Steen B. Number of teeth--a predictor of mortality in the elderly? A population study in three Nordic localities. Acta Odontol Scand 2007 November 01;65(6):335-340.

(16) Fejerskov O, Escobar G, Jossing M, Baelum V. A functional natural dentition for all--and for life? The oral healthcare system needs revision. J Oral Rehabil 2013 September 01;40(9):707-722.

(17) Baelum V, van Palenstein Helderman W, Hugoson A, Yee R, Fejerskov O. A global perspective on changes in the burden of caries and periodontitis: implications for dentistry. J Oral Rehabil 2007 December 01;34(12):872906; discussion 940.

(18) Susin C, Oppermann RV, Haugejorden O, Albandar JM. Tooth loss and associated risk indicators in an adult urban population from south Brazil. Acta Odontol Scand 2005 April 01;63(2):85-93.

(19) Thorstensson H, Johansson B. Why do some people lose teeth across their lifespan whereas others retain a functional dentition into very old age? Gerodontology 2010 March 01;27(1):19-25.

(20) Hirotomi T, Yoshihara A, Ogawa H, Miyazaki H. Tooth-related risk factors for tooth loss in community-dwelling elderly people. Community Dent Oral Epidemiol 2012 April 01;40(2):154-163.

(21) Lee CY, Chang YY, Shieh TY, Chang CS. Reasons for permanent tooth extractions in Taiwan. Asia Pac J Public Health 2015 March 01;27(2):NP2350-7.

(22) Reich E, Hiller KA. Reasons for tooth extraction in the western states of Germany. Community Dent Oral Epidemiol 1993 December 01;21(6):379383. 
(23) Chestnutt IG, Binnie VI, Taylor MM. Reasons for tooth extraction in Scotland. J Dent 2000 May 01;28(4):295-297.

(24) van der Velden U, Amaliya A, Loos BG, Timmerman MF, van der Weijden, F A, Winkel EG, et al. Java project on periodontal diseases: causes of tooth loss in a cohort of untreated individuals. J Clin Periodontol 2015 September $01 ; 42(9): 824-831$.

(25) Manji F, Baelum V, Fejerskov O. Tooth mortality in an adult rural population in Kenya. J Dent Res 1988 February 01;67(2):496-500.

(26) Reich E, Hiller KA. Reasons for tooth extraction in the western states of Germany. Community Dent Oral Epidemiol 1993 December 01;21(6):379383.

(27) Akhter R, Hassan NM, Aida J, Zaman KU, Morita M. Risk indicators for tooth loss due to caries and periodontal disease in recipients of free dental treatment in an adult population in Bangladesh. Oral Health Prev Dent 2008;6(3):199-207.

(28) Osterberg T, Carlsson GE. Dental state, prosthodontic treatment and chewing ability - a study of five cohorts of 70-year-old subjects. J Oral Rehabil 2007 August 01;34(8):553-559.

(29) Hugoson A, Koch G, Gothberg C, Helkimo AN, Lundin SA, Norderyd O, et al. Oral health of individuals aged 3-80 years in Jonkoping, Sweden during 30 years (1973-2003). II. Review of clinical and radiographic findings. Swed Dent J 2005;29(4):139-155.

(30) Muller F, Naharro M, Carlsson GE. What are the prevalence and incidence of tooth loss in the adult and elderly population in Europe? Clin Oral Implants Res 2007 June 01;18 Suppl 3:2-14.

(31) Norderyd O, Koch G, Papias A, Kohler AA, Helkimo AN, Brahm CO, et al. Oral health of individuals aged 3-80 years in Jonkoping, Sweden during 40 years (1973-2013). II. Review of clinical and radiographic findings. Swed Dent J 2015;39(2):69-86.

(32) Dye BA, Weatherspoon DJ, Lopez Mitnik G. Tooth loss among older adults according to poverty status in the United States from 1999 through 2004 and 2009 through 2014. J Am Dent Assoc 2019 January 01;150(1):923.e3.

(33) Griffin SO, Griffin PM, Li CH, Bailey WD, Brunson D, Jones JA. Changes in Older Adults' Oral Health and Disparities: 1999 to 2004 and 2011 to 2016. J Am Geriatr Soc 2019 January 30.

(34) Fure S. Ten-year incidence of tooth loss and dental caries in elderly Swedish individuals. Caries Res 2003 December 01;37(6):462-469. 
(35) Hassel AJ, Safaltin V, Grill S, Schroder J, Wahl HW, Klotz AL, et al. Risk factors for tooth loss in middle and older age after up to 10 years: An observational cohort study. Arch Oral Biol 2018 February 01;86:7-12.

(36) Carlsson GE. Critical review of some dogmas in prosthodontics. J Prosthodont Res 2009 January 01;53(1):3-10.

(37) Witter DJ, van Palenstein Helderman, W H, Creugers NH, Kayser AF. The shortened dental arch concept and its implications for oral health care. Community Dent Oral Epidemiol 1999 August 01;27(4):249-258.

(38) Kayser AF. Limited treatment goals--shortened dental arches. Periodontol 20001994 February 01;4:7-14.

(39) Hobdell M, Petersen PE, Clarkson J, Johnson N. Global goals for oral health 2020. Int Dent J 2003 October 01;53(5):285-288.

(40) Meyle J, Chapple I. Molecular aspects of the pathogenesis of periodontitis. Periodontol 20002015 October 01;69(1):7-17.

(41) Holm-Pedersen P, Russell SL, Avlund K, Viitanen M, Winblad B, Katz RV. Periodontal disease in the oldest-old living in Kungsholmen, Sweden: findings from the KEOHS project. J Clin Periodontol 2006 June 01;33(6):376384.

(42) Eke PI, Wei L, Borgnakke WS, Thornton-Evans G, Zhang X, Lu H, et al. Periodontitis prevalence in adults $>/=65$ years of age, in the USA. Periodontol 20002016 October 01;72(1):76-95.

(43) Shariff JA, Burkett S, Watson CW, Cheng B, Noble JM, Papapanou PN. Periodontal status among elderly inhabitants of northern Manhattan: The WHICAP ancillary study of oral health. J Clin Periodontol 2018 August 01;45(8):909-919.

(44) Hirotomi T, Kocher T, Yoshihara A, Biffar R, Micheelis W, Hoffmann T, et al. Comparison of periodontal conditions among three elderly populations in Japan and Germany. J Clin Periodontol 2014 July 01;41(7):633642.

(45) Wahlin A, Papias A, Jansson H, Norderyd O. Secular trends over 40 years of periodontal health and disease in individuals aged 20-80 years in Jonkoping, Sweden: Repeated cross-sectional studies. J Clin Periodontol 2018 September 01;45(9):1016-1024.

(46) Black DW, Grant JE. DSM-5® Guidebook : The Essential Companion to the Diagnostic and Statistical Manual of Mental Disorders, Fifth Edition. Washington, DC]: American Psychiatric Publishing; 2014.

(47) Norton S, Matthews FE, Barnes DE, Yaffe K, Brayne C. Potential for primary prevention of Alzheimer's disease: an analysis of population-based data. Lancet Neurol 2014 August 01;13(8):788-794. 
(48) Flicker L. Modifiable lifestyle risk factors for Alzheimer's disease. J Alzheimers Dis 2010;20(3):803-811.

(49) Prince M, Bryce R, Albanese E, Wimo A, Ribeiro W, Ferri CP. The global prevalence of dementia: a systematic review and metaanalysis. Alzheimers Dement 2013 January 01;9(1):63-75.e2.

(50) Ferri CP, Prince M, Brayne C, Brodaty H, Fratiglioni L, Ganguli M, et al. Global prevalence of dementia: a Delphi consensus study. Lancet 2005 December 17;366(9503):2112-2117.

(51) Twamley EW, Ropacki SA, Bondi MW. Neuropsychological and neuroimaging changes in preclinical Alzheimer's disease. J Int Neuropsychol Soc 2006 September 01;12(5):707-735.

(52) Dubois B, Feldman HH, Jacova C, Dekosky ST, Barberger-Gateau P, Cummings J, et al. Research criteria for the diagnosis of Alzheimer's disease: revising the NINCDS-ADRDA criteria. Lancet Neurol 2007 August 01;6(8):734-746.

(53) Possin KL. Visual spatial cognition in neurodegenerative disease. Neurocase 2010 December 01;16(6):466-487.

(54) Walker Z, Possin KL, Boeve BF, Aarsland D. Lewy body dementias. Lancet 2015 October 24;386(10004):1683-1697.

(55) Folstein MF, Folstein SE, McHugh PR. "Mini-mental state". A practical method for grading the cognitive state of patients for the clinician. J Psychiatr Res 1975 November 01;12(3):189-198.

(56) Crum RM, Anthony JC, Bassett SS, Folstein MF. Population-based norms for the Mini-Mental State Examination by age and educational level. JAMA 1993 May 12;269(18):2386-2391.

(57) Palmqvist S, Terzis B, Strobel C, Wallin A. MMSE-SR Mini Mental State Examination - svensk revidering. Stockholm: Svensk Förening för Kognitiv Medicin. 2011: Available at:

http://www.demenscentrum.se/globalassets/arbeta-meddemens_bild/skalor_instrument/mmse-sr-manual-2-0.pdf.

(58) Tombaugh TN. Test-retest reliable coefficients and 5-year change scores for the MMSE and 3MS. Arch Clin Neuropsychol 2005 June 01;20(4):485503.

(59) Eslinger PJ, Swan GE, Carmelli D. Changes in Mini-Mental State Exam in community-dwelling older persons over 6 years: relationship to health and neuropsychological measures. Neuroepidemiology 2003 February 01;22(1):23-30. 
(60) Helkala EL, Kivipelto M, Hallikainen M, Alhainen K, Heinonen H, Tuomilehto J, et al. Usefulness of repeated presentation of Mini-Mental State Examination as a diagnostic procedure--a population-based study. Acta Neurol Scand 2002 December 01;106(6):341-346.

(61) Pinto E, Peters R. Literature review of the Clock Drawing Test as a tool for cognitive screening. Dement Geriatr Cogn Disord 2009;27(3):201-213.

(62) Manos PJ. The utility of the ten-point clock test as a screen for cognitive impairment in general hospital patients. Gen Hosp Psychiatry 1997 November 01;19(6):439-444.

(63) Freedman, M., Leach, L. Kaplan, E., Schulman, K. I. \& Delis, D. C. 1994 Clock drawing: A neuropsychological analysis. New York: Oxford University Press; 1994.

(64) Mattila KJ, Nieminen MS, Valtonen VV, Rasi VP, Kesaniemi YA, Syrjala SL, et al. Association between dental health and acute myocardial infarction. BMJ 1989 March 25;298(6676):779-781.

(65) Nordendahl E, Gustafsson A, Norhammar A, Nasman P, Ryden L, Kjellstrom B, et al. Severe Periodontitis Is Associated with Myocardial Infarction in Females. J Dent Res 2018 September 01;97(10):1114-1121.

(66) Ryden L, Buhlin K, Ekstrand E, de Faire U, Gustafsson A, Holmer J, et al. Periodontitis Increases the Risk of a First Myocardial Infarction: A Report From the PAROKRANK Study. Circulation 2016 February 09;133(6):576583.

(67) Tonetti MS, Van Dyke TE, working group 1 of the joint EFP/AAP workshop. Periodontitis and atherosclerotic cardiovascular disease: consensus report of the Joint EFP/AAP Workshop on Periodontitis and Systemic Diseases. J Periodontol 2013 April 01;84(4 Suppl):S24-9.

(68) Sanz M, Kornman K, working group 3 of the joint EFP/AAP workshop. Periodontitis and adverse pregnancy outcomes: consensus report of the Joint EFP/AAP Workshop on Periodontitis and Systemic Diseases. J Periodontol 2013 April 01;84(4 Suppl):S164-9.

(69) Sanz M, Ceriello A, Buysschaert M, Chapple I, Demmer RT, Graziani F, et al. Scientific evidence on the links between periodontal diseases and diabetes: Consensus report and guidelines of the joint workshop on periodontal diseases and diabetes by the International Diabetes Federation and the European Federation of Periodontology. J Clin Periodontol 2018 February 01;45(2):138-149.

(70) Williams RC, Offenbacher S. Periodontal medicine: the emergence of a new branch of periodontology. Periodontol 20002000 June 01;23:9-12. 
(71) Onozuka M, Watanabe K, Mirbod SM, Ozono S, Nishiyama K, Karasawa $\mathrm{N}$, et al. Reduced mastication stimulates impairment of spatial memory and degeneration of hippocampal neurons in aged SAMP8 mice. Brain Res 1999 April 24;826(1):148-153.

(72) Kato T, Usami T, Noda Y, Hasegawa M, Ueda M, Nabeshima T. The effect of the loss of molar teeth on spatial memory and acetylcholine release from the parietal cortex in aged rats. Behav Brain Res 1997 February 01;83(1-2):239-242.

(73) Watanabe K, Ozono S, Nishiyama K, Saito S, Tonosaki K, Fujita M, et al. The molarless condition in aged SAMP8 mice attenuates hippocampal Fos induction linked to water maze performance. Behav Brain Res 2002 January $07 ; 128(1): 19-25$.

(74) Frota de Almeida, M N, de Siqueira Mendes Fde, C, Gurgel Felicio AP, Falsoni M, Ferreira de Andrade, M L, Bento-Torres J, et al. Spatial memory decline after masticatory deprivation and aging is associated with altered laminar distribution of CA1 astrocytes. BMC Neurosci 2012 February 29;13:23-2202.

(75) Hasegawa Y, Ono T, Hori K, Nokubi T. Influence of human jaw movement on cerebral blood flow. J Dent Res 2007 January 01;86(1):64-68.

(76) Moriya S, Tei K, Murata A, Yamazaki Y, Hata H, Muramatsu M, et al. Associations between self-assessed masticatory ability and higher brain function among the elderly. J Oral Rehabil 2011 October 01;38(10):746753.

(77) Lexomboon D, Trulsson M, Wardh I, Parker MG. Chewing ability and tooth loss: association with cognitive impairment in an elderly population study. J Am Geriatr Soc 2012 October 01;60(10):1951-1956.

(78) Fang WL, Jiang MJ, Gu BB, Wei YM, Fan SN, Liao W, et al. Tooth loss as a risk factor for dementia: systematic review and meta-analysis of 21 observational studies. BMC Psychiatry 2018 October 20;18(1):345-018.

(79) Paraskevas S, Huizinga JD, Loos BG. A systematic review and metaanalyses on C-reactive protein in relation to periodontitis. J Clin Periodontol 2008 April 01;35(4):277-290.

(80) Passoja A, Puijola I, Knuuttila M, Niemela O, Karttunen R, Raunio T, et al. Serum levels of interleukin-10 and tumour necrosis factor-alpha in chronic periodontitis. J Clin Periodontol 2010 October 01;37(10):881-887.

(81) Loos BG, Craandijk J, Hoek FJ, Wertheim-van Dillen PM, van der Velden U. Elevation of systemic markers related to cardiovascular diseases in the peripheral blood of periodontitis patients. J Periodontol 2000 October 01;71(10):1528-1534. 
(82) Bretz WA, Weyant RJ, Corby PM, Ren D, Weissfeld L, Kritchevsky SB, et al. Systemic inflammatory markers, periodontal diseases, and periodontal infections in an elderly population. J Am Geriatr Soc 2005 September 01;53(9):1532-1537.

(83) Uppoor AS, Lohi HS, Nayak D. Periodontitis and Alzheimer's disease: oral systemic link still on the rise? Gerodontology 2012 March 28.

(84) Abbayya K, Puthanakar NY, Naduwinmani S, Chidambar YS. Association between Periodontitis and Alzheimer's Disease. N Am J Med Sci 2015 June 01;7(6):241-246.

(85) Griffin WS. Neuroinflammatory cytokine signaling and Alzheimer's disease. N Engl J Med 2013 February 21;368(8):770-771.

(86) Ding Y, Ren J, Yu H, Yu W, Zhou Y. Porphyromonas gingivalis, a periodontitis causing bacterium, induces memory impairment and age-dependent neuroinflammation in mice. Immun Ageing 2018 January 30;15:6-017.

(87) Noble JM, Borrell LN, Papapanou PN, Elkind MS, Scarmeas N, Wright CB. Periodontitis is associated with cognitive impairment among older adults: analysis of NHANES-III. J Neurol Neurosurg Psychiatry 2009 November 01;80(11):1206-1211.

(88) Kamer AR, Craig RG, Pirraglia E, Dasanayake AP, Norman RG, Boylan $\mathrm{RJ}$, et al. TNF-alpha and antibodies to periodontal bacteria discriminate between Alzheimer's disease patients and normal subjects. J Neuroimmunol 2009 November 30;216(1-2):92-97.

(89) Sparks Stein P, Steffen MJ, Smith C, Jicha G, Ebersole JL, Abner E, et al. Serum antibodies to periodontal pathogens are a risk factor for Alzheimer's disease. Alzheimers Dement 2012 May 01;8(3):196-203.

(90) Riviere GR, Riviere KH, Smith KS. Molecular and immunological evidence of oral Treponema in the human brain and their association with Alzheimer's disease. Oral Microbiol Immunol 2002 April 01;17(2):113-118.

(91) Tonetti MS, Van Dyke TE, working group 1 of the joint EFP/AAP workshop. Periodontitis and atherosclerotic cardiovascular disease: consensus report of the Joint EFP/AAP Workshop on Periodontitis and Systemic Diseases. J Periodontol 2013 April 01;84(4 Suppl):S24-9.

(92) Beck JD, Elter JR, Heiss G, Couper D, Mauriello SM, Offenbacher S. Relationship of periodontal disease to carotid artery intima-media wall thickness: the atherosclerosis risk in communities (ARIC) study. Arterioscler Thromb Vasc Biol 2001 November 01;21(11):1816-1822.

(93) Holmer J, Eriksdotter M, Schultzberg M, Pussinen PJ, Buhlin K. Association between periodontitis and risk of Alzheimer's disease, mild cognitive impairment and subjective cognitive decline: A case-control study. J Clin Periodontol 2018 November 01;45(11):1287-1298. 
(94) Shin HS, Shin MS, Ahn YB, Choi BY, Nam JH, Kim HD. Periodontitis Is Associated with Cognitive Impairment in Elderly Koreans: Results from the Yangpyeong Cohort Study. J Am Geriatr Soc 2016 January 01;64(1):162167.

(95) Iwasaki M, Kimura Y, Ogawa H, Yamaga T, Ansai T, Wada T, et al. Periodontitis, periodontal inflammation, and mild cognitive impairment: A 5-year cohort study. J Periodontal Res 2018 October 21.

(96) Lagergren M, Fratiglioni L, Hallberg IR, Berglund J, Elmstahl S, Hagberg $\mathrm{B}$, et al. A longitudinal study integrating population, care and social services data. The Swedish National study on Aging and Care (SNAC). Aging Clin Exp Res 2004 April 01;16(2):158-168.

(97) Asberg M, Montgomery SA, Perris C, Schalling D, Sedvall G. A comprehensive psychopathological rating scale. Acta Psychiatr Scand Suppl $1978 ;(271)(271): 5-27$.

(98) Saunders JB, Aasland OG, Babor TF, de la Fuente, J R, Grant M. Development of the Alcohol Use Disorders Identification Test (AUDIT): WHO Collaborative Project on Early Detection of Persons with Harmful Alcohol Consumption--II. Addiction 1993 June 01;88(6):791-804.

(99) World Medical Association. World Medical Association Declaration of Helsinki: ethical principles for medical research involving human subjects. JAMA 2013 November 27;310(20):2191-2194.

(100) Luo J, Wu B, Zhao Q, Guo Q, Meng H, Yu L, et al. Association between tooth loss and cognitive function among 3063 Chinese older adults: a community-based study. PLoS One 2015 March 24;10(3):e0120986.

(101) Yamamoto T, Kondo K, Hirai H, Nakade M, Aida J, Hirata Y. Association between self-reported dental health status and onset of dementia: a 4-year prospective cohort study of older Japanese adults from the Aichi Gerontological Evaluation Study (AGES) Project. Psychosom Med 2012 April 01;74(3):241-248.

(102) Dintica CS, Rizzuto D, Marseglia A, Kalpouzos G, Welmer AK, Wardh I, et al. Tooth loss is associated with accelerated cognitive decline and volumetric brain differences: a population-based study. Neurobiol Aging 2018 July 01;67:23-30.

(103) Elsig F, Schimmel M, Duvernay E, Giannelli SV, Graf CE, Carlier S, et al. Tooth loss, chewing efficiency and cognitive impairment in geriatric patients. Gerodontology 2015 June 01;32(2):149-156.

(104) Hansson P, Eriksson Sorman D, Bergdahl J, Bergdahl M, Nyberg L, Adolfsson R, et al. Dental status is unrelated to risk of dementia: a 20-year prospective study. J Am Geriatr Soc 2014 May 01;62(5):979-981. 
(105) Wu B, Fillenbaum GG, Plassman BL, Guo L. Association Between Oral Health and Cognitive Status: A Systematic Review. J Am Geriatr Soc 2016 April 01;64(4):739-751.

(106) Gil-Montoya JA, Sanchez-Lara I, Carnero-Pardo C, Fornieles F, Montes J, Vilchez R, et al. Is Periodontitis a Risk Factor for Cognitive Impairment and Dementia? A Case-Control Study. J Periodontol 2014 October 27:114.

(107) Gil-Montoya JA, Sanchez-Lara I, Carnero-Pardo C, Fornieles-Rubio F, Montes J, Barrios R, et al. Oral Hygiene in the Elderly with Different Degrees of Cognitive Impairment and Dementia. J Am Geriatr Soc 2017 March 01;65(3):642-647.

(108) Tonsekar PP, Jiang SS, Yue G. Periodontal disease, tooth loss and dementia: Is there a link? A systematic review. Gerodontology 2017 June 01;34(2):151-163.

(109) Horder H, Johansson L, Guo X, Grimby G, Kern S, Ostling S, et al. Midlife cardiovascular fitness and dementia: A 44-year longitudinal population study in women. Neurology 2018 April 10;90(15):e1298-e1305.

(110) Atti AR, Palmer K, Volpato S, Winblad B, De Ronchi D, Fratiglioni L. Late-life body mass index and dementia incidence: nine-year follow-up data from the Kungsholmen Project. J Am Geriatr Soc 2008 January 01;56(1):111-116.

(111) Anstey KJ, Cherbuin N, Budge M, Young J. Body mass index in midlife and late-life as a risk factor for dementia: a meta-analysis of prospective studies. Obes Rev 2011 May 01;12(5):e426-37.

(112) Iwasaki M, Yoshihara A, Kimura Y, Sato M, Wada T, Sakamoto R, et al. Longitudinal relationship of severe periodontitis with cognitive decline in older Japanese. J Periodontal Res 2016 October 01;51(5):681-688.

(113) Gusman DJR, Mello-Neto JM, Alves BES, Matheus HR, Ervolino E, Theodoro LH, et al. Periodontal disease severity in subjects with dementia: A systematic review and meta-analysis. Arch Gerontol Geriatr 2018 June 01;76:147-159.

(114) Maldonado A, Laugisch O, Burgin W, Sculean A, Eick S. Clinical periodontal variables in patients with and without dementia-a systematic review and meta-analysis. Clin Oral Investig 2018 June 22.

(115) Leira Y, Dominguez C, Seoane J, Seoane-Romero J, Pias-Peleteiro JM, Takkouche B, et al. Is Periodontal Disease Associated with Alzheimer's Disease? A Systematic Review with Meta-Analysis. Neuroepidemiology $2017 ; 48(1-2): 21-31$. 
(116) Kassebaum NJ, Bernabe E, Dahiya M, Bhandari B, Murray CJ, Marcenes W. Global Burden of Severe Periodontitis in 1990-2010: A Systematic Review and Meta-regression. J Dent Res 2014 November 01;93(11):10451053.

(117) Billings M, Holtfreter B, Papapanou PN, Mitnik GL, Kocher T, Dye BA. Age-dependent distribution of periodontitis in two countries: Findings from NHANES 2009 to 2014 and SHIP-TREND 2008 to 2012. J Periodontol 2018 June 01;89 Suppl 1:S140-S158.

(118) Loe H, Anerud A, Boysen H, Morrison E. Natural history of periodontal disease in man. Rapid, moderate and no loss of attachment in Sri Lankan laborers 14 to 46 years of age. J Clin Periodontol 1986 May 01;13(5):431445 .

(119) Beck JD, Sharp T, Koch GG, Offenbacher S. A 5-year study of attachment loss and tooth loss in community-dwelling older adults. J Periodontal Res 1997 August 01;32(6):516-523.

(120) Machtei EE, Hausmann E, Dunford R, Grossi S, Ho A, Davis G, et al. Longitudinal study of predictive factors for periodontal disease and tooth loss. J Clin Periodontol 1999 June 01;26(6):374-380.

(121) Meisel P, Holtfreter B, Volzke H, Kocher T. Self-reported oral health predicts tooth loss after five and ten years in a population-based study. J Clin Periodontol 2018 October 01;45(10):1164-1172.

(122) Needleman I, Garcia R, Gkranias N, Kirkwood KL, Kocher T, Iorio AD, et al. Mean annual attachment, bone level, and tooth loss: A systematic review. J Periodontol 2018 June 01;89 Suppl 1:S120-S139.

(123) Matuliene G, Pjetursson BE, Salvi GE, Schmidlin K, Bragger U, Zwahlen $\mathrm{M}$, et al. Influence of residual pockets on progression of periodontitis and tooth loss: results after 11 years of maintenance. J Clin Periodontol 2008 August 01;35(8):685-695. 
PAPER I-IV 

I 



\title{
Tooth loss and cognitive functions among older adults
}

\author{
HELENA NILSSON ${ }^{1}$, JOHAN BERGLUND ${ }^{2,3}$ \& STEFAN RENVERT ${ }^{2,4,5}$ \\ ${ }^{1}$ Maxillofacial Unit, Halland Hospital, Halmstad, Sweden, ${ }^{2}$ Blekinge Institute of Technology, Karlskrona, Sweden, \\ ${ }^{3}$ Department of Clinical Sciences, Lund University, Lund, Sweden, ${ }^{4}$ Department of Oral Sciences, School of Health \\ and Society, Kristianstad University, Kristianstad, Sweden, and ${ }^{5}$ School of Dental Sciences, Trinity College, \\ Dublin, Ireland
}

\begin{abstract}
Objective. To evaluate the association between the number of teeth and cognitive functions adjusted for age and education level in a cohort of older adults living in Sweden. Materials and methods. The study employed a cross-sectional design in which 1147 individuals between 60-96 years underwent a clinical oral examination. The cognitive functions were assessed using Mini-Mental State Examination (MMSE) and Clock-test. The level of education was obtained from a questionnaire. Data were subjected to Chi-square tests and multivariate logistic regression analyses were employed, grouping the different variables into pre-determined categories. Results. The co-variables age and education were significantly associated with the number of teeth $(p<0.05)$. The multivariate logistic regression analysis revealed that the association between the number of teeth and the cognitive functions persisted even after adjusting for age and level of education. Conclusions. The findings suggest that the presence of teeth may be of importance for cognitive abilities in older adults.
\end{abstract}

Key Words: cognitive impairment, dementia, elderly, oral health

\section{Introduction}

The relationship between oral health and medical conditions such as diabetes mellitus, cardiovascular diseases and rheumatoid arthritis has been comprehensively studied and new knowledge has been attained regarding possible co-variation and causality [1-3]. The median age of the world's population is increasing; the proportion aged $\geq 65$ is projected to increase by $\sim 550$ million to 973 million in the coming decades [4]. With an increased age, cognitive impairment and dementia is becoming more prevalent [5]. Alzheimer's disease is the most common form of dementia and is reported to be frequent (24-33\%) among individuals in the western world in the ages above 85 years [5]. Modifiable risk factors such as physical activity, cognitive stimulation and smoking have been identified $[6,7]$. High blood pressure and obesity are medical conditions also associated with an increased risk for dementia $[6,8]$. The initial symptoms of Alzheimer's disease are decline in different cognitive domains often associated with episodic memory. Cognitive tests have been shown to be effective in predicting risk for Alzheimer's disease [9].

Previous retrospective and population-based studies have suggested an association between dental health, tooth loss and cognitive function [10-12]. Early tooth loss has been reported to be associated with the development of Alzheimer's disease [13]. Furthermore, experimental animal studies have revealed an influence on memory capacity after loss of molars [14,15]. There is, however, a lack of information regarding the influence of different explanatory covariates such as age and education. Previous research has often been based on self-reported oral status and various simplified cognitive tests that may have affected the outcome. The aim of this study was, therefore, to assess the relationship between cognitive functions, assessed by Mini-Mental State Examination (MMSE) and Clock-test and the number of teeth in a cohort of older adults in Sweden when adjusted for age and level of education.

Correspondence: Helena Nilsson, Specialisttandvården Region Halland, Maxillofacial Unit, Halland Hospital, Halmstad 301 85, Sweden. Tel: +4635134057. Fax: +4635134064. E-mail: helena.i.nilsson@regionhalland.se

(Received 1 October 2013; accepted 2 fanuary 2014)

ISSN 0001-6357 print/ISSN 1502-3850 online (c) 2014 Informa Healthcare DOI: $10.3109 / 00016357.2014 .882983$ 


\section{Materials and methods}

\section{Subjects}

All subjects in this cross-sectional study were participants in the Swedish National Study on Ageing and Care (SNAC), which is a population-based, multicentre cohort study. The study has four participating centres in Sweden and one of the centres is Blekinge (SNAC-Blekinge), which involves the Karlskrona community, with 60600 inhabitants. A more detailed description of the study design and structure is outlined by Lagergren et al. [16]. The individuals were randomly selected from the Swedish civil registration database in the age cohorts of $60,66,72$ and 78 years. In the age cohorts of $81,84,87,90,93$ and 96 years, all individuals were invited. Ten per cent of the entire population aged 60 years and older in the community participated in the study. The individuals were enrolled between 20012004 and, in total, 2312 were invited and 1402 accepted. The response rate was $62 \%$. Reasons for not participating were feeling too sick to be able to participate $(n=91)$, non-responding $(n=64)$ and unwillingness to participate $(n=755)$. Individuals at ages 60 and 66 were allocated to the young old age cohort, those aged 72 and 78 to the old age cohort and individuals $>81$ years of age were allocated to the old-old age cohort. The participants were invited by mail to take part in a medical, psychological and dental examination by the members of the research team. The examination could also be performed in their homes if they were unable to come to the research centre. All subjects gave their signed informed consent. Subjects also signed an approved release form for their medical records. The Research Ethics Committee at Lund University approved the study (LU 605-00, LU 744-00).

\section{Cognitive tests}

Mini-Mental State Examination (MMSE). This test is one of the most widely used tests to screen for cognitive status and cognitive impairment. The test consists of 20 items, resulting in a total score of 30 [17]. The test result may reflect cognitive abilities such as orientation, memory, attention and concentration, language and praxis $[18,19]$. Test results lower than 29 are considered to reflect pathological changes and in this study a score $<25$ was used as a cut-off value [20].

Clock-test. This is a brief cognitive test widely used in assessment of dementia [21]. The participants were asked to draw an analogue clock face in a pre-drawn circle with the numbers in correct position and then the arms indicating the time 'ten minutes past eleven' [22]. The results are scored from $0-10$ and reflect verbal comprehension, executive function and visuoconstructional skills [23]. Correlation between impaired results on clock-test and pathology in parietal lobes has been identified in Alzheimer's disease [24]. In this study, a score $<8$ was used as the cut-off value for lower cognitive function [22].

Education. The level of education was captured from a comprehensive questionnaire and categorized according to final school grade, $\leq 9$ years or more.

\section{Oral examination}

An oral examination including clinical registration of the number of teeth present was performed by a specially trained dental hygienist. Panoramic radiographs were taken using an orthopantomograph (Instrumentarium Dental, OP 100; Tuuaula, Finland; standard exposure $75 \mathrm{kV} / 10 \mathrm{~mA}$ ). Presence or absence of teeth was also assessed from the radiographs. If a disagreement in the number of teeth present occurred, due to, for example, pontics in fixed dental prosthesis, implants and root-remnants, the radiographs were re-assessed and the number of teeth counted on the radiograph were used in the analysis. Erupted third molars were included in the analysis. The study individuals were allocated into three groups according to number of teeth: edentulous, $1-19$ teeth and $\geq 20$ teeth.

\section{Statistical methods}

A statistical software program (IBM SPSS version 21.0, IBM Statistics, Amorak, NY) was used for the analysis. Descriptive statistics were used to present the population. Associations between tooth loss, on the one hand, and age cohort, sex and educational level, on the other hand, were tested using the Chi-2 test. Associations between the candidate explanatory variables (i.e. tooth loss, age cohort, sex and educational level) and the cognitive function variables were analysed using logistic regression. The association between tooth loss and the cognitive function variables were analysed first by univariate logistic regression and thereafter with adjustment for the influential explanatory co-variables by multivariate logistic regression. Odds ratios (OR), 95\% confidence interval $(\mathrm{CI})$ and $p$-values were calculated; $p$-values $<0.05$ were regarded as statistically significant.

\section{Results}

A total of 1402 individuals (58.2\% women) were included in the study. Data on dental status was lacking in 255 individuals and, thus, the final results were based on 1147 subjects. The relationship between the number of teeth and age, gender and level of education is shown in Table I. The 
Table I. Chi-2 analysis of the explanatory covariables age, education and gender and number of teeth.

\begin{tabular}{|c|c|c|c|c|c|}
\hline & 0 teeth, $n(\%)$ & $1-19$ teeth, $n(\%)$ & $\geq 20, n(\%)$ & Total, $n(\%)$ & $\chi^{2}$ tests \\
\hline Young old, 60, 66 years & $18(4.9 \%)$ & $85(23.1 \%)$ & $265(72.0 \%)$ & $368(100.0 \%)$ & 0.000 \\
\hline Old, 72,78 years & $46(14.9 \%)$ & $128(41.4 \%)$ & $135(43.7 \%)$ & $309(100.0 \%)$ & 0.000 \\
\hline Old old, $\geq 81$ years & $136(28.9 \%)$ & $242(51.5 \%)$ & $92(19.6 \%)$ & $470(100.0 \%)$ & 0.000 \\
\hline Total & $200(17.4 \%)$ & $455(39.7 \%)$ & $492(42.9 \%)$ & $1147(100.0 \%)$ & \\
\hline \multicolumn{6}{|l|}{ Education } \\
\hline$\leq 9$ years & $179(95.7 \%)$ & $399(92.6 \%)$ & $351(73.0 \%)$ & $929(84.5 \%)$ & 0.000 \\
\hline$>9$ years & $8(4.3 \%)$ & $32(7.4 \%)$ & $130(27.0 \%)$ & $170(15.5 \%)$ & 0.000 \\
\hline Total & $187(100 \%)$ & $431(100 \%)$ & $481(100 \%)$ & $1099(100 \%)$ & \\
\hline \multicolumn{6}{|l|}{ Gender } \\
\hline Female & $126(62.6 \%)$ & $243(53.4 \%)$ & $269(54.7 \%)$ & $638(55.5 \%)$ & NS \\
\hline Male & $74(37.4 \%)$ & $212(46.6 \%)$ & $223(45.3 \%)$ & $509(44.5 \%)$ & NS \\
\hline Total & $200(100 \%)$ & $455(100 \%)$ & $492(100 \%)$ & $1147(100 \%)$ & \\
\hline
\end{tabular}

explanatory co-variables age and education were significantly associated to number of teeth $(p<0.05)$. Results from logistic regression regarding the number of teeth and the MMSE and Clock-test, unadjusted for age and education, are presented in Tables II and III. The risk for low cognitive scores was statistically related to the number of teeth. The odds ratio for having MMSE $<25$ was 3.2 in the dentate group (1-19 teeth) and 9.2 in the edentulous group. The corresponding values for the Clock-test $<8$ were 2.9 and 4.3, respectively.

Results from the multivariate logistic regression analysis when age and education were entered into the model are also presented in Tables II and III. The results demonstrated that the influence of the number of teeth on cognitive functions persisted for the edentulous groups when the results were adjusted for age and education. A statistically significant difference between the dentate groups having more or less than 20 teeth remained concerning the Clock-test $<8(p=0.03)$. No gender differences could be identified.

\section{Discussion}

This cross-sectional study examined the association between tooth loss and cognitive function in a sample of individuals aged 60 years and older. It is generally considered that results obtained using MMSE and the

Table II. Multivariate logistic regression for the outcome MMSE $<25$ and the explanatory variables number of teeth, age and education.

\begin{tabular}{|c|c|c|c|c|c|c|}
\hline \multirow[b]{2}{*}{ Explanatory variable category } & \multicolumn{3}{|c|}{ Without adjustments } & \multicolumn{3}{|c|}{ With adjustments } \\
\hline & OR $(95 \% \mathrm{CI})^{\star}$ & $n$ & $p$-value & OR $(95 \% \mathrm{CI})^{\star}$ & $n$ & $p$-value \\
\hline \multicolumn{7}{|l|}{ Number of teeth } \\
\hline 0 & $9.2(5.9-14.3)$ & 196 & 0.000 & $3.2(1.9-53)$ & 183 & $<0.001$ \\
\hline $1-19$ & $3.2(2.1-4.8)$ & 451 & 0.000 & $1.3(0.84-22)$ & 427 & 0.22 \\
\hline$\geq 20$ & 1.0 (reference) & 491 & & 1.0 (reference) & 480 & \\
\hline \multicolumn{7}{|l|}{ Age } \\
\hline Young old; 60, 66 years & & & & 1.0 (reference) & 363 & \\
\hline Old; 72,78 years & & & & $2.7(1.3-5.4)$ & 299 & 0.005 \\
\hline Old old; $\geq 81$ years & & & & $8.5(4.4-16.2)$ & 428 & $<0.001$ \\
\hline \multicolumn{7}{|l|}{ Education } \\
\hline$\leq 9$ years & & & & $2.7(1.3-5.9)$ & 921 & 0.01 \\
\hline$>9$ years & & & & 1.0 (reference) & 169 & \\
\hline
\end{tabular}

* Odds ratio with $95 \%$ confidence interval. 
Table III. Multivariate logistic regression analysis for the outcome Clock-test $<8$ and the explanatory variables number of teeth, age and education.

\begin{tabular}{|c|c|c|c|c|c|c|}
\hline \multirow[b]{2}{*}{ Explanatory variable category } & \multicolumn{3}{|c|}{ Without adjustments } & \multicolumn{3}{|c|}{ With adjustments } \\
\hline & OR $(95 \% \mathrm{CI})^{\star}$ & $n$ & $p$-value & OR $(95 \% \mathrm{CI})^{\star}$ & $n$ & $p$-value \\
\hline \multicolumn{7}{|l|}{ Number of teeth } \\
\hline 0 & $4.3(2.9-6.5)$ & 168 & 0.000 & $1.9(1.2-3.0)$ & 160 & 0.007 \\
\hline $1-19$ & $2.9(2.1-4.1)$ & 431 & 0.000 & $1.5(1.1-2.3)$ & 410 & 0.03 \\
\hline$\geq 20$ & 1.0 (reference) & 482 & & 1.0 (reference) & 471 & \\
\hline \multicolumn{7}{|l|}{ Age } \\
\hline Young old; 60, 66 years & & & & 1.0 (reference) & 362 & \\
\hline Old; 72,78 years & & & & $2.1(1.3-3.4)$ & 292 & 0.002 \\
\hline Old old; $\geq 81$ years & & & & $5.0(3.2-7.8)$ & 387 & $<0.001$ \\
\hline \multicolumn{7}{|l|}{ Education } \\
\hline$\leq 9$ years & & & & $1.6(0.9-2.7)$ & 877 & 0.09 \\
\hline$>9$ years & & & & 1.0 (reference) & 164 & \\
\hline
\end{tabular}

$\star$ Odds ratio with $95 \%$ confidence interval.

Clock-test are strongly affected by age and the level of education. In this study the tests are used as screening tools for cognitive functions and, thus, an arbitrary cut-off level $<25$ was adopted. Age and level of education were used as covariates. Our main and novel finding was that the number of teeth was of importance for the outcome of the cognitive tests, even when adjusted for the age and education. The edentulous group showed greater odds of having the lower cut-off value on both MMSE and Clock-test. Regarding the Clock-test, a difference between the dentate groups (1-19 teeth and more than 20 teeth) could be identified. Our findings are mainly in accordance with previous studies $[25,26]$. SparksStein et al. [26] reported that few retained teeth were significantly associated with prevalence of dementia in a group of Roman Catholic sisters. In a longitudinal follow-up study on men in the Boston area, tooth loss and periodontal disease progression independently increased the risks of low cognitive test scores at follow-up [27]. In contrast to the present study, Lexonboom et al. [12] reported that the association between tooth loss and cognitive impairment was due to gender, age and education as the odds ratio became non-significant when these variables were entered into the model [12].

One of the strengths with the present paper was that the oral data were not self-reported. The teeth were registered both clinically and with radiographs in contrast to several earlier reports based on selfreported data $[10,12]$ or analyses of dental charts [26]. The grouping according to the number of teeth was based on the discussion that 20 teeth are needed for persistent oral health and function [28]. However, we have not further analysed the teeth's positions in the arch and its influence on the occlusion except for the prevalence of molar teeth. We could not identify any difference between molar and non-molar teeth. There were not enough individuals with implant-supported prosthesis to make a subanalysis.

In the present paper two cognitive tests were used. This may provide a broader perspective of the individual's cognitive function. The tests were carried out and analysed by clinicians specially trained for the purpose in order to improve the reliability of the results. One reason for the discrepancies of results between the present paper and others $[12,25,29]$ may be related to the sample selection and the exclusion criteria applied. Lexomboon et al. [12] excluded individuals with dementia, stroke and individuals with hearing problems. Bergdahl et al. [25] and Grabe et al. [29] excluded individuals with diseases such as mental illness, cardiovascular diseases and cerebral thrombosis. In the present report, all individuals that were able to visit the research centre and were capable to perform the cognitive tests were included. Therefore, we consider our findings to be of good external validity. It should be underlined that the drop-out group lacking dental examination ( $n=255$ ) were older then the study group; $75 \%$ belonged to the old-old cohort and performed inferior results on the cognitive tests.

One possible limitation of the present paper was that age and education were given the same impact as co-variables in the different age cohorts. The Swedish education system changed significantly in the middle of the $20^{\text {th }}$ century, resulting in increased access to higher education for individuals in the young-old cohort compared to the individuals in the two other age cohorts. Additionally, the individuals in the young old cohort may have been exposed to more 
preventive-oriented dental services. In the older cohorts teeth may have been extracted due to lack of dental services and lack of a dental insurance system.

Another limitation with the present cross-sectional study design is that it is not possible to know if loss of teeth or cognitive impairment occurs first. To answer such a question longitudinal studies are needed.

Different explanatory theories regarding the interactions between dental status and cognitive function have been discussed. Whether it is the chewing ability, number of teeth or the burden of oral inflammatory diseases through life is still an open question. Periodontitis may contribute to the pathological process in cognitive impairment and dementia [30]. This needs to be further elucidated in longitudinal studies.

\section{Conclusions}

Within the limitation of the present study, a statistically significant association of the number of teeth on cognitive abilities of older adults were demonstrated when adjusted for age and level of education. The findings reinforce the assumption that the presence of teeth may be of importance for cognitive abilities in older adults.

\section{Acknowledgements}

The Swedish National study on Aging and Care, SNAC, (www.snac.org) is financially supported by the Ministry of Health and Social Affairs, Sweden and the participating County Councils, Municipalities and University Departments. We are grateful to the participants, the participating counties and municipalities. Special thanks to Anders Holmen and Ulf Strömberg for valuable support with the statistical work and to region Halland for financial support.

Declaration of interest: The authors report no conflicts of interest. The authors alone are responsible for the content and writing of the paper.

\section{References}

[1] Teeuw WJ, Gerdes VE, Loos BG. Effect of periodontal treatment on glycemic control of diabetic patients: a systematic review and meta-analysis. Diabetes Care 2010; 33:421-7

[2] Linden GJ, Lyons A, Scannapieco FA. Periodontal systemic associations: review of the evidence. J Periodontol 2013;84: S8-S19.

[3] Tonetti MS, Van Dyke TE; working group 1 of the joint EFP/ AAP workshop. Periodontitis and atherosclerotic cardiovascular disease: consensus report of the Joint EFP/AAP Workshop on Periodontitis and Systemic Diseases. J Periodontol 2013;84:S24-9.
[4] From the Centers for Disease Control and Prevention. Public health and aging: trends in aging-United States and worldwide. JAMA 2003;289:1371-3.

[5] Ferri CP, Prince M, Brayne C, Brodaty H, Fratiglioni L, Ganguli $\mathrm{M}$, et al. Global prevalence of dementia: a Delphi consensus study. Lancet 2005;366:2112-17.

[6] Flicker L. Modifiable lifestyle risk factors for Alzheimer's disease. J Alzheimers Dis 2010;20:803-11.

[7] Barnes DE, Yaffe K. The projected effect of risk factor reduction on Alzheimer's disease prevalence. Lancet Neurol 2011;10:819-28.

[8] Watts AS, Loskutova N, Burns JM, Johnson DK. Metabolic Syndrome and Cognitive Decline in early alzheimer's disease and healthy older adults. J Alzheimers Dis 2013;35:253-65.

[9] Palmqvist S, Hertze J, Minthon L, Wattmo C, Zetterberg H, Blennow $\mathrm{K}$, et al. Comparison of brief cognitive tests and CSF biomarkers in predicting Alzheimer's disease in mild cognitive impairment: six-year follow-up study. PLoS ONE 2012;7 e38639.

[10] Paganini-Hill A, White SC, Atchison KA. Dentition, dental health habits, and dementia: the leisure world cohort study. J Am Geriatr Soc 2012;60:1556-63.

[11] Ribeiro GR, Costa JL, Bovi Ambrosano GM, Rodrigues Garcia RC. Oral health of the elderly with Alzheimer's disease. Oral Surg Oral Med Oral Pathol Oral Radiol 2012;114:338-43.

[12] Lexomboon D, Trulsson M, Wardh I, Parker MG. Chewing ability and tooth loss: association with cognitive impairmen in an elderly population study. J Am Geriatr Soc 2012;60: 1951-6.

[13] Gatz M, Mortimer JA, Fratiglioni L, Johansson B, Berg S, Reynolds CA, et al. Potentially modifiable risk factors for dementia in identical twins. Alzheimers Dement 2006;2:110-17.

[14] Kato $T$, Usami $T$, Noda $Y$, Hasegawa $M$, Ueda $M$, Nabeshima T. The effect of the loss of molar teeth on spatial memory and acetylcholine release from the parietal cortex in aged rats. Behav Brain Res 1997;83:239-42.

[15] Onozuka M, Watanabe K, Mirbod SM, Ozono S, Nishiyama K, Karasawa N, et al. Reduced mastication stimulates impairment of spatial memory and degeneration of hippocampal neurons in aged SAMP8 mice. Brain Res 1999;826:148-53.

[16] Lagergren $M$, Fratiglioni L, Hallberg IR, Berglund J, Elmstahl S, Hagberg B, et al. A longitudinal study integrating population, care and social services data. The Swedish National study on Aging and Care (SNAC). Aging Clin Exp Res 2004;16:158-68.

[17] Folstein MF, Folstein SE, McHugh PR. "Mini-mental state". A practical method for grading the cognitive state of patients for the clinician. J Psychiatr Res 1975;12:189-98.

[18] Jones RN, Gallo JJ. Education and sex differences in the mini-mental state examination: effects of differential item functioning. J Gerontol B Psychol Sci Soc Sci 2002;57:P548-58.

[19] Banos JH, Franklin LM. Factor structure of the Mini-Mental State Examination in adult psychiatric inpatients. Psychol Assess 2002;14:397-400.

[20] Nelson PT, Abner EL, Schmitt FA, Kryscio RJ, Jicha GA, Smith CD, et al. Modeling the association between 43 different clinical and pathological variables and the severity of cognitive impairment in a large autopsy cohort of elderly persons. Brain Pathol 2010;20:66-79.

[21] Ismail Z, Rajii TK, Shulman KI. Brief cognitive screening instruments: an update. Int J Geriatr Psychiatry 2010;25: 111-20.

[22] Manos PJ, Wu R. The ten point clock test: a quick screen and grading method for cognitive impairment in medical and surgical patients. Int J Psychiatry Med 1994;24:229-44.

[23] Freedman M, Leach L, Kaplan E, Schulman KI, Delis DC. Clock drawing [Elektronisk resurs] a neuropsychological analysis. New York: Oxford University Press; 1994. 
[24] Ueda H, Kitabayashi Y, Narumoto J, Nakamura K, Kita H, Kishikawa Y, et al. Relationship between clock drawing test performance and regional cerebral blood flow in Alzheimer's disease: a single photon emission computed tomography study. Psychiatry Clin Neurosci 2002;56:25-9.

[25] Bergdahl M, Habib R, Bergdahl J, Nyberg L, Nilsson LG. Natural teeth and cognitive function in humans. Scand J Psychol 2007;48:557-65.

[26] Stein PS, Desrosiers M, Donegan SJ, Yepes JF, Kryscio RJ. Tooth loss, dementia and neuropathology in the Nun study. J Am Dent Assoc 2007;138:1314-22; quiz 1381-2.

[27] Kaye EK, Valencia A, Baba N, Spiro A 3rd, Dietrich T, Garcia RI. Tooth loss and periodontal disease predict poor cognitive function in older men. J Am Geriatr Soc 2010;58: 713-18.

[28] Muller F, Naharro M, Carlsson GE. What are the prevalence and incidence of tooth loss in the adult and elderly population in Europe? Clin Oral Implants Res 2007;18:2-14.

[29] Grabe HJ, Schwahn C, Volzke H, Spitzer C, Freyberger HJ, John U, et al. Tooth loss and cognitive impairment. J Clin Periodontol 2009;36:550-7.

[30] Kamer AR, Dasanayake AP, Craig RG, Glodzik-Sobanska L, Bry M, de Leon MJ. Alzheimer's disease and peripheral infections: the possible contribution from periodontal infections, model and hypothesis. J Alzheimers Dis 2008;13:437-49. 
III 



\title{
Longitudinal evaluation of periodontitis and development of cognitive decline among older adults
}

\author{
Helena Nilsson $^{1}$ (1) | Johan Sanmartin Berglund ${ }^{2,3}$ | Stefan Renvert ${ }^{2,4,5}$ (C)
}

\author{
${ }^{1}$ Maxillofacial Unit, Halland Hospital, Halmstad, \\ Sweden \\ ${ }^{2}$ Blekinge Institute of Technology, Karlskrona, \\ Sweden \\ ${ }^{3}$ Department of Clinical Sciences, Lund \\ University, Lund, Sweden \\ ${ }^{4}$ School of Health and Society, Kristianstad \\ University, Kristianstad, Sweden \\ ${ }^{5}$ School of Dental Science, Trinity College, \\ Dublin, Ireland \\ Correspondence \\ Helena Nilsson, Specialisttandvården Region \\ Halland, Maxillofacial Unit, Halland Hospital, \\ Halmstad, Sweden. \\ Email: helena.i.nilsson@regionhalland.se \\ Funding information \\ This study was financially supported by \\ Region Halland Sweden and Southern Health \\ Care Region Sweden [220291]. The Swedish \\ National Study on Ageing and Care, SNAC \\ (www.snac.org) is financially supported by \\ the Ministry of Health and Social Affairs, \\ Sweden and the participating County \\ Councils, Municipalities and University \\ Departments.
}

\begin{abstract}
Aim: To determine whether having periodontitis is associated with cognitive decline among older adults.

Material and Methods: A prospective population study of older adults, Swedish National Study on Ageing and Care, (SNAC) provided repeated registrations of cognitive functions. Cognitive decline was defined as $\geq 3$-points deterioration from a predetermined level at baseline, using the Mini-Mental State Examination (MMSE). Between 2001 and 2003, 715 individuals had a medical as well as a clinical and radiographic dental examination. The individuals were re-examined after 6 years. Periodontitis was defined as $\geq 4 \mathrm{~mm}$ bone loss at $\geq 30 \%$ of tooth sites. Social variables were captured from questionnaires.

Results: The multivariate logistic regression analysis demonstrated a statistically significant association between prevalence of periodontitis and cognitive decline after adjustments of confounding factors of importance.

Conclusions: A history of periodontitis may be of importance for cognitive functions among older adults.

KEYWORDS

epidemiology, inflammation, neurocognitive disorders, older adults, periodontal diseases
\end{abstract}

\section{1 | INTRODUCTION}

Dementia has been defined as a clinical syndrome characterized by cognitive decline, sufficient to interfere with daily functioning (World Health Organization, 1992). The ongoing demographic transitions, leading to an increasing proportion of older adults, have a profound impact on the prevalence of dementia (Ferri et al., 2005; Prince et al., 2013). Hence, cognitive impairment and dementia are considered as a major public health problem with large financial, human and social burdens (Murray et al., 2013; Wimo et al., 2017).

The most common form of dementia is Alzheimer's disease (AD) and modifiable risk factors related to $A D$ are midlife obesity, midlife hypertension, diabetes, physical inactivity, smoking, low education and depression (Norton, Matthews, Barnes, Yaffe, \& Brayne, 2014).
Lifestyle-related factors such as alcohol consumption and a history of traumatic brain injury have also been associated to cognitive functions and dementia in elderly individuals (Li, Risacher, McAllister, \& Saykin, 2016; Peters, Peters, Warner, Beckett, \& Bulpitt, 2008).

Recent systematic reviews suggest that older people with dementia have multiple oral health problems (Delwel et al., 2018; Gusman et al., 2018; Leira et al., 2017; Maldonado, Laugisch, Burgin, Sculean, \& Eick, 2018). However, studies on the relationship between periodontitis and cognitive decline are few but indicate an association (Gil-Montoya et al., 2014; Syrjala et al., 2012; Zenthofer et al., 2017). One possible explanation may be related to changes in daily functioning, associated with cognitive decline, affecting oral hygiene routines, resulting in higher plaque and bleeding index (GilMontoya, Sanchez-Lara et al., 2017; Zenthofer, Schroder, Cabrera, 
Rammelsberg, \& Hassel, 2014). Another possible explanation to the reported association between periodontitis and cognitive decline may be related to the influence of a peripheral inflammation (Kamer et al., 2008).

Higher brain amyloid load has been reported as a central feature of Alzheimer's disease and clinical attachment loss $(C A L) \geq 3 \mathrm{~mm}$ has been associated with higher brain amyloid- $\beta(A \beta)$ load among elderly individuals (Kamer et al., 2015). In a recent case-control study, higher plasma $A \beta_{1-42}$ peptide concentrations were reported in individuals with severe periodontal disease compared to individuals with healthy periodontal status (Gil-Montoya, Barrios et al., 2017). Additionally, lipopolysaccharides from periodontal pathogens have been identified in the brain tissues of patients with Alzheimer's disease in post-mortem analysis (Poole, Singhrao, Kesavalu, Curtis, \& Crean, 2013) and serum IgG levels to periodontal microbiota has been associated to risk for incident Alzheimer's disease (Noble et al., 2014)

In a retrospective case-control study, a modest higher risk for dementia was reported among individuals with periodontitis after adjustment for sociodemographic characteristics and comorbidities (Lee et al., 2016). In a 3-year follow-up study, a twofold higher risk for cognitive decline was reported for individuals with severe periodontitis compared to individuals without periodontitis (Iwasaki et al., 2016). To further explore a potential association between periodontitis and cognitive decline, additional longitudinal studies are, however, warranted. The objective of this study was to determine whether a diagnosis of periodontitis in individuals $\geq 60$ years of age at baseline was associated with cognitive decline in a 6-year follow-up study.

\section{2 | MATERIAL AND METHODS}

The Swedish National Study on Ageing and Care (SNAC) is a population-based, prospective and longitudinal study running at four research centres. At one of the research centres, SNACBlekinge, 2312 individuals were invited by mail to participate in the study. Aiming to represent the elderly population in Sweden, a randomised selection was made from the Swedish civil registration database in the age cohorts, $60,66,72,78$. In the age cohorts 81 , 84,87 (and older), all individuals in the community were invited to participate in the study. Those who did not reply were contacted by telephone (three attempts). In total, 1,402 agreed to participate and were invited by mail to take part in a medical, psychological and dental examination performed in a research clinic by professionals specially trained for the purpose. The sample of older adults in the selected age cohorts (60-96 years at baseline 2001-2003) is followed over time and all live in Karlskrona, Sweden. In this study, individuals were assigned to the young-old age group (60, 66 years), the old age group (72, 28 years) and the old-old age group (81 years and older). All participants signed informed consent. The Research Ethics Committee at Lund, Sweden approved the study (LU 604-00, LU 744-00).

\section{Clinical Relevance}

Scientific rationale for the study: It is important to identify modifiable risk indicators for cognitive impairment and dementia. It has been proposed that diseases with an inflammatory background may have an impact on cognitive decline. Evidence of periodontitis as a putative risk indicator for the development of cognitive decline is limited. Principal findings: This study showed that in a group of older adults in Sweden, a history of periodontal disease was an independent risk indicator for the development of cognitive decline.

Practical implications: Clinicians should provide adequate periodontal care to the elderly population.

\section{1 | Definitions of variables}

The cognitive outcome variable, Mini-Mental State Examination (MMSE), (Folstein, Folstein, \& McHugh, 1975) was evaluated at baseline and at the 6-year follow-up examinations. Information about the level of education was collected from questionnaire and categorized according to final school grade; elementary ( $\leq 9$ years) or higher education (>9 years). Living conditions were grouped into living alone or living with someone. Body mass index was calculated and categorized according to World Health Organizations (WHO: s) definition ( $<25$ defined as underweight and normal, and pre-obese and obese 225) (World Health Organization, 2003). Known ischaemic heart disease was defined as previous percutaneous coronary intervention $(\mathrm{PCl})$, coronary surgery, myocardial infarction or angina pectoris. Information about smoking habits were collected from a questionnaire: "Do you smoke, regularly, occasionally, former or never?" Level of alcohol consumption was evaluated with the Alcohol Use Disorder Identification Test, AUDIT, a self-reported screening developed by the WHO to assess alcohol consumption and its consequences. It contains ten items, resulting in a total test score of 40 points. The test has been validated (Saunders, Aasland, Babor, de la Fuente, \& Grant, 1993).The cut-off for harmful drinking behaviour was set to $\geq 8$ points (Conigrave, Hall, \& Saunders, 1995). Information regarding traumatic brain injury was captured from questionnaires and categorized into head trauma with loss of consciousness: yes or no. Level of depression was evaluated using the MADRS (Montgomery-Åsberg Depression Rating Scale) (Asberg, Montgomery, Perris, Schalling, \& Sedvall, 1978) with the following cut-off: 0-6, absence of depression; 7-19, mild depression; 20-34 moderate depression; and 35 and above, severe depression. Outcomes from the 6-year follow-up were used.

\section{2 | Dental examination}

All individuals received a comprehensive clinical and radiographic dental examination by one of the two experienced dental hygienists. 
The clinical examination included registration of number of teeth present, probing pocket depth (PPD) measured at four sites at al existing teeth using periodontal probes (CP-12 probes, HU Friedy Inc.Chicago, IL, USA). The deepest probing depth for each tooth was used to calculate the proportion of teeth with a PPD value $\geq 5 \mathrm{~mm}$. Bleeding on probing was likewise examined and the proportion of teeth with bleeding at any of the four surfaces was registered. Intraclass correlation (ICC) analysis result between randomly selected cases for double assessments regarding the reproducibility of PPD values at the deepest site between the two clinicians performing the examinations was 0.76 ( $95 \%$ confidence interval $(\mathrm{Cl}) 0.67,0.82$; $p<0.001)$. Panoramic radiographs were taken using an orthopantomograph (Instrumentarium Dental, OP 100; Tuusula, Finland) with a standard exposure of $75 \mathrm{kV} / 10 \mathrm{~mA}$. The extent of alveolar bone loss was evaluated at the mesial and distal aspect of each tooth. For the purpose, a millimetre graded transparent ruler and $2 x$ magnification viewer and a light box source were used. The number of readable interproximal sites was used to calculate the proportion of sites with distance from the cement-enamel junction (CEJ) to the alveolar bone level exceeding 4 and $5 \mathrm{~mm}$, respectively. In the statistical analysis, periodontal bone-loss, $\geq 4 \mathrm{~mm}$ distance from CEJ to marginal bone level on $\geq 30 \%$ of readable sites was used as an indicator of a history of periodontal disease. An experienced independent examiner masked to age, gender, dental and medical information performed all the radiographic measurements. Reliability analysis was done for the double readings of the $\mathrm{X}$-rays. The ICC correlation coefficient for the distance between the apex and CEJ was $0.93(95 \% \mathrm{Cl}=091-0.96$, $p<0.01$ ), based on a total of 91 observations, with a mean difference of $0.94 \mathrm{~mm}(S D \pm 1.3)$

\section{3 | Cognitive test}

Mini-Mental State Examination, MMSE, one of the most widely used cognitive screening test was used. The test consists of 20 items and the total sum of the test scores is maximum 30 (worst to best) (Folstein et al., 1975). The test has been assessed with reliable change index $(\mathrm{RCl})$ and a change of $2-3$ is considered an actual change that is not caused by practice or measurement effects (Eslinger, Swan, \& Carmelli, 2003; Iverson, 1998; Tombaugh, 2005). In this study, individuals with MMSE-score $<25$ at baseline were excluded and cognitive decline was defined as $\geq 3$-points deterioration from baseline to the 6-year follow-up.

\section{4 | Statistical analysis}

A statistical software program (IBM SPSS version 22.0, IBM Statistics, Amorak, NY,USA) was used for the analysis. Descriptive statistics were used to present the population. A Chi-square test for independence was performed to evaluate potential associations between the candidate explanatory covariables and the dependent variable; experience of cognitive decline. The association between a history of periodontitis, defined as having periodontal bone-loss $\geq 4 \mathrm{~mm}$ distance from CEJ to marginal bone level on $\geq 30 \%$ of readable sites and baseline characteristics was analysed using the Chi-square test. Low age, high education, living with someone, never smoked, no traumatic brain injury, no ischaemic heart disease, AUDIT $<8$ and $\mathrm{BMI} \geq 25$ were used as references in the multivariate logistic regression analysis. The impact of periodontal bone loss on the risk for cognitive decline was analysed first univariate, and thereafter, the covariables were added in blocks additionally based on area; demographic, medical and social. Odds ratio $(\mathrm{OR}), 95 \%$ confidence interval $(\mathrm{Cl})$ and $p$-values were calculated; $p$-values $<0.05$ were regarded as statistically significant.

\section{3 | RESULTS}

The study population consisted of individuals who were examined both at baseline (2001-2003), and at the 6-year follow-up (2007-2009). At baseline, 1402 individuals were examined. At the 6-year examination 452 of the baseline population had died, $110(11,6 \%)$ refused further participation, 22 individuals denied participation in the cognitive test, 14 had only completed parts of the test due to functional disabilities (visual or hearing difficulties, paresis) and five choose to abort before the test was fulfilled. After exclusion of individuals with MMSE-score $<25$ at baseline, 715 individuals remained. To moderate for the potential influence of depression on the cognitive test-outcome at the 6-year follow-up, additional 11 individuals with moderate and severe depression according to Svanborg ( $\geq 20$, MADRS) at the 6-year followup examination were excluded. Thus, 704 individuals were available for evaluation. One-hundred fifteen individuals experienced $a \geq 3$ points decline in MMSE-results during the 6-year follow-up. Such a decline in cognitive function was significantly associated with high age, elementary education, living alone, experience of ischaemic heart disease, $\mathrm{BMI}<25$, being edentulous, having 1-19 teeth and bone loss $\geq 4 \mathrm{~mm}$ at $\geq 30 \%$ of readable sites (Table 1 ).

Data on dental status were available in 662 of the 704 selected individuals (94\%). In 566 individuals, panoramic radiographs were available for analysis of alveolar bone loss in which 214 (38\%) had findings of bone loss $\geq 4 \mathrm{~mm}$ at $\geq 30 \%$ of readable sites. Bone loss $\geq 4 \mathrm{~mm}$ at $\geq 30 \%$ of readable sites was significantly associated with cognitive decline but also with high age, lower education, male gender, current or former smoker, experience of ischaemic heart disease, living alone, fewer teeth (1-19) and presence of pockets ( $\geq 5 \mathrm{~mm}$ on $30 \%$ of teeth) (Table 2). The unadjusted odds ratio (OR) for participants with bone-loss $\geq 4 \mathrm{~mm}$ at $\geq 30 \%$ of readable sites compared to those without for incident cognitive decline were $2.8(\mathrm{Cl} 1.7-4.5)$ and in the fully adjusted model 2.2 (Cl 1.2-3.8), (Table 3). Other variables reaching statistical significance in the fully adjusted model were age, education and BMI.

\section{4 | DISCUSSION}

The main finding of this prospective longitudinal cohort study was that periodontitis, defined as bone loss $\geq 4 \mathrm{~mm}$ at $\geq 30 \%$ of readable 
TABLE 1 Characteristics of the study population at baseline divided into cognitive decliners, based on deterioration of $\geq 3 p$ from baseline to 6-year follow-up using Mini-Mental State Examination (MMSE)

\begin{tabular}{|c|c|c|c|}
\hline & $\begin{array}{l}\text { Not fulfilling } \\
\text { criteria for } \\
\text { cognitive } \\
\text { decline }^{\mathrm{a}} n(\%)\end{array}$ & $\begin{array}{l}\text { Cognitive } \\
\text { decliners, } \\
\geq 3 p \text { MMSE } \\
n(\%)\end{array}$ & $p$-value \\
\hline \multicolumn{4}{|l|}{ Baseline characteristics } \\
\hline \multicolumn{4}{|l|}{ Age } \\
\hline 60,66 & $308(94)$ & $19(6)$ & \\
\hline 72,78 & $165(80)$ & $42(20)$ & \\
\hline $81-96$ & $116(68)$ & $54(32)$ & $<0.001$ \\
\hline \multicolumn{4}{|l|}{ Gender } \\
\hline Female & $330(83)$ & $67(17)$ & \\
\hline Male & $259(84)$ & $48(16)$ & 0.6 \\
\hline \multicolumn{4}{|l|}{ Education } \\
\hline Elementary & $461(82)$ & $101(18)$ & \\
\hline Higher & $116(94)$ & $7(6)$ & 0.001 \\
\hline \multicolumn{4}{|l|}{ Living alone } \\
\hline Yes & $167(78)$ & $47(22)$ & \\
\hline No & $417(87)$ & $63(13)$ & 0.003 \\
\hline \multicolumn{4}{|c|}{ Ischaemic heart disease } \\
\hline Yes & $88(75)$ & $29(25)$ & \\
\hline No & $501(85)$ & $86(15)$ & 0.007 \\
\hline \multicolumn{4}{|l|}{ BMI } \\
\hline $\begin{array}{l}\text { Underweight and } \\
\text { normal }<25\end{array}$ & $151(77)$ & $44(23)$ & \\
\hline $\begin{array}{l}\text { Pre-obese and } \\
\text { obese } \geq 25\end{array}$ & $429(86)$ & $70(14)$ & 0.006 \\
\hline \multicolumn{4}{|l|}{ Traumatic brain injury } \\
\hline Yes & $84(87)$ & $13(13)$ & \\
\hline No & $501(83)$ & $101(17)$ & 0.4 \\
\hline \multicolumn{4}{|l|}{ Smoking } \\
\hline Current or former & $277(85)$ & $49(15)$ & \\
\hline Never & $301(83)$ & $62(17)$ & 0.46 \\
\hline \multicolumn{4}{|c|}{ Alcohol (Alcohol Use Disorders Intervention Scale, AUDIT $\geq 8$ ) } \\
\hline Yes & $19(95)$ & $1(5)$ & \\
\hline No & $546(84)$ & $105(16)$ & 0.18 \\
\hline \multicolumn{4}{|l|}{ Edentulous } \\
\hline Yes & $48(74)$ & $17(26)$ & \\
\hline No & $509(85)$ & $88(15)$ & 0.02 \\
\hline \multicolumn{4}{|c|}{ Number of teeth (edentulous excluded) } \\
\hline $1-19$ & $180(76)$ & $56(24)$ & \\
\hline 20-32 & $329(91)$ & $32(9)$ & $<0.001$ \\
\hline \multicolumn{4}{|c|}{ Pockets according to category } \\
\hline 0 & $472(86)$ & $78(14)$ & \\
\hline $\begin{array}{l}1=\geq 5 \mathrm{~mm} \text { on } 30 \% \\
\text { of teeth }\end{array}$ & $33(80.5)$ & $8(19.5)$ & 0.35 \\
\hline
\end{tabular}

TABLE 1 (Continued)

\begin{tabular}{|c|c|c|c|}
\hline & $\begin{array}{l}\text { Not fulfilling } \\
\text { criteria for } \\
\text { cognitive } \\
\text { decline }^{a} n(\%)\end{array}$ & $\begin{array}{l}\text { Cognitive } \\
\text { decliners, } \\
\geq 3 p \text { MMSE } \\
n(\%)\end{array}$ & $p$-value \\
\hline \multicolumn{4}{|c|}{ Bleeding on probing(Bop) } \\
\hline 0 & $350(87)$ & $52(13)$ & \\
\hline $1=\geq 30 \%$ of teeth & $155(82)$ & $34(18)$ & 0.1 \\
\hline \multicolumn{4}{|l|}{ Bone-loss } \\
\hline 0 & $319(91)$ & $33(9)$ & \\
\hline $\begin{array}{l}1=\geq 4 \text { mm distance } \\
\text { from cement- } \\
\text { enamel junction } \\
\text { (CEJ) to marginal } \\
\text { bone level on } \\
\geq 30 \% \text { of readable } \\
\text { sites }\end{array}$ & $166(78)$ & $48(22)$ & $<0.001$ \\
\hline
\end{tabular}

${ }^{a}$ Stable or minor cognitive decline (1-2p MMSE).

sites registered at panoramic $\mathrm{X}$-rays at baseline, was an independent risk indicator for cognitive decline after 6 years.

Cognitive impairment and neurocognitive disorders have a multifactorial aetiology and in the present study adjustments were made for demographic, lifestyle and medical factors. It is well known that the impact of different risk factors most likely starts long before signs of cognitive decline are clinically evident. Therefore, in this type of study, the use of alveolar-bone loss is relevant for defining a course of periodontal disease. Previous studies evaluating cognitive function and dementia in relation to oral health parameters are mainly cross-sectional. Hence, the possibility to discuss causality is limited. As cognitive decline progresses, changes in daily functioning will emerge, influencing factors such as diet and oral hygiene. Such changes may influence the risk for caries and gingivitis in these patients. In the present study, only individuals with MMSE $\geq 25$ at baseline were included and therefore a possible causal relationship between a history of periodontitis and cognitive decline can be suggested.

In the light of the current trends, with an increasing proportion of elderly, and apparently increasing prevalence of dementia, our findings may be of importance also in a public health perspective. Current available medication exerts no clear effect on the clinical course of dementia and no curative treatments are available. Identifying and moderate modifiable risk factors are therefore critical as they may prevent or postpone the clinical onset of dementia. Few studies have evaluated the impact of periodontitis on the risk for cognitive decline longitudinally. In a recent follow-up study over 3 years, a higher risk for cognitive decline, estimated as a decrease of $\geq 3$ points in MMSE score, was demonstrated, among individuals with severe periodontitis, defined as $\geq 2$ interproximal sites with clinical attachment loss of $\geq 6 \mathrm{~mm}$ and $\geq 1$ interproximal sites with probing depth $\geq 5 \mathrm{~mm}$ (CDC/AAP), compared to individuals without periodontitis, after controlling for baseline health 
WI LEY- ${ }_{\text {Periodontology }}^{\text {Jounal }}$ Clinical

\begin{tabular}{|c|c|c|c|}
\hline & $\begin{array}{l}\text { Not fulfilling the criteria } \\
\text { for periodontal bone-loss } \\
n(\%)\end{array}$ & $\begin{array}{l}\text { Periodontal } \\
\text { bone-loss } \\
n(\%)\end{array}$ & $p$-value \\
\hline \multicolumn{4}{|l|}{ Baseline characteristics } \\
\hline \multicolumn{4}{|l|}{ Age } \\
\hline 60,66 & $204(72)$ & $78(28)$ & \\
\hline 72,78 & $105(62)$ & $65(38)$ & \\
\hline $81-96$ & $43(38)$ & $71(62)$ & $<0.001$ \\
\hline \multicolumn{4}{|l|}{ Gender } \\
\hline Female & $213(67)$ & $105(33)$ & \\
\hline Male & $139(56)$ & $109(44)$ & $<0.01$ \\
\hline \multicolumn{4}{|l|}{ Education } \\
\hline Elementary & $271(60)$ & $183(40)$ & \\
\hline Higher & $78(75)$ & $26(25)$ & $<0.01$ \\
\hline \multicolumn{4}{|l|}{ Living alone } \\
\hline Yes & $87(55)$ & $70(45)$ & \\
\hline No & $264(65)$ & $143(35)$ & 0.04 \\
\hline \multicolumn{4}{|l|}{ Ischaemic heartdisease } \\
\hline Yes & $42(48)$ & $45(52)$ & \\
\hline No & $310(65)$ & $169(35)$ & $<0.01$ \\
\hline \multicolumn{4}{|l|}{ BMI } \\
\hline $\begin{array}{l}\text { Underweight and normal } \\
<25\end{array}$ & $97(59)$ & $68(41)$ & \\
\hline Pre-obese and obese $\geq 25$ & $254(63.5)$ & $146(36.5)$ & 0.3 \\
\hline \multicolumn{4}{|l|}{ Traumatic brain injury } \\
\hline Yes & $49(62)$ & $30(38)$ & \\
\hline No & $302(62)$ & $183(38)$ & 0.97 \\
\hline \multicolumn{4}{|l|}{ Smoking } \\
\hline Current or former & $143(54)$ & $123(46)$ & \\
\hline Never & $205(70)$ & $87(30)$ & $<0.001$ \\
\hline \multicolumn{4}{|c|}{ Alcohol (Alcohol Use Disorders Intervention Scale, AUDIT $\geq 8$ ) } \\
\hline Yes & $9(50)$ & $9(50)$ & \\
\hline No & $332(84)$ & $193(16)$ & 0.2 \\
\hline \multicolumn{4}{|l|}{ Number of teeth } \\
\hline $1-19$ & $96(43)$ & $129(57)$ & \\
\hline $20-32$ & $256(75)$ & $85(25)$ & $<0.001$ \\
\hline \multicolumn{4}{|l|}{ Pockets according to category } \\
\hline 0 & $341(66)$ & $179(34)$ & \\
\hline $1=\geq 5 \mathrm{~mm}$ on $30 \%$ of teeth & $6(15)$ & $34(85)$ & $<0.001$ \\
\hline \multicolumn{4}{|l|}{ Bleeding on probing (Bop) } \\
\hline 0 & $244(64)$ & $136(36)$ & \\
\hline $1=\geq 30 \%$ of teeth & $103(57)$ & $77(43)$ & 0.1 \\
\hline
\end{tabular}

TABLE 2 Characteristics of the study population at baseline divided into individuals having periodontal bone-loss, $\geq 4 \mathrm{~mm}$ distance from cement-enamel junction (CEJ) to marginal bone level on $\geq 30 \%$ of readable sites characteristics of importance (Iwasaki et al., 2016). These results are consistent with our findings. Our results are also consistent with the ones reported by Lee and co-workers (Lee et al., 2016) demonstrating that individuals with periodontitis had a higher risk of developing dementia.
However, our results are in contrast to the ones reported by Arrive' and co-workers who were unable to find an association between periodontitis and dementia in a prospective follow-up study, over 15 years, in a sample of individuals aged 60-88 years, living in France(Arrive et al., 2012). A possible explanation to the 
TA B LE 3 Multivariate logistic regression analysis for the outcome cognitive decline, based on deterioration $\geq 3 p$ from baseline to 6-year follow-up using Mini-Mental State Examination (MMSE), the odds ratio for periodontal bone-loss with additional adjustments for demographic, medical and social variables

\begin{tabular}{|c|c|c|c|c|c|}
\hline & $\begin{array}{l}\text { Crude model } \\
n=566\end{array}$ & $\begin{array}{l}\text { Model } 1 \\
n=566\end{array}$ & $\begin{array}{l}\text { Model } 2 \\
n=558\end{array}$ & $\begin{array}{l}\text { Model } 3 \\
n=557\end{array}$ & $\begin{array}{l}\text { Model } 4 \\
n=530\end{array}$ \\
\hline Periodontal bone-loss & $2.8(1.7-4.5)$ & $2(1.2-3.3)$ & $2(1.1-3.3)$ & $1.9(1.1-3.2)$ & $2.2(1.2-3.8)$ \\
\hline \multicolumn{6}{|l|}{ Age } \\
\hline 72,76 & & $3.2(1.7-6.1)$ & $2.8(1.4-5.4)$ & $2.8(1.4-5.6)$ & $2.8(1.4-5.6)$ \\
\hline $81-96$ & & $6.2(3.2-12.1)$ & $5.8(2.9-11.7)$ & $5.5(2.7-11.1)$ & $5.3(2.5-11.1)$ \\
\hline Male & & $1.1(0.6-1.8)$ & $1.0(0.6-1.7)$ & $1.1(0.6-1.9)$ & $1.0(0.5-1.8)$ \\
\hline Living alone & & & $1.1(0.6-2.1)$ & $1.1(0.6-2.0)$ & $1.2(0.7-2.3)$ \\
\hline Education, elementary & & & $3.3(1.3-8.7)$ & $3.8(1.4-10.2)$ & $5(1.7-14.7)$ \\
\hline Ischaemic heart disease & & & & $1.2(0.6-2.4)$ & $1.2(0.6-2.3)$ \\
\hline $\begin{array}{l}\text { Body Mass Index (BMI), under- } \\
\text { weight and normal <25 }\end{array}$ & & & & $2.4(1.4-4.1)$ & $2.1(1.2-3.7)$ \\
\hline Traumatic brain injury & & & & & $0.8(0.4-1.9)$ \\
\hline Smoking, current or former & & & & & $1.3(0.7-2.3)$ \\
\hline Alcohol, AUDIT $\geq 8$ & & & & & $0.5(0.05-4.0)$ \\
\hline
\end{tabular}

Note. Logistic regression model, Model 1 = adjustment for periodontal bone-loss, age and gender, Model $2=$ model $1+$ adjustment for living alone and education, Model $3=$ model $2+$ adjustment for ischaemic heart disease and BMI, Model $4=$ adjustment for all variables. Values in bold signify statistical significance $p<0.05$. Confidence interval, $\mathrm{Cl}(95 \%)$.

conflicting results may be related to the definition of periodontitis used. In the study by Arrive' and co-workers, presence of periodontitis was evaluated using the Community Periodontal Index (CPI) (World Health Organization, 1997), which is considered as a screening tool for periodontal disease, whereas in our study periodontitis was based on actual bone loss, measured on radiographs. This underline the importance of including attachment or bone loss in the definition of periodontitis, reflecting a life-time burden of periodontal disease, when exploring a potential association to systemic diseases. A strength of our study is that a large cohort of elderly individuals were followed for a period of 6 years. The randomized population-based sample may also allow us to generalize the results even though the risk for selective attrition must be considered. Individuals who drop out for reasons other than death are often older and more functionally impaired. Individuals that are ill and frail may be less likely to respond and come to the research centre and in this study that is a prerequisite, as the final results rely on data from panoramic $\mathrm{X}$-rays. When comparing baseline characteristics, for the group not selected or available in the final analysis, we found this group to be older, and more likely; having lower education, living alone, having ischaemic heart disease, having $\mathrm{BMI}<25$, having less teeth (1-19) and being edentulous, more likely having boneloss ( $\geq 4 \mathrm{~mm}$ distance from CEJ to marginal bone level on $\geq 30 \%$ of readable sites) and pockets according to category ( $\geq 5 \mathrm{~mm}$ on $30 \%$ of teeth), than the selected study cohort (704), (Table S1). These results suggest, in addition to the exclusion of individuals with lower cognitive test outcome (MMSE <25) at baseline, that any influence of selective attrition would be that the results are underestimated. A methodological strength with the present study is that the same research team has followed the individuals during the whole study period. Other studies have added cognitive data to pre-existing oral health data (Stein, Desrosiers, Donegan, Yepes, \& Kryscio, 2007; Stein, Kryscio, Desrosiers, Donegan, \& Gibbs, 2010) or used self-reported data regarding oral health status (Batty et al., 2013; Gatz et al., 2006; PaganiniHill, White, \& Atchison, 2012).

Mini-Mental State Examination (MMSE) is a suitable instrument for screening for cognitive abilities in epidemiological research since it is validated and easy to administer. However, it also has some well-known limitations. The outcome relies on language skills and therefore individuals with hearing and visual disabilities had to be excluded even if they were cognitively healthy. Additionally, its ability to differentiate between subtypes of cognitive impairment and dementia has been questioned (Tombaugh \& McIntyre, 1992). The study therefore needs to be repeated with other cognitive tests and with different subtypes of dementia. The underlying mechanisms explaining the association between periodontitis and cognitive deterioration are not clear and may vary between different types of dementia. Both vascular dementia and dementia of Alzheimer's type can be associated with systemic inflammation and as increasing evidence suggests that periodontitis may induce a systemic inflammatory burden, this could be a connecting pathway(Paraskevas, Huizinga, \& Loos, 2008; Passoja et al., 2010). The association between experience of ischaemic heart disease and periodontitis reported in the present study support this hypothesis.

The present study demonstrated that a history of periodontitis is associated with decline in cognitive functions after 6-years follow-up, which may indicate that periodontitis is a risk indicator for 
cognitive decline. Long-term intervention studies are warranted to evaluate if periodontal treatment can influence progression of cognitive decline.

\section{CONFLICT OF INTERESTS}

The authors declare that there are no conflict of interests in this study.

\section{ORCID}

Helena Nilsson (ID) http://orcid.org/0000-0001-7315-1166

Stefan Renvert (D) http://orcid.org/0000-0003-0992-2362

\section{REFERENCES}

Arrive, E., Letenneur, L., Matharan, F., Laporte, C., Helmer, C., Barberger-Gateau, P., ... Dartigues, J. F. (2012). Oral health condition of french elderly and risk of dementia: A longitudinal cohort study. Community Dentistry and Oral Epidemiology, 40(3), 230-238. https://doi.org/10.1111/j.1600-0528.2011.00650.x; 10.1111/j.1600-0528.2011.00650.x

Asberg, M., Montgomery, S. A., Perris, C., Schalling, D., \& Sedvall, G. (1978). A comprehensive psychopathological rating scale. Act Psychiatrica Scandinavica. Supplementum, 271, 5-27. https://doi. org/10.1111/j.1600-0447.1978.tb02357.x

Batty, G. D., Li, Q., Huxley, R., Zoungas, S., Taylor, B. A., Neal, B, ... VANCE Collaborative group. (2013). Oral disease in relation to future risk of dementia and cognitive decline: Prospective cohort study based on the action in diabetes and vascular disease: Preterax and diamicron modified-release controlled evaluation (ADVANCE) trial. European Psychiatry: The Journal of the Association of European Psychiatrists, 28(1), 49-52. https://doi.org/10.1016/j. eurpsy.2011.07.005

Conigrave, K. M., Hall, W. D., \& Saunders, J. B. (1995). The AUDIT questionnaire: Choosing a cut-off score. alcohol use disorder identification test. Addiction (Abingdon, England), 90(10), 1349-1356. https:// doi.org/10.1111/j.1360-0443.1995.tb03552.x

Delwel, S., Binnekade, T. T., Perez, R. S. G. M., Hertogh, C. M. P. M., Scherder, E. J. A., \& Lobbezoo, F. (2018). Oral hygiene and oral health in older people with dementia: A comprehensive review with focus on oral soft tissues. Clinical Oral Investigations, 22(1), 93-108. https:// doi.org/10.1007/s00784-017-2264-2

Eslinger, P. J., Swan, G. E., \& Carmelli, D. (2003). Changes in minimental state exam in community-dwelling older persons ove 6 years: Relationship to health and neuropsychological mea sures. Neuroepidemiology, 22(1), 23-30. 67113 https://doi. org/10.1159/000067113

Ferri, C. P., Prince, M., Brayne, C., Brodaty, H., Fratiglioni, L., \& Ganguli, M., ... Alzheimer's Disease International. (2005). Global prevalence of dementia: A delphi consensus study. Lancet, 366(9503), 2112-2117. https://doi.org/10.1016/S0140-6736(05)67889-0

Folstein, M. F., Folstein, S. E., \& McHugh, P. R. (1975). "Mini-mental state". A practical method for grading the cognitive state of patients for the clinician. Journal of Psychiatric Research, 12(3), 189-198. https://doi. org/10.1016/0022-3956(75)90026-6

Gatz, M., Mortimer, J. A., Fratiglioni, L., Johansson, B., Berg, S., Reynolds, C. A., \& Pedersen, N. L. (2006). Potentially modifiable risk factor for dementia in identical twins. Alzheimer's \& Dementia: The Journal of the Alzheimer's Association, 2(2), 110-117. https://doi.org/10.1016/j. jalz.2006.01.002
Gil-Montoya, J. A., Barrios, R., Santana, S., Sanchez-Lara, I., Pardo, C. C., Fornieles-Rubio, F., ... Burgos, J. S. (2017). Association between periodontitis and amyloid-beta peptide in elderly people with and without cognitive impairment. Journal of Periodontology, 88(10), 1051-1058. https://doi.org/10.1902/jop.2017.170071

Gil-Montoya, J. A., Sanchez-Lara, I., Carnero-Pardo, C., Fornieles, F., Montes, J., Vilchez, R., ... Bravo, M. (2014). Is periodontitis a risk factor for cognitive impairment and dementia? A case-control study. Journal of Periodontology, 86(2), 244-253. https://doi.org/10.1902/ jop.2014.140340

Gil-Montoya, J. A., Sanchez-Lara, I., Carnero-Pardo, C., Fornieles-Rubio, F., Montes, J., Barrios, R., ... Bravo, M. (2017). Oral hygiene in the elderly with different degrees of cognitive impairment and dementia. Journal of the American Geriatrics Society, 65(3), 642-647. https://doi. org/10.1111/jgs.14697

Gusman, D. J. R., Mello-Neto, J. M., Alves, B. E. S., Matheus, H. R., Ervolino, E., Theodoro, L. H., \& de Almeida, J. M. (2018). Periodontal disease severity in subjects with dementia: A systematic review and meta-analysis. Archives of Gerontology and Geriatrics, 76, 147-159. S0167-4943(18)30035-9 [pii] https://doi.org/10.1016/j. archger.2018.02.016

Iverson, G. L. (1998). Interpretation of mini-mental state examination scores in community-dwelling elderly and geriatric neuropsychiatry patients. International Journal of Geriatric Psychiatry, 13(10), 661-666. AID-GPS838 > 3.0.CO;2-0 [pii] https://doi.org/10.1002/ (ISSN)1099-1166

Iwasaki, M., Yoshihara, A., Kimura, Y., Sato, M., Wada, T., Sakamoto, R., ... Matsubayashi, K. (2016). Longitudinal relationship of severe periodontitis with cognitive decline in older japanese. Journal of Periodontal Research, 51(5), 681-688. https://doi.org/10.1111/ jre.12348

Kamer, A. R., Craig, R. G., Dasanayake, A. P., Brys, M., Glodzik-Sobanska, L., \& de Leon, M. J. (2008). Inflammation and alzheimer's disease: Possible role of periodontal diseases. Alzheimer's \& Dementia: The Journal of the Alzheimer's Association, 4(4), 242-250. https://doi. org/10.1016/j.jalz.2007.08.004

Kamer, A. R., Pirraglia, E., Tsui, W., Rusinek, H., Vallabhajosula, S., Mosconi, L., ... de Leon, M. J. (2015). Periodontal disease associates with higher brain amyloid load in normal elderly. Neurobiology of Aging, 36(2), 627-633. https://doi.org/10.1016/j.neurobiolaging.2014.10.038

Lee, Y. T., Lee, H. C., Hu, C. J., Huang, L. K., Chao, S. P., Lin, C. P., ... Chen, C. C. (2016). Periodontitis as a modifiable risk factor for dementia: A nationwide population-based cohort study. Journal of the American Geriatrics Society, 65(2), 301-305. https://doi.org/10.1111/jgs.14449

Leira, Y., Dominguez, C., Seoane, J., Seoane-Romero, J., Pias-Peleteiro, J. M., Takkouche, B., ... Aldrey, J. M. (2017). Is periodontal disease associated with alzheimer's disease? A systematic review with meta-analysis Neuroepidemiology, 48(1-2), 21-31. https://doi.org/10.1159/00045841

Li, W., Risacher, S. L., McAllister, T. W., \& Saykin, A. J. (2016). Traumatic brain injury and age at onset of cognitive impairment in older adults. Journal of Neurology, 263(7), 1280-1285. https://doi.org/10.1007/ s00415-016-8093-4

Maldonado, A., Laugisch, O., Burgin, W., Sculean, A., \& Eick, S. (2018). Clinical periodontal variables in patients with and without dementia-a systematic review and meta-analysis. Clinical Oral Investigations. https://doi.org/10.1007/s00784-018-2523-x

Murray, C. J., Atkinson, C., Bhalla, K., Birbeck, G., Burstein, R., Chou, D., ... U S Burden of Disease Collaborators. (2013). The state of US health, 1990-2010: Burden of diseases, injuries, and risk factors. JAMA, 310(6), 591-608. https://doi.org/10.1001/jama.2013.13805

Noble, J. M., Scarmeas, N., Celenti, R. S., Elkind, M. S., Wright, C. B. Schupf, N., \& Papapanou, P. N. (2014). Serum IgG antibody levels to periodontal microbiota are associated with incident alzheimer disease. PLoS ONE, 9(12), e114959. https://doi.org/10.1371/journal. pone.0114959 
Norton, S., Matthews, F. E., Barnes, D. E., Yaffe, K., \& Brayne, C. (2014). Potential for primary prevention of alzheimer's disease: An analysis of population-based data. The Lancet. Neurology, 13(8), 788-794. https://doi.org/10.1016/s1474-4422(14)70136-x

Paganini-Hill, A., White, S. C., \& Atchison, K. A. (2012). Dentition, dental health habits, and dementia: The leisure world cohort study. Journal of the American Geriatrics Society, 60(8), 1556-1563. https://doi. org/10.1111/j.1532-5415.2012.04064.x

Paraskevas, S., Huizinga, J. D., \& Loos, B. G. (2008). A systematic review and meta-analyses on $\mathrm{C}$-reactive protein in relation to periodontitis. Journal of Clinical Periodontology, 35(4), 277-290. https://doi. org/10.1111/j.1600-051x.2007.01173.x

Passoja, A., Puijola, I., Knuuttila, M., Niemela, O., Karttunen, R. Raunio, T., \& Tervonen, T. (2010). Serum levels of interleukin-10 and tumour necrosis factor-alpha in chronic periodontitis. Journal of Clinical Periodontology, 37(10), 881-887. https://doi. org/10.1111/j.1600-051x.2010.01602.x

Peters, R., Peters, J., Warner, J., Beckett, N., \& Bulpitt, C. (2008). Alcohol, dementia and cognitive decline in the elderly: A systematic review. Age and Ageing, 37(5), 505-512. https://doi.org/10.1093/ageing/afn095

Poole, S., Singhrao, S. K., Kesavalu, L., Curtis, M. A., \& Crean, S. (2013). Determining the presence of periodontopathic virulence factors in short-term postmortem alzheimer's disease brain tissue. Journal of Alzheimer's Disease (JAD), 36(4), 665-677. https://doi.org/10.3233/ jad-121918

Prince, M., Bryce, R., Albanese, E., Wimo, A., Ribeiro, W., \& Ferri, C. P. (2013). The global prevalence of dementia: A systematic review and metaanalysis. Alzheimer's \& Dementia. The Journal of the Alzheimer's Association, 9(1), 63-75.e2. https://doi.org/10.1016/j. jalz.2012.11.007

Saunders, J. B., Aasland, O. G., Babor, T. F., de la Fuente, J. R, \& Grant, M. (1993). Development of the alcohol use disorders identification test (AUDIT): WHO collaborative project on early detection of persons with harmful alcohol consumption-II. Addiction (Abingdon, England), 88(6), 791-804. https://doi.org/10.1111/j.1360-0443.1993. tb02093.x

Stein, P. S., Desrosiers, M., Donegan, S. J., Yepes, J. F., \& Kryscio, R. J. (2007). Tooth loss, dementia and neuropathology in the nun study. Journal of the American Dental Association (1939), 138(10), 13141322; quiz 1381. https://doi.org/10.14219/jada.archive.2007.0046

Stein, P. S., Kryscio, R. J., Desrosiers, M., Donegan, S. J., \& Gibbs, M. B. (2010). Tooth loss, apolipoprotein E, and decline in delayed word recall. Journal of Dental Research, 89(5), 473-477. https://doi. org/10.1177/0022034509357881

Syrjala, A. M., Ylostalo, P., Ruoppi, P., Komulainen, K., Hartikainen, S., Sulkava, R., \& Knuuttila, M. (2012). Dementia and oral health among subjects aged 75 years or older. Gerodontology, 29(1), 36-42. https://doi.org/10.1111/j.1741-2358.2010.00396.x 10.1111/j.1741-2358.2010.00396.x
Tombaugh, T. N. (2005). Test-retest reliable coefficients and 5year change scores for the MMSE and 3MS. Archives of Clinical Neuropsychology: The Official Journal of the National Academy of Neuropsychologists, 20(4), 485-503. S0887-6177(04)00183-0 [pii] https://doi.org/10.1016/j.acn.2004.11.004

Tombaugh, T. N., \& McIntyre, N. J. (1992). The mini-mental state examination: A comprehensive review. Journal of the American Geriatrics Society, 40(9), 922-935. https://doi.org/10.1111/j.1532-5415.1992. tb01992.x

Wimo, A., Guerchet, M., Ali, G. C., Wu, Y. T., Prina, A. M., Winblad, B., ... Prince, M. (2017). The worldwide costs of dementia 2015 and comparisons with 2010. Alzheimer's \& Dementia. The Journal of the Alzheimer's Association, 13(1), 1-7. S1552-5260(16)30043-7 [pii]

World Health Organization. (1992). The ICD-10 classification of mental and behavioural disorders: Clinical descriptions and diagnostic guidelines. Geneva, Switzerland: World Health Organization. Retrieved from http://www.who.int/iris/handle/10665/37958

World Health Organization. (1997). Oral health surveys: Basic methods, 4th ed. Geneva, Switzerland: World Health Organization. Retrieved from http://apps.who.int/iris/handle/10665/41905

World Health Organization. (2003). Obesity and overweight. Retrieved from https://web.archive.org/web/20111210035353/http:/www. who.int/dietphysicalactivity/publications/facts/obesity/en

Zenthofer, A., Baumgart, D., Cabrera, T., Rammelsberg, P., Schroder, J., Corcodel, N., \& Hassel, A. J. (2017). Poor dental hygiene and periodontal health in nursing home residents with dementia: An observational study. Odontology, 105(2), 208-213. https://doi.org/10.1007/ s10266-016-0246-5

Zenthofer, A., Schroder, J., Cabrera, T., Rammelsberg, P., \& Hassel, A. J. (2014). Comparison of oral health among older people with and without dementia. Community Dental Health, 31(1), 27-31.

\section{SUPPORTING INFORMATION}

Additional supporting information may be found online in the Supporting Information section at the end of the article.

How to cite this article: Nilsson $\mathrm{H}$, Sanmartin Berglund J, Renvert S. Longitudinal evaluation of periodontitis and development of cognitive decline among older adults. J Clin Periodontol. 2018;45:1142-1149. https://doi.org/10.1111/ jcpe.12992 


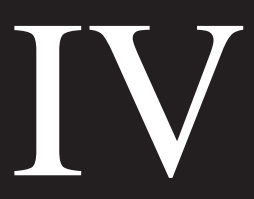



DR. HELENA IDA NILSSON (Orcid ID : 0000-0001-7315-1166)

PROF. STEFAN RENVERT (Orcid ID : 0000-0003-0992-2362)

Article type : Original Article Clinical Periodontology

\section{Longitudinal evaluation of periodontitis and tooth loss among older}

\section{adults.}

DDS Helena Nilsson ${ }^{1} \mathrm{MD}, \mathrm{PhD}$ Johan Sanmartin Berglund ${ }^{2,3}$

DDS, PhD Stefan Renvert $2,4,5,6$

${ }^{1}$ Maxillofacial Unit, Halland Hospital, Halmstad, Sweden

${ }^{2}$ Blekinge Institute of Technology, Karlskrona, Sweden

${ }^{3}$ Department of Clinical Sciences, Lund University, Lund, Sweden

${ }^{4}$ Faculty of Health, Kristianstad University, Kristianstad, Sweden

${ }^{5}$ School of Dental Science, Trinity College, Dublin, Ireland

${ }^{6}$ Faculty of Dentistry, The University of Hong Kong, Hong Kong SAR, China

This article has been accepted for publication and undergone full peer review but has not been through the copyediting, typesetting, pagination and proofreading process, which may lead to differences between this version and the Version of Record. Please cite this article as doi: $10.1111 /$ jcpe. 13167

This article is protected by copyright. All rights reserved. 
Correspondence to Dr Helena Nilsson

Specialisttandvården Region Halland

30185 Halmstad, Sweden

Phone: 004635134057

Helena.i.nilsson@regionhalland.se

Fax +4635134064

Running title: Longitudinal evaluation of periodontitis and tooth loss among older adults.

Keyword: Public Health, Epidemiology, Periodontitis, Older adults, Tooth loss

Acknowledgement

The work was financially supported by Region Halland Sweden.The Swedish National Study on Ageing and Care, SNAC (www.snac.org) is financially supported by the Ministry of Health and Social Affairs, Sweden and the participating County Councils, Municipalities and University Departments. The sponsors had no role in any aspect of the study design or reporting of findings. Conflict of interest: none

Special thanks to Sasa Pejicic for valuable support with the statistical work.

This article is protected by copyright. All rights reserved. 


\section{Abstract:}

Aim: to evaluate pattern of change in periodontal variables and tooth loss in a twelve-year follow-up study of older adults living in Sweden.

Methods: In a prospective population study of older adults a clinical and radiographic dental examination were performed at baseline (2001-2003) and after 12 years (2013-2015).

In 375 individuals, the number and proportion of sites with a distance $\geq 4 \mathrm{~mm}$ and $\geq 5 \mathrm{~mm}$ from cemento-enamel junction to the bone level and the number and proportion of teeth with pockets $\geq$ $5 \mathrm{~mm}$ and number of teeth lost were calculated. Dental caries was registered. Periodontitis was defined as having $\geq 2$ sites with $\geq 5 \mathrm{~mm}$ distance from cemento-enamel junction to the marginal bone level and $\geq 1$ tooth with pockets $\geq 5 \mathrm{~mm}$.

Results: A diagnosis of periodontitis was evident in $39 \%$ of the individuals and $23 \%$ of the individuals lost $\geq 3$ teeth over the study period. The proportion of sites with $\geq 4 \mathrm{~mm}$ and $\geq 5 \mathrm{~mm}$ bone loss increased with age while the proportion of teeth with pockets remained stable. Periodontitis was the strongest predictor for losing $\geq 3$ teeth, OR $2.9(p<0.001)$ in the final model.

Conclusions: Periodontitis is a risk factor for future tooth loss among older adults.

Scientific rationale for the study: The ageing population, retaining natural teeth through life, is becoming a challenge for dental healthcare systems. Understanding of the impact of periodontal disease and dental caries on the incidence of tooth loss over time, among older adults, is limited.

This article is protected by copyright. All rights reserved. 
Principal findings: This study demonstrated that in a group of older adults in Sweden, the proportion of sites with bone-loss increased with age, while the proportion of teeth with periodontal pockets remained stable. Periodontitis was a significant risk predictor for multiple tooth loss over the study period.

Practical implications: It is of importance to provide adequate dental care to the elderly population.

\section{Introduction}

Ongoing demographic transitions result in ageing populations in many parts of the world (United Nations, Department of Economic and, 2015). In high-income countries, these changes are mainly due to increased life expectancy among elderly (Christensen, Doblhammer, Rau, \& Vaupel, 2009). Whether these added life years are accompanied by good general health and persistent quality of life or chronic diseases and disability, is however less clear (World, 2015). Oral health, is an essential factor in healthy ageing with associations to disability and mortality (Holm-Pedersen, Schultz-Larsen, Christiansen, \& Avlund, 2008; Muller, Shimazaki, Kahabuka, \& Schimmel, 2017). The benefits of a healthy natural dentition, in old age, have been emphasized in relation to masticatory performance, diet, food intake, quality of life and cognitive functioning (Muller et al., 2017). Periodontitis, resulting in alveolar bone loss and eventually tooth loss affects a considerable proportion of the adult population (Eke et al., 2016; Kassebaum et al., 2014a) . The prevalence and incidence seams to peak in midlife (Kassebaum et al., 2014) but due to the chronic and cumulative nature, disease experience increases with age (Baelum, Luan, Chen, \& Fejerskov, 1997; Beck, Sharp, Koch, \& Offenbacher, 1997; Eke et al., 2012). The influence of ageing on periodontitis is complex, but has been suggested to be related to an accumulated exposure of the disease rather than increasing susceptibility. However, altering immune functioning: immune senescence, associated with aging

This article is protected by copyright. All rights reserved. 
has been suggested as a plausible biological mechanism that may affect the susceptibility to periodontitis among elderly (Preshaw, Henne, Taylor, Valentine, \& Conrads, 2017). Another hypothesis, that may explain an increased susceptibility to periodontitis, relates to changes in proliferative capabilities of cells and reduced wound healing capacity through a decrease in type I collagen (Caceres, Oyarzun, \& Smith, 2014; Hajishengallis, 2010; Lim, Liu, Mah, Chen, \& Helms, 2014). In addition to conceivable biological alterations, emerging deterioration in physical and psychological abilities may influence lifestyle factors and access to dental care with potential influence on the risk for oral diseases (Batchelor, 2015; Pretty et al., 2014; Terezakis, Needleman, Kumar, Moles, \& Agudo, 2011). The influence of age on the distribution of periodontitis was recently evaluated in two population-based samples in two different countries, Germany and the United States. A linear increase in mean clinical attachment loss (CAL) with age was demonstrated in both samples. The mean pocket depth (PD) remained constant and the contribution of recession to CAL increased with age (Billings et al., 2018) . A recent systematic review, evaluating progression of periodontitis, reported that there were no significant differences in annual attachment level change between age cohorts (Needleman et al., 2018) . A three-fold higher mean attachment loss was however reported in countries with developing economies compared to developed economies (Needleman et al., 2018). Progressive periodontitis and caries are considered major causes of tooth loss among adults (Jepsen et al., 2017). The economic burden in terms of direct costs for treating caries, periodontitis and replacing teeth lost is considerable (Listl, Galloway, Mossey, \& Marcenes, 2015; Righolt, Jevdjevic, Marcenes, \& Listl, 2018). In industrialized countries more teeth are retained (Kassebaum et al., 2014b; Schwendicke et al., 2018) increasing the number of teeth that are at risk for both caries and periodontal disease. Hence, longitudinal studies of older adults, evaluating both oral and general health, aiming to identify factors associated with dental caries, periodontitis and tooth loss are important, not only for individuals affected but also for stakeholders, providing dental services and determining priorities for research, policies and fundings, as the populations are ageing (Tonetti et al., 2017) . Acknowledging the lack of information regarding oral diseases and its

This article is protected by copyright. All rights reserved. 
determinants in the older age cohorts, the aim with the present study was to evaluate pattern of change in periodontal variables and tooth loss in a twelve-year follow-up study of older adults living in Sweden.

\section{Material and methods}

The Swedish National Study on Ageing and Care (SNAC) is a population-based, prospective and longitudinal study running at four research centres. At one of the research centres, SNAC- Blekinge, 2312 individuals were invited by mail to participate in the study. Aiming to represent the elderly population in Sweden a randomised selection was made from the Swedish civil registration database in the age cohorts: $60,66,72,78$. In the age cohorts $81,84,87$ (and older) all individuals in the community were invited to participate in the study. Those who did not reply were contacted by telephone (three attempts). In total, 1402 agreed to participate and were invited by mail to take part in a medical, psychological and dental examination performed in a research clinic by professionals specially trained for the purpose. The sample of older adults in the selected age cohorts is followed over time and all live in Karlskrona, Sweden. Twelve years later, 619 individuals of the original 1402, were available and 476 agreed to participate in the 12 -year follow-up study. Reasons for declining further participation were: too ill (25), non-responded (12), moved (18), not interested (53), died during the examination time (35). In the present study, individuals were assigned to the young-old age group (60, 66 years), the old age group $(72,28$ years) and the old-old age group (81 years and older). All participants signed informed consent. The Research Ethics Committee at Lund, Sweden approved the study (LU 604-00, LU 128-00).

This article is protected by copyright. All rights reserved. 


\section{Definition of variables}

Body mass index was calculated and categorised according to World Health Organizations (WHO: s) definition ( $<24.9$ defined as underweight and normal, and pre-obesity 25-29.9 and obesity $>30$ ) . Known ischemic heart disease was defined as previous percutaneous coronary intervention (PCI), coronary surgery, myocardial infarction or angina pectoris. Information about smoking habits were collected from a questionnaire: " Do you smoke, regularly, occasionally, former or never" ?

Information about the level of education was collected from questionnaire and categorised according to final school grade; elementary ( $\leq 9$ years) or higher education ( $>9$ years).

Utilization of dental health care services was categorized into, visiting the dental office, at least once a year or less common. Living conditions were grouped into living alone or living with someone. The Mini-mental State Examination,(MMSE) was used to evaluate cognitive functioning and a cut-off score $<28$ was adopted. Dental hygiene habits were captured from questionnaires regarding tooth brushing frequency and use of interdental care devices.

Information about diabetes was based on self-reporting data. Information about financial problems was collected from a questionnaire: “ Do you experience difficulties managing your finances in your daily life ", yes or no.

This article is protected by copyright. All rights reserved. 


\section{Dental examination}

During the baseline examination, 2001-2003 all individuals were subjected to a comprehensive clinical and radiographic dental examination by two experienced dental hygienists, members of the research team. The clinical examination included registration of teeth present and periodontal probing. Probing depth (PD) was assessed from the gingival margin to the base of the pocket at four sites at all existing teeth using periodontal probes (CP-12 probes, HU Friedy Inc.Chicago, IL, USA). Dental caries was registered at the buccal and lingual surface of each tooth and categorised into having an open manifest lesion "yes or no" on each surface. Intra-class correlation (ICC) analysis result between randomly selected cases for double assessments regarding the reproducibility of PD values at the deepest site between the two clinicians performing the examinations was 0.76 (95\% confidence interval $(\mathrm{Cl}) 0.67,0.82 ; p<0.001)$. Panoramic radiographs were taken using an orthopantomograph (Instrumentarium Dental, OP 100; Tuusula, Finland) with a standard exposure of $75 \mathrm{kV} / 10 \mathrm{~mA}$. The extent of alveolar bone loss was evaluated at the mesial and distal aspect of each tooth (Persson, Hollender, \& Persson, 1998) . For the purpose, a millimeter graded transparent ruler and $2 x$ magnification viewer and a light box source were used. The number of readable interproximal sites was used to calculate the proportion of sites with distance from the cementoenamel junction (CEJ) to the alveolar bone level exceeding 4 and $5 \mathrm{~mm}$ respectively. An experienced independent examiner masked to age, gender, dental and medical information performed all the radiographic measurements. Reliability analyses were done for the double readings of the X-rays. The ICC correlation coefficient for the distance between the apex and CEJ was $0.93(95 \% \mathrm{Cl}=0,91$ $0,96, p<0.01)$, After twelve years the participants were invited for a re-examination performed in the same manner as the baseline examination despite that the $\mathrm{x}$-rays were digital,Gendex Orthoralix $920070 \mathrm{kV}, 4 \mathrm{~mA}$.

This article is protected by copyright. All rights reserved. 


\section{Statistical analyses}

A statistical software program (IBM SPSS version 24.0, IBM Statistics, Amorak, NY,USA) was used for the analysis. The population was described in relation to demographic and medical variables in the different age cohorts. Mean number of teeth, mean number and proportion of teeth with pockets $\geq$ $5 \mathrm{~mm}$ and mean number and proportion of sites with bone- loss $\geq 4 \mathrm{~mm}$ and $\geq 5 \mathrm{~mm}$ was computed for the baseline examination and for the twelve-year follow-up and analysed using ANOVA. As the deviation from mean value, for each age cohort was large, suggesting distribution with long tails, the median value was also calculated. When testing for differences in median between the age groups a non-parametric test for independent samples was used. A Chi-square test for independence was used to explore the association between age and periodontitis and dental caries respectively. The difference in tooth loss between the age cohorts was analysed using both One-way ANOVA and Kruskal-Wallis test. Number of teeth (median and mean) was analysed in the group having periodontitis at baseline, (at least two sites $\geq 5 \mathrm{~mm}$ distance from CEJ to marginal bone level and at least one tooth with pockets $\geq 5 \mathrm{~mm}$ ), compared to the healthy group (no tooth with pockets $\geq 5 \mathrm{~mm}$ and less than two sites $\geq 5 \mathrm{~mm}$ distance from CEJ to marginal bone level). Number of teeth lost during follow-up, in periodontitis compared to the healthy group, was analysed using Student-T-test and Mann-Whitney $\mathrm{U}$ test. Candidate explanatory variables for losing $\geq 3$ teeth were periodontitis, age, gender, level of education, use of interdental care devices, frequency of dental visits, living alone, diabetes, MMSE, ischemic heart disease, BMI and dental caries. The impact of the candidate explanatory variables on the risk of losing $\geq 3$ teeth was analysed first by univariate analysis and thereafter the influential explanatory variables were analysed using direct logistic regression. Odds ratio (OR), 95\% confidence interval $(\mathrm{Cl})$ and $p$-values were calculated; $p$-values $<0.05$ were regarded as statistically significant.

This article is protected by copyright. All rights reserved. 


\section{Results}

The characteristics of the study participants are presented in Table 1. Amongst the 476 individuals that agreed to participate in the 12-year follow-up, 451 were willing to take part in the oral examination. After exclusion of individuals lacking x-rays at baseline (49) and edentulous at baseline (27), 375 (women 59\%) individuals were available for the final analysis. In 60 individuals, the 12-year examination was performed in their homes due to inability attending the research centre. At the 12year follow-up, alveolar bone-loss was measured in 284 individuals that agreed to participate in the radiographic examination.

The prevalence of periodontitis, defined as having at least two sites with $\geq 5 \mathrm{~mm}$ distance from CEJ to marginal bone level and at least one tooth with pockets $\geq 5 \mathrm{~mm}$, was $39 \%$. Having periodontitis was associated with current smoking at baseline $(p<0.001)$. No significant differences were identified regarding prevalence of periodontitis between the different age cohorts, (Table 2). The proportion of readable sites $\geq 4 \mathrm{~mm}$ and $\geq 5 \mathrm{~mm}$, respectively, increased with age, (Table 2). The prevalence of dental caries, defined as having at least one tooth with an manifest lesion at the buccal or lingual surface, was $7.2 \%$ and no differences between the age cohort were identified, (Table 2).

No significant differences were found between age cohorts, regarding number and proportion of teeth with pockets $\geq 5 \mathrm{~mm}$, (Table 2). No significant differences in tooth loss (mean) were identified between the different age cohorts, (Table 2). There was however a significant impact of age between the Young old $(60,66)$ and the Oldold $(\geq 81)$ cohort on the risk of loosing $\geq 3$ teeth in the logistic regression model (Table 5). Comparing the group of individuals having periodontitis to the group characterised as healthy, a significant difference in tooth loss over the 12-year follow-up was observed ( $p<0.001)$, (Table 3 ).

This article is protected by copyright. All rights reserved. 
Loss of $\geq 3$ teeth was evident in $23 \%$ of the individuals and mean annual tooth loss was 0.15 . The group losing $\geq 3$ teeth demonstrated a lower number of teeth at baseline and a higher number of sites with bone loss $\geq 5 \mathrm{~mm}$ and teeth with pockets $\geq 5 \mathrm{~mm}$ (Table 4). A diagnosis of periodontitis, dental caries, living alone and age were significant predictors of losing $\geq 3$ teeth in the univariate analysis. In the multivariate analysis, a diagnosis of periodontitis (OR 2.9, $\mathrm{Cl} 1.8-4.9$ ), living alone (OR 2.0, $\mathrm{Cl}$ 1.1-3.5) and age (OR 2.6, $\mathrm{Cl}$ 1.1-5.7) were significant predictors for losing $\geq 3$ teeth, (Table 5).

\section{Discussion}

In this longitudinal cohort study of older adults living in Sweden, we found that $39 \%$ of the individuals had periodontitis. In a report on the prevalence of periodontitis from United States roughly $68 \%$ of the population aged $\geq 65$ years had periodontitis and the severe form affected $11 \%$ of the population (Eke et al., 2016). One explanation to the various prevalence rates reported may be related to the differences in definition used. In the study by Eke, severe periodontitis was defined using a combination of interproximal attachment loss and evidence of periodontal pockets $\geq 5 \mathrm{~mm}$ whereas in our study periodontitis was defined by actual bone loss in combination with $\geq$ one tooth with a periodontal pocket $\geq 5 \mathrm{~mm}$. The approach of combining attachment loss or bone loss and periodontal pockets has been disputed, as the same level of pocket depth or attachment loss in different age cohorts may have different implications regarding disease progression and tooth loss (Papapanou \& Susin, 2017). Substantial different levels of periodontitis has been demonstrated in various geographic areas (Billings et al., 2018; Hirotomi et al., 2014). In our study, mean proportion of bone-loss increased with age while number and proportion of teeth with periodontal pockets remained unchanged. These results are in accordance with the results reported by Billings and coworkers (Billings et al., 2018) . Recessions are considered to be a major contributor to attachment loss in the older age cohorts (Billings et al., 2018). This could be a reason why the number of pockets

This article is protected by copyright. All rights reserved. 
don't increase with age. In the present study, progression in terms of mean annual tooth loss was 0.15. A recent systemic review and meta-analysis reported an overall mean annual tooth loss of 0.20 and for individuals $>50$ years, 0.23 was reported (Needleman et al., 2018). The impact of caries and periodontal disease on tooth loss have been extensively studied (Jepsen et al., 2017). In this study, both caries and periodontitis increased the risk for multiple tooth and in the final regression model, periodontitis remained significant. Our results are consistent with the results reported by Machtei and coworkers demonstrating a higher level of bone-loss and clinical attachment loss at baseline in individuals losing teeth during the follow-up period compared to the group of individuals not losing teeth (Machtei et al., 1999). Our finding that people living alone loose more teeth are supported by Gulcan and coworkers demonstrating that major tooth loss where more likely to occur among singles than married indviduals (Gulcan, Ekback, Ordell, Lie, \& Astrom, 2015). Our study has numerous strengths including serial $x$-rays, full-mouth examinations and available demographic, social and medical variables. As periodontal disease, in the majority of cases, is a slow progressive disease, the long follow-up time is an advantage. In order to include data from as many individuals as possible, members from the research center examined a number of individuals in their homes. Hence, the drop-out rate could be reduced.

Except from the change from analog to digital panoramic $x$-rays, the data collection was done according to the same study protocol and mainly by the same members of the research team as in the baseline examination, which must be considered a strength.

The randomised population-based sample may also allow us to generalize the results.

This article is protected by copyright. All rights reserved. 
The risk for selective attrition must however be considered. Individuals with complicated forms of ischemic heart disease, diabetes and cognitive diseases may therefore not be present for the 12 year follow-up and selection bias, indicating that the comparatively healthier individuals are present at the follow-up examination, is therefore plausible. Considering our sample as a fairly independent cohort of older adults with a high level of dental care attendance and high frequency of dental hygiene routines, our results cannot be compared to those reported from cohorts of care-dependent elderly, living in nursing homes (Andersson, Renvert, Sjogren, \& Zimmerman, 2017).

Lack of measurements regarding clinical attachment level change and progression on site level could be considered a limitation. Reports based on mean attachment level change are nevertheless influenced by the fact that only very few sites within a subject progress beyond the range for periodontal measurements error. Another limitation with the present study was that only manifest caries lesions on buccal and lingual surfaces was registered and that no reproducibility measurements was performed.

The low number of participants in the age cohorts $\geq 81$ years at baseline and the large interquartile ranges/standard deviations reported in this age cohort can be considered a limitation. One should however consider that these individuals are $\geq 93$ at the follow-up examination, making the cohort extraordinary. Knowledge regarding disease progression and tooth loss are mainly derived from epidemiological studies of cohorts lacking preventive dentistry or selected cohorts from oral health care (Loe, Anerud, Boysen, \& Smith, 1978; Manji, Baelum, \& Fejerskov, 1988; Papapanou \& Wennstrom, 1990). Additionally, the majority of the studies are from young or middle-aged cohorts and therefore this study contributes with additional knowledge to existing evidence. Oral health has been highlighted by the World Health Organization and targets has been proposed to increase the number of older individuals with functional dentitions and increase the proportion of individuals with a healthy periodontium (Hobdell, Petersen, Clarkson, \& Johnson, 2003) .

This article is protected by copyright. All rights reserved. 
As the resources for dental care are limited it is of major importance to identify factors associated with progressive disease and tooth loss.

This study demonstrated that periodontitis is associated with multiple tooth loss over a 12-year follow-up period among older adults. Further studies focusing on how preventive and therapeutic regimes can maintain oral health into older age are warranted.

This article is protected by copyright. All rights reserved. 
Table 1.

Characteristics of the study population

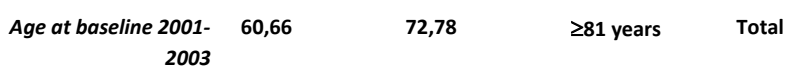

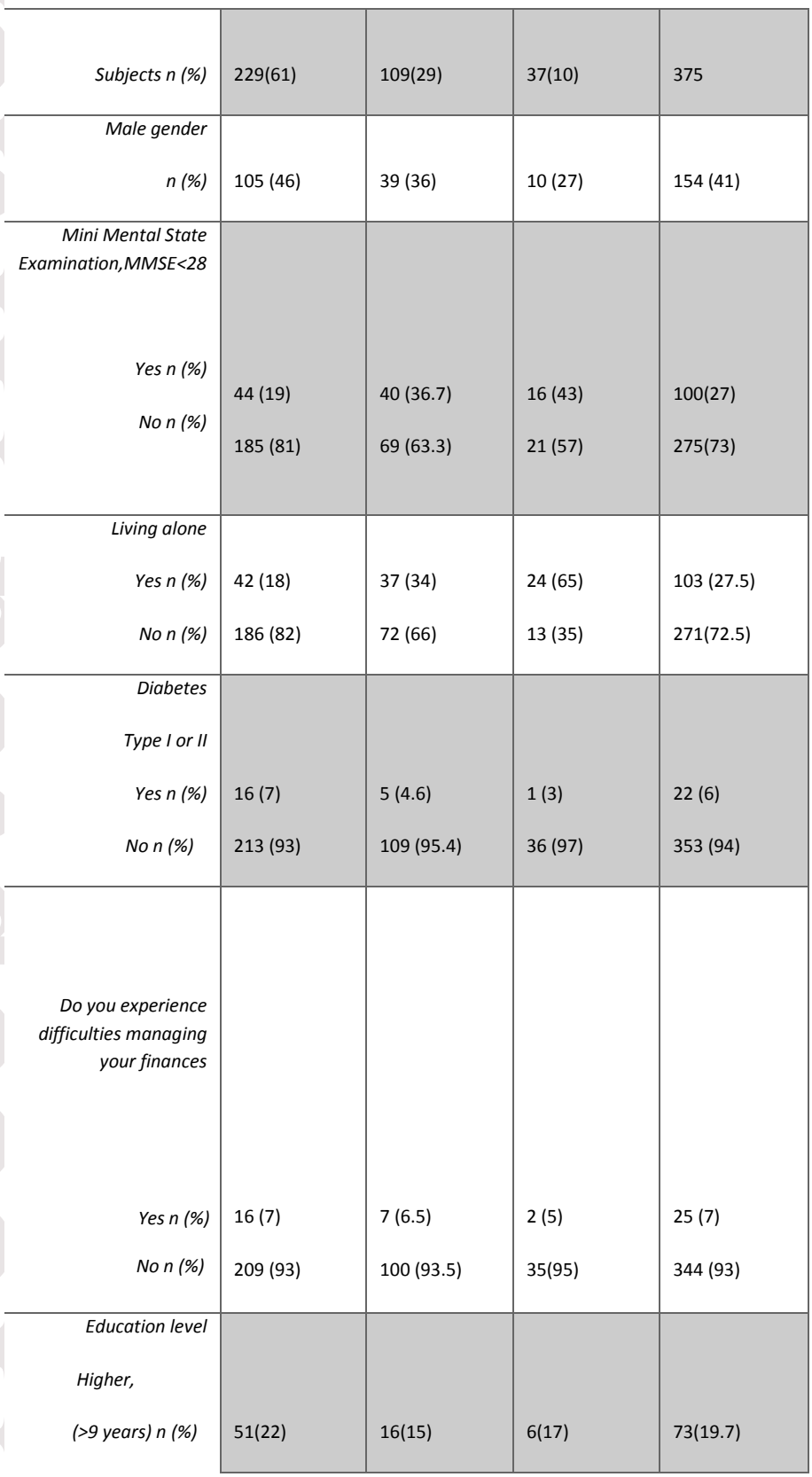

This article is protected by copyright. All rights reserved. 


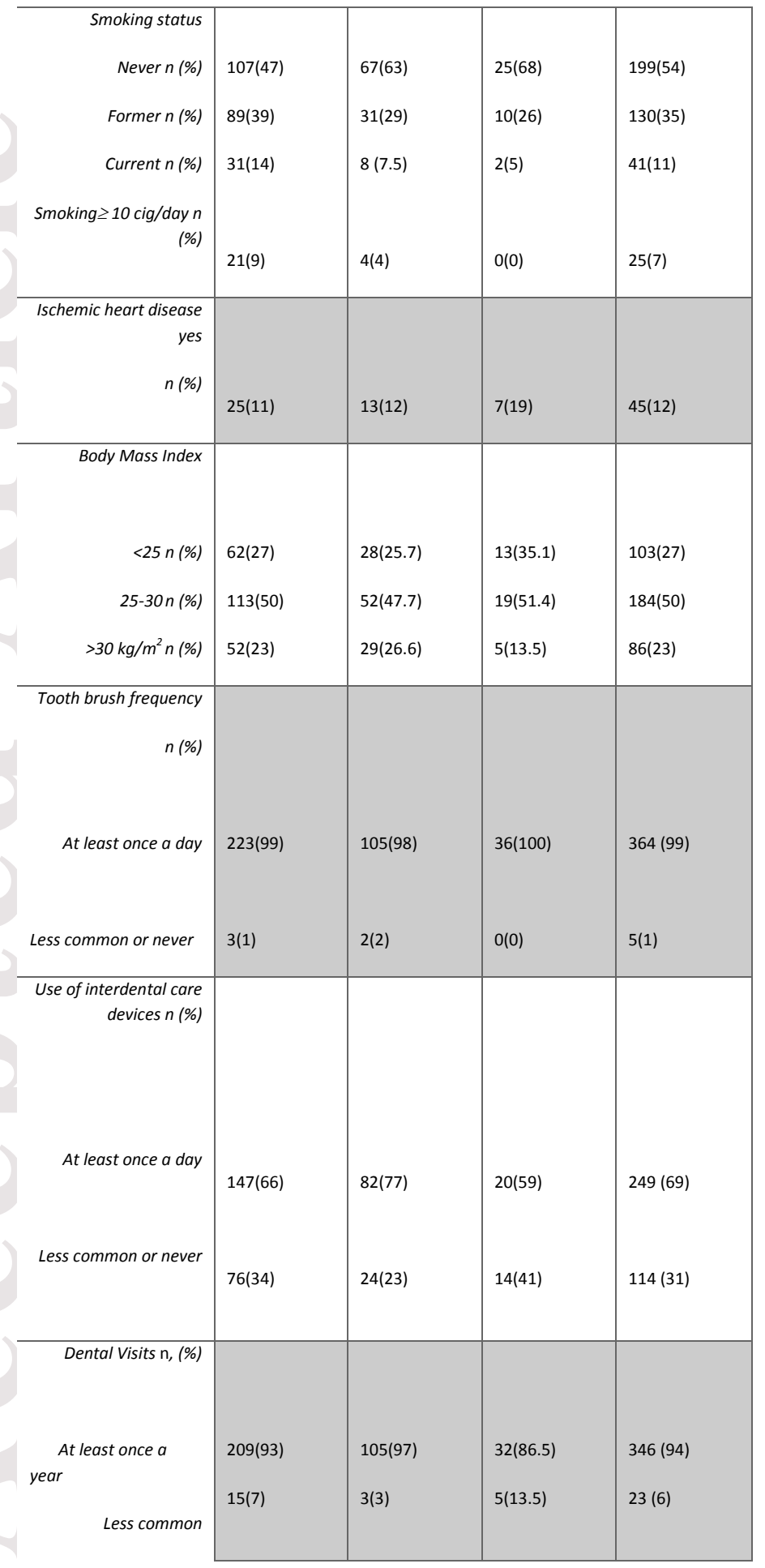

This article is protected by copyright. All rights reserved. 
Table 2

Clinical and radiographic measurements, at baseline and 12-year follow-up.

\begin{tabular}{|c|c|c|c|c|}
\hline $\begin{array}{r}\text { Age at baseline } 2001- \\
2003\end{array}$ & 60,66 (Young Old) & 72,78 (Old) & $\geq 81$ years (OldOld) & Total \\
\hline 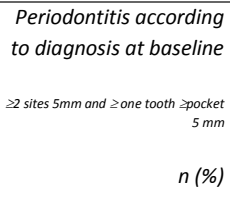 & $83(36.4)$ & $50(46)$ & $13(35.1)$ & NS \\
\hline $\begin{array}{r}\text { Dental caries, } \\
\text { buccal or } \\
\text { lingual surface } \geq 1 \text { tooth }\end{array}$ & $14(6.2)$ & $8(7.3)$ & $5(13.5)$ & NS \\
\hline $\begin{array}{r}\text { Tooth count, including } \\
\text { third molar } \\
\text { Baseline } \\
\text { 12-year follow-up } \\
\text { Tooth loss, mean }\end{array}$ & $\begin{array}{l}23.2 \text { SD } 5.3 \\
21.6 \text { SD } 6.3 \\
1.6 \text { SD } 2.5\end{array}$ & $\begin{array}{l}19.8 \text { SD } 6.7 \\
18.0 \text { SD } 7.2 \\
1.8 \text { SD } 2.5\end{array}$ & $\begin{array}{l}14.7 \text { SD } 6.2 \\
12.4 \text { SD } 6 \\
2.5 \text { SD } 3\end{array}$ & $\begin{array}{l}p<0.001^{*} \\
p<0.001^{*} \\
\text { NS }\end{array}$ \\
\hline $\begin{array}{r}\text { Number of readable } \\
\text { sites } \geq 4 \mathrm{~mm} \\
\text { Baseline, mean } \\
\text { Median } \\
\text { 12-year follow-up, mean } \\
\text { Median }\end{array}$ & $\begin{array}{l}5.9 \text { SD } 6.3 \\
4 \text { IQR } 8 \\
6.3 \text { SD } 5.2 \\
6 \text { IQR } 7\end{array}$ & $\begin{array}{l}7.6 \text { SD } 6.5 \\
6 \text { IQR } 8.5 \\
7.0 \text { SD } 5.1 \\
7 \text { IQR } 8.5\end{array}$ & $\begin{array}{l}7.2 \text { SD } 6.1 \\
6 \text { IQR } 8.5 \\
5.5 \text { SD } 3.5 \\
6 \text { IQR } 6.75\end{array}$ & $\begin{array}{l}\text { NS } \\
p=0.01^{* *} \\
\text { NS } \\
\text { NS }\end{array}$ \\
\hline $\begin{array}{r}\text { Number of readable } \\
\text { sites } \geq 5 \mathrm{~mm} \\
\text { Baseline. mean } \\
\text { Median }\end{array}$ & $\begin{array}{l}2.7 \mathrm{SD} 4 \\
1 \mathrm{IQR} 4\end{array}$ & $\begin{array}{l}4.1 \text { SD } 4.6 \\
3 \text { IQR } 5\end{array}$ & $\begin{array}{l}3.8 \text { SD } 4.3 \\
2 \text { IQR } 6\end{array}$ & $\begin{array}{l}p=0.02^{* *} \\
p<0.01^{* *}\end{array}$ \\
\hline
\end{tabular}

This article is protected by copyright. All rights reserved. 


\begin{tabular}{|c|c|c|c|c|}
\hline Median & $\begin{array}{l}3.7 \text { SD } 4.1 \\
3 \text { IQR } 6\end{array}$ & $\begin{array}{l}4.9 \text { SD } 4.0 \\
5.0 \text { IQR } 6.5\end{array}$ & $\begin{array}{l}4.0 \text { SD } 2.7 \\
4 \text { IQR } 4\end{array}$ & $\begin{array}{l}\text { NS } \\
\text { NS }\end{array}$ \\
\hline $\begin{array}{r}\text { Proportion of readable } \\
\text { sites } \geq 4 \mathrm{~mm} \\
\text { Baseline, mean } \\
\text { Median } \\
\text { 12-year follow-up, mean } \\
\text { Median }\end{array}$ & $\begin{array}{l}19 \text { SD } 20.1 \\
13 \text { IQR } 25.1 \\
25.3 \text { SD } 21.3 \\
22.2 \text { IQR } 30.9\end{array}$ & $\begin{array}{l}28.1 \text { SD } 25.8 \\
20 \text { IQR } 31.1 \\
34.5 \text { SD } 27.4 \\
33.3 \text { SD IQR } 41.2\end{array}$ & $\begin{array}{l}36.8 \text { SD } 25.4 \\
33.3 \text { IQR } 39.2 \\
43.1 \text { SD } 36.3 \\
34.6 \text { IQR } 58.1\end{array}$ & $\begin{array}{l}p=0.01^{* * *} \\
p<0.001^{* * *} \\
p=0.003^{* *} \\
p=0.01^{* *}\end{array}$ \\
\hline $\begin{array}{r}\text { Proportion of readable } \\
\text { sites } \geq 5 \mathrm{~mm} \\
\text { Baseline,mean } \\
\text { Median } \\
\text { 12-year follow-up, mean } \\
\text { Median }\end{array}$ & $\begin{array}{l}9.2 \text { SD } 14.5 \\
3.33 \text { IQR } 12.5 \\
16.4 \text { SD } 19.7 \\
9.7 \text { IQR } 26.7\end{array}$ & $\begin{array}{l}16.6 \text { SD } 22.1 \\
8.8 \text { IQR } 19 \\
26.1 \text { SD } 25.8 \\
20.0 \text { IQR } 32.1\end{array}$ & $\begin{array}{l}18.1 \text { SD } 17.7 \\
13.3 \text { IQR } 29.3 \\
35.5 \text { SD } 38.1 \\
23.8 \text { IQR } 59.7\end{array}$ & $\begin{array}{l}p<0.001^{* * *} \\
p<0.001^{* * *} \\
p<0.001^{* * *} \\
p<0.01^{* *}\end{array}$ \\
\hline $\begin{array}{r}\text { Mean number of teeth } \\
\text { with pockets } \geq 5 \mathrm{~mm} \\
\text { Baseline } \\
\text { Median } \\
12 \text {-year follow-up } \\
\text { Median }\end{array}$ & $\begin{array}{l}1.9 \text { SD } 2.4 \\
1 \text { IQR } 3 \\
1.4 \text { SD } 2.3 \\
1 \text { IQR } 2\end{array}$ & $\begin{array}{l}1.8 \text { SD } 2.1 \\
1 \text { IQR } 3 \\
1.6 \text { SD } 2.4 \\
1 \text { IQR } 2\end{array}$ & $\begin{array}{l}1.1 \text { SD } 1.9 \\
1 \text { IQR } 1.25 \\
0.4 \text { SD } 0.6 \\
0 \text { IQR } 1\end{array}$ & $\begin{array}{l}\text { NS } \\
\text { NS }\end{array}$ \\
\hline $\begin{array}{r}\text { Mean proportion (\%) of } \\
\text { teeth with pockets } \geq \\
5 \mathrm{~mm}\end{array}$ & & & & \\
\hline Baseline & 9 SD 11.9 & 9.1 SD 10.6 & 8.5 SD 13 & \\
\hline $\begin{array}{r}\text { Median } \\
12 \text {-year follow-up }\end{array}$ & $\begin{array}{l}5 \text { IQR } 12 \\
7.2 \text { SD } 12.5\end{array}$ & $\begin{array}{l}5.6 \mathrm{IQR} 14.3 \\
8.6 \mathrm{SD} 11.7\end{array}$ & $\begin{array}{l}4.0 \mathrm{IQR} 12.5 \\
2.4 \mathrm{SD} 4.1\end{array}$ & NS \\
\hline Median & 3.7 IQR 9.3 & 4.3 IQR 15 & 0 IQR 6.0 & NS \\
\hline
\end{tabular}

This article is protected by copyright. All rights reserved. 
Analysis using ANOVA and Kruskal-Wallis,Bonferroni correction

NS= non-significant

* Statistically significant differences between all age groups

** Statistically significant differences between Young Old and Old

*** Statistically significant differences between Young Old and Old, Young Old and OldOld

This article is protected by copyright. All rights reserved. 
Table 3

Presence of teeth at baseline and at the 12-year follow-up according to periodontal status at baseline *

Total sample $(n=223)$

Periodontitis

Healthy

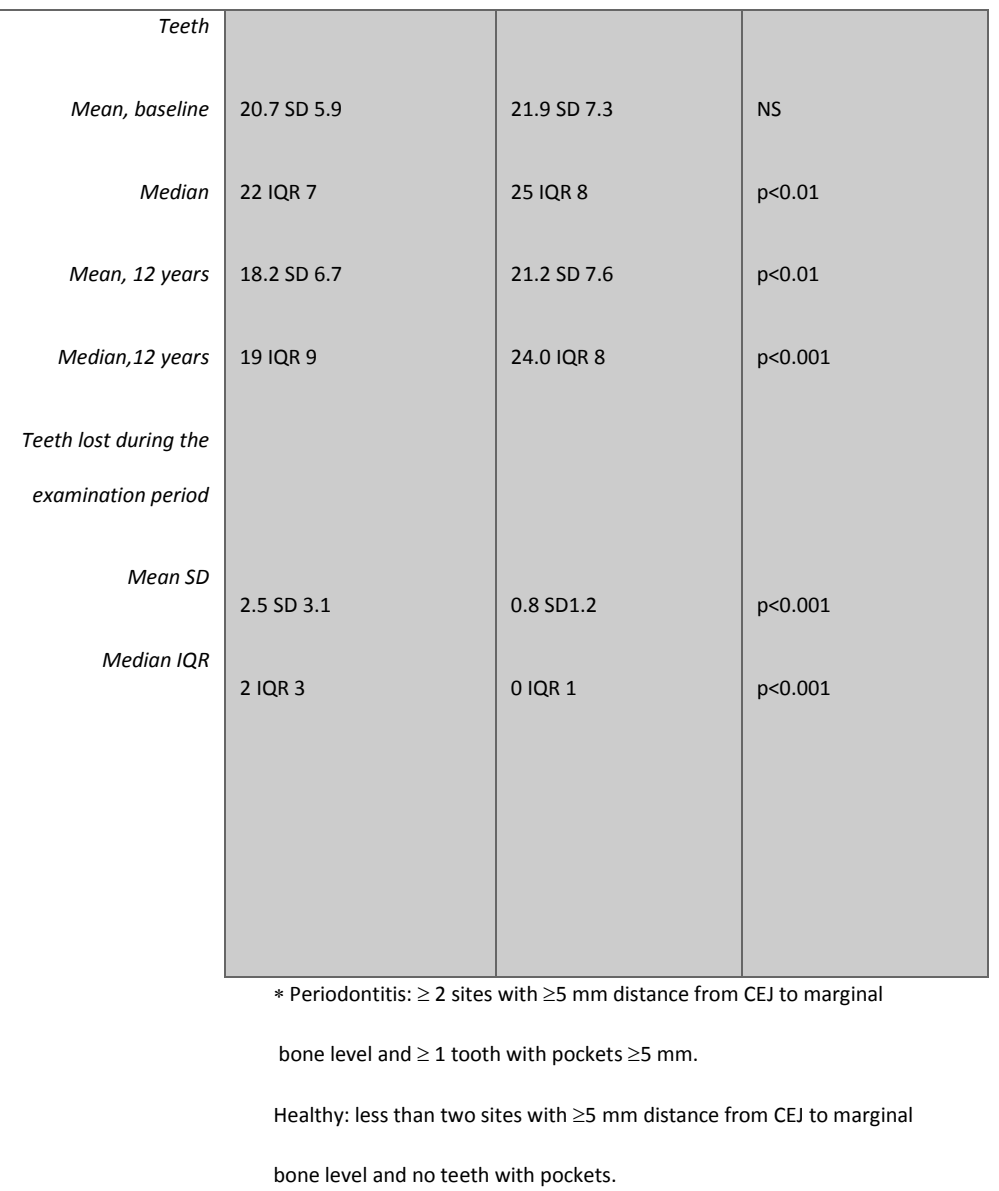

This article is protected by copyright. All rights reserved. 
Table 4

Baseline periodontal status and presence of teeth and consequent loss of $\geq 3$ teeth

\begin{tabular}{|c|c|c|}
\hline Variable & $\begin{array}{l}\text { Mean baseline value in } \\
\text { subjects with no tooth loss }\end{array}$ & $\begin{array}{l}\text { Mean baseline value in } \\
\text { subject with loss of } \geq 3 \text { teeth }\end{array}$ \\
\hline
\end{tabular}

\begin{tabular}{|c|c|c|c|}
\hline \multicolumn{4}{|l|}{ Number of teeth at baseline } \\
\hline Mean & 22.2 SD 6 & 19.1 SD 6.5 & $<0.001$ \\
\hline Median & 24 IQR 6 & 20 IQR 9 & $<0.001$ \\
\hline \multicolumn{4}{|l|}{ Number of sites $\geq 5 \mathrm{~mm}$} \\
\hline Mean & 2.6 SD 3.7 & 5.4 SD 5.3 & $<0.001$ \\
\hline Median & 1 IQR 3 & $4.0 \operatorname{IQR} 6.5$ & $<0.001$ \\
\hline \multicolumn{4}{|l|}{ Number of teeth } \\
\hline \multicolumn{4}{|l|}{ with pocket $\geq 5 \mathrm{~mm}$} \\
\hline Mean & 1.5 SD 2.0 & 2.7 SD 2.8 & $<0.01$ \\
\hline Median & 1 IQR 2 & 2 IQR 4.25 & $<0.01$ \\
\hline
\end{tabular}

This article is protected by copyright. All rights reserved. 
Table 5

Multivariate logistic regression for the outcome tooth loss of $\geq 3$ over the 12 -year study period.

\begin{tabular}{|c|c|c|c|c|}
\hline & $\begin{array}{l}\text { Univariate } \\
\text { analysis }\end{array}$ & $p$-value & $\begin{array}{l}\text { Multivariate } \\
\text { analysis }(n=369)\end{array}$ & p-value \\
\hline & $\begin{array}{l}\text { OR } \\
(95 \% \mathrm{Cl})\end{array}$ & & $\begin{array}{l}\text { OR } \\
(95 \% \mathrm{Cl})\end{array}$ & \\
\hline $\begin{array}{l}\text { Periodontitis } \\
\geq 2 \text { sites } 5 \mathrm{~mm} \text { and } \geq \text { one tooth } \geq \text { pocket } 5 \mathrm{~mm}\end{array}$ & $\begin{array}{l}2.8 \\
(1.7-4.6)\end{array}$ & $<0.001$ & $\begin{array}{l}2.9 \\
(1.8-4.9)\end{array}$ & $<0.001$ \\
\hline Age & & & & \\
\hline 72,78 & $1.4(0.8-2.5)$ & 0.2 & $1.2(0.6-2.1)$ & \\
\hline$\geq 81$ & $3.3(1.6-6.8)$ & 0.01 & 2.6(1.1-5.7) & 0.02 \\
\hline Male & $1.3(0.8-2.1)$ & 0.3 & & \\
\hline $\begin{array}{l}\text { Dental caries, having at least one } \\
\text { tooth with an open cavity }\end{array}$ & $\begin{array}{l}2.5 \\
(1.1-5.6)\end{array}$ & 0.03 & $2.2(0.9-5.3)$ & 0.08 \\
\hline Dental visits, not on yearly basis & $\begin{array}{l}0.9 \\
(0.3-2.7)\end{array}$ & 0.9 & & \\
\hline Living alone & $\begin{array}{l}2.3 \\
(1.4-3.9)\end{array}$ & 0.001 & $\begin{array}{l}2.0 \\
(1.1-3.5)\end{array}$ & 0.02 \\
\hline Education, elementary $\leq 9$ years & $\begin{array}{l}1.6 \\
(0.8-3.2)\end{array}$ & 0.15 & & \\
\hline Ischemic heart disease & 0.9 & 0.9 & & \\
\hline
\end{tabular}

This article is protected by copyright. All rights reserved. 


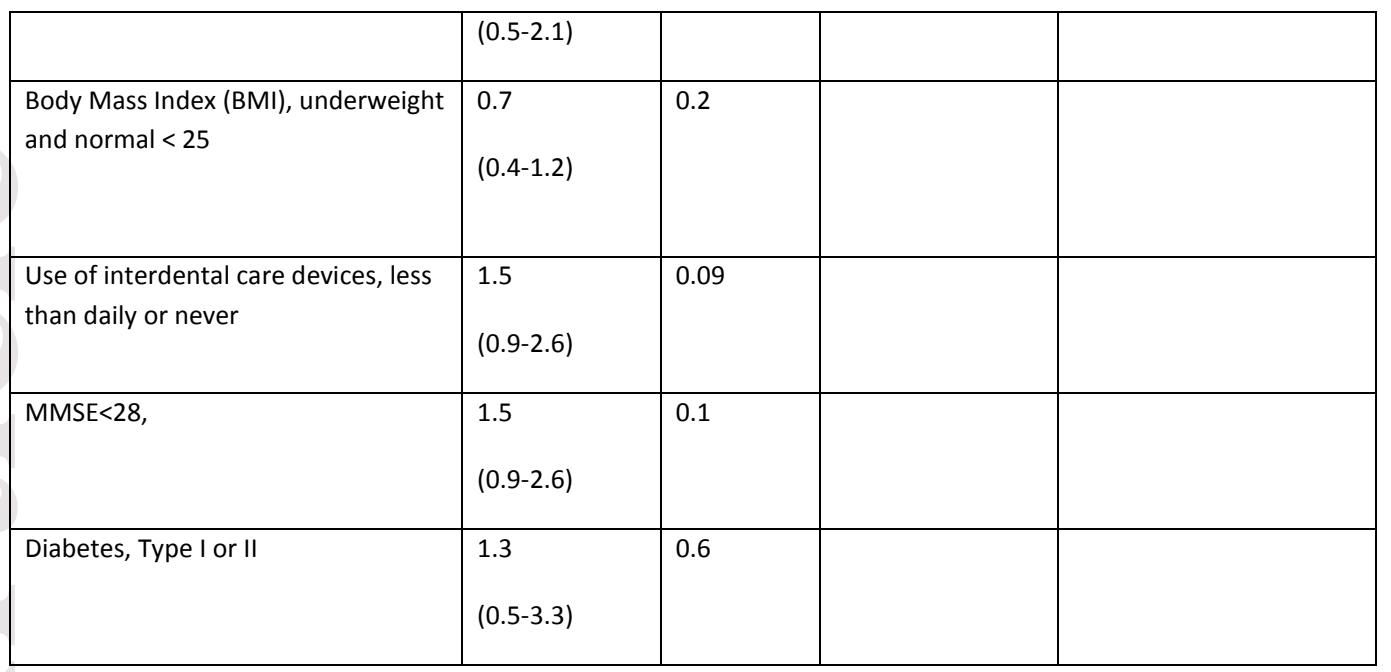

Logistic regression model, Univariate analysis

and multivariate analysis (only influential explanatory variables included, $n=369$ )

Values in bold signify statistical significance $p<0.05$. Confidence interval, $\mathrm{Cl}(95 \%)$

This article is protected by copyright. All rights reserved. 


\section{References}

Andersson, P., Renvert, S., Sjogren, P., \& Zimmerman, M. (2017). Dental status in nursing home residents with domiciliary dental care in sweden. Community Dental Health, 34(4), 203-207. doi:10.1922/CDH_4100Andersson05 [doi]

Baelum, V., Luan, W. M., Chen, X., \& Fejerskov, O. (1997). A 10-year study of the progression of destructive periodontal disease in adult and elderly chinese. Journal of Periodontology, 68(11), 1033-1042. doi:10.1902/jop.1997.68.11.1033 [doi]

Batchelor, P. (2015). The changing epidemiology of oral diseases in the elderly, their growing importance for care and how they can be managed. Age and Ageing, 44(6), 1064-1070. doi:10.1093/ageing/afv148 [doi]

Beck, J. D., Sharp, T., Koch, G. G., \& Offenbacher, S. (1997). A 5-year study of attachment loss and tooth loss in community-dwelling older adults. Journal of Periodontal Research, 32(6), 516-523.

Billings, M., Holtfreter, B., Papapanou, P. N., Mitnik, G. L., Kocher, T., \& Dye, B. A. (2018). Agedependent distribution of periodontitis in two countries: Findings from NHANES 2009 to 2014 and SHIP-TREND 2008 to 2012. Journal of Periodontology, 89 Suppl 1, S140-S158. doi:10.1002/JPER.17-0670 [doi]

Caceres, M., Oyarzun, A., \& Smith, P. C. (2014). Defective wound-healing in aging gingival tissue. Journal of Dental Research, 93(7), 691-697. doi:10.1177/0022034514533126 [doi]

Christensen, K., Doblhammer, G., Rau, R., \& Vaupel, J. W. (2009). Ageing populations: The challenges ahead. Lancet (London, England), 374(9696), 1196-1208. doi:10.1016/S0140-6736(09)61460-4 [doi]

This article is protected by copyright. All rights reserved. 
Eke, P. I., Dye, B. A., Wei, L., Thornton-Evans, G. O., Genco, R. J., \& CDC Periodontal Disease Surveillance workgroup: James Beck (University of North Carolina, Chapel Hill. (2012). Prevalence of periodontitis in adults in the united states: 2009 and 2010. Journal of Dental Research, 91(10), 914-920. doi:0022034512457373 [pii]

Eke, P. I., Wei, L., Borgnakke, W. S., Thornton-Evans, G., Zhang, X., Lu, H., . . Genco, R. J. (2016). Periodontitis prevalence in adults $>/=65$ years of age, in the USA. Periodontology $2000,72(1)$, 76-95. doi:10.1111/prd.12145 [doi]

Gulcan, F., Ekback, G., Ordell, S., Lie, S. A., \& Astrom, A. N. (2015). Inequality in oral health related to early and later life social conditions: A study of elderly in norway and sweden. BMC Oral Health, 15, 20-015. doi:10.1186/s12903-015-0005-y [doi]

Hajishengallis, G. (2010). Too old to fight? aging and its toll on innate immunity. Molecular Oral Microbiology, 25(1), 25-37. doi:10.1111/j.2041-1014.2009.00562.x [doi]

Hirotomi, T., Kocher, T., Yoshihara, A., Biffar, R., Micheelis, W., Hoffmann, T., . . Holtfreter, B. (2014). Comparison of periodontal conditions among three elderly populations in japan and germany. Journal of Clinical Periodontology, 41(7), 633-642. doi:10.1111/jcpe.12267 [doi]

Hobdell, M., Petersen, P. E., Clarkson, J., \& Johnson, N. (2003). Global goals for oral health 2020. International Dental Journal, 53(5), 285-288.

Holm-Pedersen, P., Schultz-Larsen, K., Christiansen, N., \& Avlund, K. (2008). Tooth loss and subsequent disability and mortality in old age. Journal of the American Geriatrics Society, 56(3), 429-435. doi:10.1111/j.1532-5415.2007.01602.x [doi]

Jepsen, S., Blanco, J., Buchalla, W., Carvalho, J. C., Dietrich, T., Dorfer, C., . . Machiulskiene, V. (2017). Prevention and control of dental caries and periodontal diseases at individual and

This article is protected by copyright. All rights reserved. 
population level: Consensus report of group 3 of joint EFP/ORCA workshop on the boundaries between caries and periodontal diseases. Journal of Clinical Periodontology, 44 Suppl 18, S85S93. doi:10.1111/jcpe.12687 [doi]

Kassebaum, N. J., Bernabe, E., Dahiya, M., Bhandari, B., Murray, C. J., \& Marcenes, W. (2014a). Global burden of severe periodontitis in 1990-2010: A systematic review and meta-regression. Journal of Dental Research, 93(11), 1045-1053. doi:0022034514552491 [pii]

Kassebaum, N. J., Bernabe, E., Dahiya, M., Bhandari, B., Murray, C. J., \& Marcenes, W. (2014b). Global burden of severe tooth loss: A systematic review and meta-analysis. Journal of Dental Research, 93(7 Suppl), 20S-28S. doi:10.1177/0022034514537828 [doi]

Lim, W. H., Liu, B., Mah, S. J., Chen, S., \& Helms, J. A. (2014). The molecular and cellular effects of ageing on the periodontal ligament. Journal of Clinical Periodontology, 41(10), 935-942. doi:10.1111/jcpe.12277 [doi]

Listl, S., Galloway, J., Mossey, P. A., \& Marcenes, W. (2015). Global economic impact of dental diseases. Journal of Dental Research, 94(10), 1355-1361. doi:10.1177/0022034515602879 [doi]

Loe, H., Anerud, A., Boysen, H., \& Smith, M. (1978). The natural history of periodontal disease in man. the rate of periodontal destruction before 40 years of age. Journal of Periodontology, 49(12), 607-620. doi:10.1902/jop.1978.49.12.607 [doi]

Machtei, E. E., Hausmann, E., Dunford, R., Grossi, S., Ho, A., Davis, G., . . Genco, R. J. (1999). Longitudinal study of predictive factors for periodontal disease and tooth loss. Journal of Clinical Periodontology, 26(6), 374-380.

Manji, F., Baelum, V., \& Fejerskov, O. (1988). Tooth mortality in an adult rural population in kenya. Journal of Dental Research, 67(2), 496-500. doi:10.1177/00220345880670021301 [doi]

This article is protected by copyright. All rights reserved. 
Muller, F., Shimazaki, Y., Kahabuka, F., \& Schimmel, M. (2017). Oral health for an ageing population: The importance of a natural dentition in older adults. International Dental Journal, 67 Suppl 2, 7-13. doi:10.1111/idj.12329 [doi]

Needleman, I., Garcia, R., Gkranias, N., Kirkwood, K. L., Kocher, T., Iorio, A. D., . . Petrie, A. (2018). Mean annual attachment, bone level, and tooth loss: A systematic review. Journal of Periodontology, 89 Suppl 1, S120-S139. doi:10.1002/JPER.17-0062 [doi]

Papapanou, P. N., \& Susin, C. (2017). Periodontitis epidemiology: Is periodontitis under-recognized, over-diagnosed, or both? Periodontology 2000, 75(1), 45-51. doi:10.1111/prd.12200 [doi]

Papapanou, P. N., \& Wennstrom, J. L. (1990). A 10-year retrospective study of periodontal disease progression. clinical characteristics of subjects with pronounced and minimal disease development. Journal of Clinical Periodontology, 17(2), 78-84.

Persson, R. E., Hollender, L. G., \& Persson, G. R. (1998). Assessment of alveolar bone levels from intraoral radiographs in subjects between ages 15 and 94 years seeking dental care. Journal of Clinical Periodontology, 25(8), 647-654.

Preshaw, P. M., Henne, K., Taylor, J. J., Valentine, R. A., \& Conrads, G. (2017). Age-related changes in immune function (immune senescence) in caries and periodontal diseases: A systematic review. Journal of Clinical Periodontology, 44 Suppl 18, S153-S177. doi:10.1111/jcpe.12675 [doi]

Pretty, I. A., Ellwood, R. P., Lo, E. C., MacEntee, M. I., Muller, F., Rooney, E., .. Wolff, M. S. (2014). The seattle care pathway for securing oral health in older patients. Gerodontology, 31 Suppl 1, 77-87. doi:10.1111/ger.12098 [doi]

This article is protected by copyright. All rights reserved. 
Righolt, A. J., Jevdjevic, M., Marcenes, W., \& Listl, S. (2018). Global-, regional-, and country-level economic impacts of dental diseases in 2015. Journal of Dental Research, 97(5), 501-507. doi:10.1177/0022034517750572 [doi]

Schwendicke, F., Krois, J., Kocher, T., Hoffmann, T., Micheelis, W., \& Jordan, R. A. (2018). More teeth in more elderly: Periodontal treatment needs in germany 1997-2030. Journal of Clinical Periodontology, 45(12), 1400-1407. doi:10.1111/jcpe.13020 [doi]

Terezakis, E., Needleman, I., Kumar, N., Moles, D., \& Agudo, E. (2011). The impact of hospitalization on oral health: A systematic review. Journal of Clinical Periodontology, 38(7), 628-636. doi:10.1111/j.1600-051X.2011.01727.x [doi]

Tonetti, M. S., Bottenberg, P., Conrads, G., Eickholz, P., Heasman, P., Huysmans, M. C., . . Paris, S. (2017). Dental caries and periodontal diseases in the ageing population: Call to action to protect and enhance oral health and well-being as an essential component of healthy ageing consensus report of group 4 of the joint EFP/ORCA workshop on the boundaries between caries and periodontal diseases. Journal of Clinical Periodontology, 44 Suppl 18, S135-S144. doi:10.1111/jcpe.12681 [doi]

United Nations, Department of Economic and. (2015). World population prospects: The 2015 revision, key findings and advance tables. (). Retrieved from https://esa.un.org/unpd/wpp/Publications/Files/Key_Findings_WPP_2015.pdf; https://esa.un.org/unpd/wpp/Publications/Files/Key_Findings_WPP_2015.pdf

World, H. O. (2015). World report on ageing and health. Geneva, Switzerland: World Health Organization.

This article is protected by copyright. All rights reserved. 

ISBN 978-9I-7 IO4-997-I (print)

ISBN 978-9I-7IO4-998-8 (pdf)

MALMÖ UNIVERSITY 20506 MALMÖ, SWEDEN WWW.MAU.SE 